Review Article

\title{
Measurement and Clinical Significance of Biomarkers of Oxidative Stress in Humans
}

\author{
Ilaria Marrocco, ${ }^{1}$ Fabio Altieri, ${ }^{1}$ and Ilaria Peluso ${ }^{2}$ \\ ${ }^{1}$ Department of Biochemical Sciences "A. Rossi Fanelli", Sapienza University, P.le A. Moro 5, 00185 Rome, Italy \\ ${ }^{2}$ Center for Food and Nutrition, Council for Agricultural Research and Economics (CREA-AN), Via Ardeatina 546, \\ 00178 Rome, Italy
}

Correspondence should be addressed to Ilaria Peluso; i.peluso@tiscali.it

Received 14 March 2017; Revised 26 April 2017; Accepted 21 May 2017; Published 18 June 2017

Academic Editor: Antonio Ayala

Copyright ( 2017 Ilaria Marrocco et al. This is an open access article distributed under the Creative Commons Attribution License, which permits unrestricted use, distribution, and reproduction in any medium, provided the original work is properly cited.

Oxidative stress is the result of the imbalance between reactive oxygen species (ROS) formation and enzymatic and nonenzymatic antioxidants. Biomarkers of oxidative stress are relevant in the evaluation of the disease status and of the health-enhancing effects of antioxidants. We aim to discuss the major methodological bias of methods used for the evaluation of oxidative stress in humans. There is a lack of consensus concerning the validation, standardization, and reproducibility of methods for the measurement of the following: (1) ROS in leukocytes and platelets by flow cytometry, (2) markers based on ROS-induced modifications of lipids, DNA, and proteins, (3) enzymatic players of redox status, and (4) total antioxidant capacity of human body fluids. It has been suggested that the bias of each method could be overcome by using indexes of oxidative stress that include more than one marker. However, the choice of the markers considered in the global index should be dictated by the aim of the study and its design, as well as by the clinical relevance in the selected subjects. In conclusion, the clinical significance of biomarkers of oxidative stress in humans must come from a critical analysis of the markers that should give an overall index of redox status in particular conditions.

\section{Introduction}

The redox equilibrium is important in preserving the correct functionality of cellular vital functions [1]. Oxidative stress is defined as the imbalance in the redox characteristics of some cellular environment which can be the result of either biochemical processes leading to the production of reactive species, exposure to damaging agents (i.e., environmental pollutants and radiations), or limited capabilities of endogenous antioxidant systems [2-4]. Reactive oxygen and nitrogen species (ROS/RNS) produced under oxidative stress are known to damage all cellular biomolecules (lipids, sugars, proteins, and polynucleotides) $[5,6]$. Thus, several defense systems have been involved within the cells to prevent uncontrolled ROS increase. These systems include nonenzymatic molecules (glutathione, vitamins A, C, and E, and several antioxidants present in foods) as well as enzymatic scavengers of ROS, with superoxide dismutase (SOD), catalase (CAT), and glutathione peroxidase (GPX) being the best-known defense systems [1].

Mitochondria are the predominant source of ROS in all cell types [7]. Superoxide $\left(\mathrm{O}_{2}^{--}\right)$is mainly generated at the level of the mitochondrial electron transport chain and can be converted to hydrogen peroxide $\left(\mathrm{H}_{2} \mathrm{O}_{2}\right)$ by SOD or undergo spontaneous dismutation [1]. In the presence of transition metal ions, for example, iron and copper ions, $\mathrm{H}_{2} \mathrm{O}_{2}$ can generate via Fenton reaction the highly reactive hydroxyl radical $\left(\mathrm{HO}^{\bullet}\right)$. Reactive species may also be enzymatically produced by xanthine oxidase (XO), uncoupled nitric oxide synthases (NOS), and NADPH oxidase (NOX). ROS production is related not only to cell damage or death, but physiological and signalling roles for ROS have also been ascertained. Reactive species are the principal source of defensive pro-oxidants generated in the respiratory burst of neutrophils $[8,9]$. Upon activation, neutrophils produce various ROS via myeloperoxidase (MPO) and RNS via inducible 
TABLE 1: Fluorescent probes used for the measurements of reactive oxygen and nitrogen species by flow cytometry.

\begin{tabular}{|c|c|c|c|c|c|}
\hline Probe (localization) & ROS/RNS & Fluorescence & Leukocytes & Platelets & Limitations and confoundings \\
\hline DCFH-DA (intracellular) & $\begin{array}{l}\mathrm{HO}^{\bullet} \\
\mathrm{ONOO}^{-} \\
\mathrm{ROO}^{\bullet} \\
\mathrm{NO}_{2}^{\bullet} \\
\text { Indirect } \\
\mathrm{H}_{2} \mathrm{O}_{2}\end{array}$ & $\uparrow$ green $(\mathrm{DCF})$ & Yes & Yes & $\begin{array}{c}\text { Hemolysis } \\
\text { Self-propagation of DCF radicals } \\
\text { MDR substrates or inducers } \\
\text { Esterase inhibitors } \\
\text { Plasma esterase in whole blood or PRP } \\
\text { EDTA and citrate } \\
\text { Antioxidants }\end{array}$ \\
\hline $\begin{array}{l}\text { DAF-2 DA/DAF-FM } \\
\text { DA (intracellular) }\end{array}$ & $\mathrm{NO}^{\bullet}$ & $\uparrow$ green (DAF-Ts) & Yes & No & $\begin{array}{l}\text { MDR substrates or inducers } \\
\text { Esterase inhibitors } \\
\text { Plasma esterase in whole blood }\end{array}$ \\
\hline DHR123 (intracellular) & $\begin{array}{l}\mathrm{HClO} \\
\mathrm{H}_{2} \mathrm{O}_{2} \\
\mathrm{ONOO}^{-}\end{array}$ & $\uparrow$ green (Rho123) & Yes & No & $\begin{array}{c}\text { Self-propagation of DHR radicals } \\
\text { MDR substrates or inducers } \\
\text { Antioxidants }\end{array}$ \\
\hline HE (intracellular) & $\mathrm{O}_{2}^{\bullet-}$ & $\uparrow$ red (ethidium) & Yes & No & Intercalating agents \\
\hline $\begin{array}{l}\text { C11-BODIPY } \\
\text { (membrane) }\end{array}$ & $\begin{array}{l}\mathrm{HO}^{\bullet} \\
\mathrm{ROO}^{\bullet}\end{array}$ & Shift from red to green & Yes & Yes & $\begin{array}{l}\text { Hemolysis } \\
\text { Antioxidants }\end{array}$ \\
\hline
\end{tabular}

C11-BODIPY ${ }^{581 / 591}$ : 4,4-difluoro-5-(4-phenyl-1,3-butadienyl)-4-bora-3a,4a-diaza-s-indacene-3-undecanoic acid; DAF-2 DA: 4,5-diaminofluorescein diacetate; DAF-FM DA: 4-amino-5-methylamino-2',7'-difluorofluorescein diacetate; DAF-Ts: triazolofluoresceins; DCF: $2^{\prime}, 7^{\prime}$-dichlorofluorescein; DCFH-DA: dihydrochlorofluorescein diacetate; DHR123: dihydrorhodamine 123; EDTA: ethylenediaminetetraacetic acid, $\mathrm{H}_{2} \mathrm{O}_{2}$ : hydrogen peroxide; $\mathrm{HClO}$ : hypochlorous acid; HE: hydroethidine; MDR: multidrug resistance; $\mathrm{NO}^{\bullet}$ : nitrogen monoxide; $\mathrm{NO}_{2}^{\bullet}$ : nitrogen dioxide; $\mathrm{O}_{2}^{\bullet-}$ : superoxide radical; $\mathrm{HO}^{\bullet}$ : hydroxyl radical; $\mathrm{ONOO}^{-}$: peroxynitrite; PRP: platelet-rich plasma; Rho123: rhodamine 123; ROO`: peroxyl radicals.

nitric oxide synthase (iNOS). MPO catalyzes the $\mathrm{H}_{2} \mathrm{O}_{2}$ dependent formation of hypochlorous acid $(\mathrm{HClO})$ while iNOS produces nitric oxide $\left(\mathrm{NO}^{\bullet}\right)$, which then reacts with $\mathrm{O}_{2}{ }^{\bullet-}$ to form peroxynitrite $\left(\mathrm{ONOO}^{-}\right)$[10]. NOX associated with cell membrane catalyzes the generation of superoxide radicals that play a physiological role in cancer invasion, hypoxia, and integrin signaling [11-13]. Furthermore, ROS can modulate the expression of several genes through the redox regulation of the nuclear factor-erythroid 2-related factor 2 (Nfr2) and the nuclear factor kappa-light-chain-enhancer of activated B cells (NF-kB) [1, 14]. A concerted modulation of these pathways has been suggested in inflammation and carcinogenesis [14].

During the past decade, research has revealed a widespread involvement of oxidative stress in a number of disease processes, including cancer, cardiovascular disease (CVD), atherosclerosis, diabetes, arthritis, neurodegenerative disorders, and pulmonary, renal, and hepatic diseases [1, 5, 15-23]. These pathologic states have increased incidence with age, and oxidative stress is believed to be a major factor in ageing and ageingassociated diseases [24-26]. Thus, oxidative stress markers are important tools to assess the biological redox status, disease state and progression, and the health-enhancing effects of antioxidants in humans. Identifying markers of oxidative stress has been the focus of many studies, and several markers from various biomolecule sources have been proposed over the past decades. However, for some of them, there is a lack of consensus concerning validation, standardization, and reproducibility. We aim to discuss the major bias of these methods.

\section{Measurement of Reactive Species in Leukocytes and Platelets by Flow Cytometry}

In humans, under physiological conditions, ROS and RNS generated by leukocytes, through NOX and iNOS, have a role in the innate immune response to infection $[8,9]$. However, ROS and RNS can induce lipid peroxidation of polyunsaturated fatty acids (PUFAs), which propagate via peroxyl radicals $\left(\mathrm{ROO}^{\circ}\right)$ within the membrane, as well as in the low-density lipoproteins (LDL) $[5,2721]$. In particular, in the context of metabolic syndrome and chronic inflammation, the oxidized LDL (oxLDL) activate leukocytes and/or platelets to produce ROS and RNS [27-29].

The direct quantification of ROS/RNS is a valuable and promising biomarker that can reflect the disease process. However, given the short half-life of these species, their measurement in biological systems is a complex task. Approaches include electron spin resonance, fluorescence magnetic resonance, and mass spectrometry techniques [30,31], but their use has been limited to cell cultures and other in vitro applications. Although free radicals' production can be measured by spectrophotometric or luminescence methods [32, 33], all extracellular free radicals' measurements are deeply affected by cell count and viability.

On the other hand, flow cytometry is one of the most powerful tools for single-cell analysis of the immune system [34] and it is routinely used in the diagnosis and progression evaluation of blood cancers [35-38] and human immunodeficiency virus (HIV) infection [39-41]. In addition to the role of oxidative burst evaluation by flow cytometry in the diagnosis of chronic granulomatous disease [42], this instrumentation has been used for many years to evaluate oxidative burst in many conditions, such as autoimmune neutropenia [43] and asymptomatic HIV+ individuals [44].

Many fluorescent probes for the detection of reactive species have been developed in the last years, with a different degree of specificity and sensitivity [45]. The fluorescent probes used for the detection of reactive species in blood cells via flow cytometry are summarized in Table 1. 
For instance, intracellularly converted diacetate derivatives of probes such as dihydrochlorofluorescein diacetate (DCFH-DA), 4,5-diaminofluorescein diacetate (DAF-2 DA), and 4-amino-5-methylamino- $2^{\prime}, 7^{\prime}$-difluorofluorescein diacetate (DAF-FM DA) have widely been used for ROS/RNS detection $[32,33,45-47]$. Once taken up by cells, these probes are hydrolyzed by intracellular esterases, generating the nonfluorescent and membrane-impermeable DCFH, DAF-2, or DAF-FM. Subsequent oxidation by ROS/RNS results in the formation of the fluorescent $2^{\prime}, 7^{\prime}$-dichlorofluorescein (DCF) and triazolofluoresceins (DAF-Ts), respectively.

$\mathrm{DCFH}$, the more commonly used probe, does not directly react with $\mathrm{H}_{2} \mathrm{O}_{2}$ to form the fluorescent product. DCFH can be instead oxidized to DCF by several one-electron-oxidizing species including $\mathrm{HO}^{\bullet}$ radicals, products formed from peroxidase or heme proteins reacting with $\mathrm{H}_{2} \mathrm{O}_{2}, \mathrm{HClO}$, and nitrogen dioxide $\left(\mathrm{NO}_{2}^{\bullet}\right)$ generated by myeloperoxidase and peroxynitrite decomposition. DCFH oxidation can also be promoted by $\mathrm{Fe}^{2+}$ in the presence of $\mathrm{O}_{2}$ or $\mathrm{H}_{2} \mathrm{O}_{2}$. The 1electron oxidation of DCFH generates the DCF semiquinone anion radical $\left(\mathrm{DCF}^{\bullet-}\right)$. This intermediate can rapidly react with $\mathrm{O}_{2}$ to form $\mathrm{O}_{2}^{--}$, which in turn can dismutate yielding additional $\mathrm{H}_{2} \mathrm{O}_{2}$ and establishing a redox-cycling mechanism that leads to an artificial amplification of the fluorescence signal [46].

While DCFH is used in both platelets and leukocytes, dihydrorhodamine 123 (DHR123) and hydroethidine (HE) are used only in the evaluation of the oxidative burst by polymorphonuclear leukocytes (PMN) (Table 1).

DHR123 is an uncharged nonfluorescent probe that passively diffuses across cell membranes and is converted upon oxidation to the fluorescent membrane-impermeant rhodamine 123 (Rho123), which predominantly localizes in the mitochondria $[32,33,45,47]$. HE passively diffuses into cells and is preferentially oxidized by $\mathrm{O}_{2}^{\bullet-}$ to ethidium, which results in intercalation in DNA and consequently a significant enhancement of its red fluorescence intensity [32, 33, 45, 47].

The 4,4-difluoro-5-(4-phenyl-1,3-butadienyl)-4-bora3a,4a-diaza-s-indacene-3-undecanoic acid (C11-BODIPY ${ }^{581 / 591}$ ) probe is the only lipophilic probe used to evaluate ROS in leukocytes and platelets [48, 49]. C11BODIPY $^{581 / 591}$ is a derivatized 11 -carbon fatty acid in which the boron dipyrromethene difluoride (BODIPY) core is substituted by a phenyl group via a conjugated diene $[50,51]$. This conjugated diene interconnection is oxidation sensitive, and when oxidized by $\mathrm{HO}^{\bullet}$ or $\mathrm{ROO}^{\bullet}$, disruption and shortening of the conjugated electron resonance structures between the phenyl group and the BODIPY core shifts C11-BODIPY ${ }^{581 / 591}$ 's fluorescence from red to green $[50,51]$. Conversely, $\mathrm{ONOO}^{-}$induces not only oxidation but also nitration of BODIPY, reducing red fluorescence but not necessarily increasing green fluorescence [52]. Although excimers of the oxidized form are red fluorescent, labelling conditions up to $30 \mu \mathrm{M}$ provides sufficient staining of the plasma and organelle membranes well below the range in which self-quenching or excimer formation occurs [51]. Therefore, excimers do not interfere with the fluorescence of BODIPY and the measured red signal depends only on the reduced form of the probe.
Furthermore, neither C11-BODIPY ${ }^{581 / 591}$ nor its oxidation products are able to spontaneously leak from the lipid bilayer [51] and the ratio of oxidized to nonoxidized C11-BODIPY ${ }^{581 / 591}$ can be used to normalize probe incorporation in cells of different size (lymphocytes, monocytes, and granulocytes) [49]. Only hemolysis and antioxidants, in particular the end-product of purine metabolism, uric acid (UA), could bias the measurement of ROS generation $[49,53]$.

On the contrary, when analyzing the results of intracellular probes, many factors must be taken into account (Table 1).

Ethidium displacement by molecules, such as chemotherapeutics [54] or flavonoids [47], could decrease the ethidium fluorescence signal, making the interpretation of data difficult.

Artefactual amplification of the fluorescence intensity has been suggested to occur via intermediate radicals for both DCF and DHR [46], whereas the presence of quenching and reducing antioxidants could either decrease [55] or increase [56] the oxidation of probes without affecting ROS production. Heme proteins and reduced iron $\left(\mathrm{Fe}^{2+}\right)$ have been shown to oxidize DCFH, and the suitability of DCFHDA for measuring intracellular ROS is increasingly being questioned [46].

In addition to the aforementioned limitations, the fluorescence signal is dependent not only on the oxidation of the probe but also on its concentration. In this context, multidrug resistance- (MDR-) mediated transport has low substrate specificity. Multidrug resistance-related protein 2(MRP2-) mediated DCF extrusion has been reported in human leukocytes [57], and it is well known that Rho123 can be extruded by the MDR [47]. The inclusion of H2DCF-DA in the dilution buffer in order to avoid dye leakage has been suggested [58]. However, overloading with probe generates cell morphology changes and artifacts in platelets $[59,60]$. In this context, it should be pointed out that lyophilic derivatives of intracellular fluorescent probes are substrates of P-glycoprotein (Pgp) and MRP1 [47]. Furthermore, MDR expression is affected by intracellular variation of glutathione (GSH) [61] and oxidative stress [62-65], as well as by various dietary factors [66-69], inflammatory cytokines [70-72], disease states [73-75], and drugs [76-81]. In particular, aspirin, indomethacin, and ibuprofen are substrates for MRP4 [76] and may interfere with fluorescent probe staining. Most importantly, aspirin treatment over a period of 15 days significantly increased MRP4 mRNA and protein expression in platelets of healthy volunteers [78]. MRP4 is involved in the storage of cyclic nucleotides in dense granules [82-84], and MRP4 inhibition impairs platelet aggregation [85]. Besides the aforementioned effects, MRP4 also has a role, together with MRP1 [86], in the efflux of leukotrienes [87]. Therefore, in addition to the potential confounding effect on the fluorescence signal [88], the presence of intracellular probes per se could reduce platelet activation in vitro.

In addition, intracellular esterase activity was shown to be impaired in damaged platelets and highly correlated with ADP-induced aggregation [89], whereas plasma esterases $[59,60]$ and/or inhibition of esterases [47] could potentially interfere with probe staining and fluorescence signal 


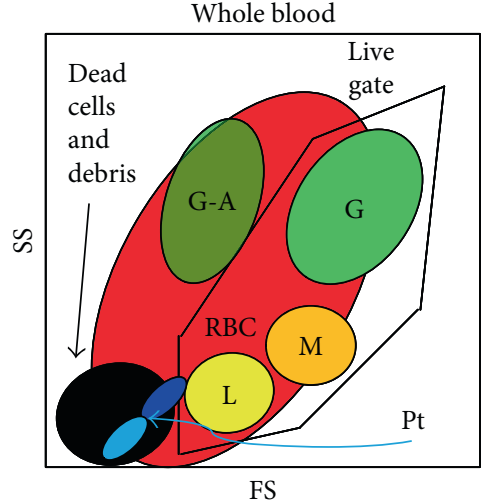

(a) Whole blood

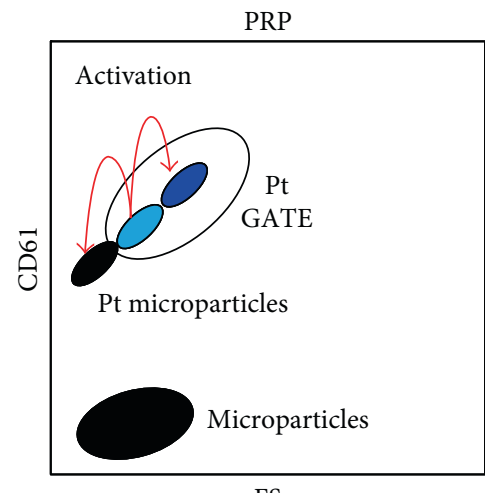

FS

(c) PRP

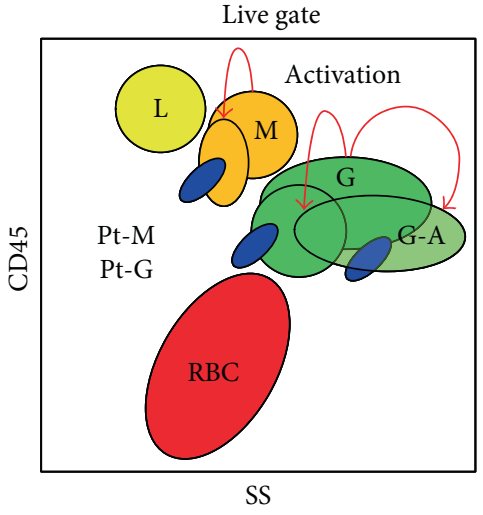

(b) Live gate

Pt gate

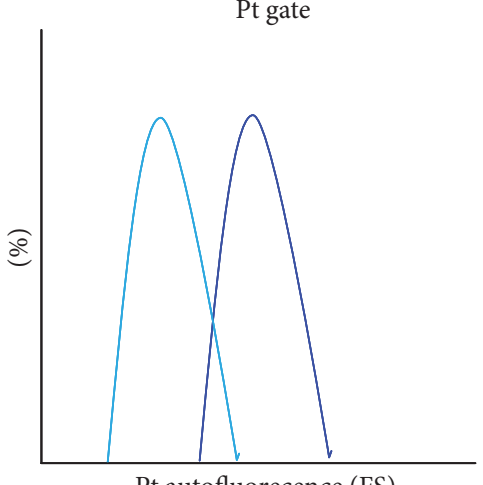

(d) PT gate

FIGURE 1: Gating strategies in the measure of free-radical production by flow cytometry. Different leukocytes populations (lymphocytes: L, monocytes: M, and granulocytes: G) in whole blood can be identified by CD45 (b) in the live gate assigned in the forward scatter (FS) and side scatter (SS) dot plot (a) by excluding dead cells and debris. Red blood cells (RBC) can be excluded as CD45 negative (b). Platelets (Pt) can be identified by CD61 in platelet-rich plasma (PRP) (c). In activated samples, platelet microparticles (c) and leukocyte-platelet aggregates (b: Pt-G and Pt-M) are formed and Pt-G are more prone to apoptosis (G-A). After platelet activation, FS increases due to platelet aggregation inducing an increase in autofluorescence (d).

intensity when using DCFH-DA, DAF-2 DA, and DAF-FM DA in whole blood and platelet-rich plasma (PRP) methods.

Despite the fact that whole blood methods provide more physiologically relevant data when evaluating ROS production in leukocytes [32], washing impairs ADP-induced aggregability of platelets [90] and alters their structure [91], whereas ethylenediaminetetraacetic acid (EDTA) and citrate increase DCFH oxidation [56].

Moreover, whole blood, PRP, and platelet-poor plasma [92] also contain XO, and therefore, UA may be produced during the incubation period with ROS-inducers, potentially falsifying results. Urate crystals induced oxidative burst [27] and the activation and lysis of platelets in vitro $[93,94]$.

With this in mind, it is well known that there is an increased platelet destruction and production in some patients with primary gout $[95,96]$ and that platelet apoptosis and microparticles derived from platelets, erythrocytes, leukocytes, and/or endothelial cells are higher in subjects with CVD [97-99], dyslipidemia [100], and metabolic syndrome [101]. On the other hand, lipid-lowering treatment [100] and the XO inhibitor febuxostat [102] were shown to decrease microparticle count. Gender differences have been reported for microparticle count. Specifically, higher levels of microparticles have been found in women compared with men [103]. Endotoxin induced the formation of platelet microparticles [104], introducing potential confounding factors in conditions of increased levels of lipopolysaccharide, such as the postprandial state [105] and metabolic [106] and inflammatory diseases [107]. Spontaneous activation, generating both microparticles and inducing microaggregation of platelets, occurs in type 2 diabetic patients [108], increases with age in healthy subjects [109], and is affected by blood collection and processing procedures $[109,110]$. On the other hand, platelet aggregates with leukocytes are a marker of activated platelets in CVD patients [111-114], potentially reducing the platelet count in PRP. All these factors must be taken into account when evaluating data from case-control studies that compared ROS-production in unstimulated samples of disease and healthy subjects.

The combination of fluorescently labeled antibodies against targets such as the pan-leukocyte marker CD45 [49] and the platelet marker CD61 [48] and/or physical properties such as size (FS: forward scatter) and internal complexity (SS: side scatter) can identify different leukocyte populations and platelets (Figure 1). 
TABLE 2: Markers based on ROS-induced modifications.

\begin{tabular}{|c|c|c|}
\hline Markers & Methods & Limitations and confoundings \\
\hline \multicolumn{3}{|l|}{ Lipid oxidation } \\
\hline HNE & HPLC, GC-MS Immunoassay & \\
\hline MDA, alkenals, alkadienals & $\begin{array}{c}\text { Spectrophotometric/fluorimetric } \\
\text { (TBARS), HPLC (UV or fluorescence) } \\
\text { Immunoassay }\end{array}$ & $\begin{array}{l}\text { Sugars, amino acids, bilirubin and albumin, } \\
\text { hemolysis }\end{array}$ \\
\hline F2-IsoPs & $\begin{array}{l}\text { Gas/liquid chromatography coupled with } \\
\text { mass spectroscopy techniques Immunoassay }\end{array}$ & Hemolysis Antibody specificity \\
\hline \multicolumn{3}{|l|}{ DNA oxidation } \\
\hline $\begin{array}{l}\text { 8oxodG, 5-chlorocytosine, } \\
\text { 5-chlorouracil, } \varepsilon \mathrm{dA}, \varepsilon \mathrm{dC}\end{array}$ & ELISA assays, HPLC-ECD, HPLC/GC-MS & Antibody specificity \\
\hline \multicolumn{3}{|l|}{ Protein oxidation } \\
\hline ALEs, AGEs & $\begin{array}{l}\text { HPLC, Western blot after one-dimensional } \\
\text { or two-dimensional electrophoretic } \\
\text { separation, immunohistochemistry, ELISA }\end{array}$ & $\begin{array}{l}\text { Structural heterogeneity of these } \\
\text { products Antibody specificity }\end{array}$ \\
\hline Carbonils & Spectrophotometric, HPLC, ELISA & \\
\hline 3-NO-Tyr & HPLC/GC-MS, ELISA & $\begin{array}{l}\text { Possible nitration of tyrosine residues in the } \\
\text { sample by the presence of nitrite and the acid } \\
\text { conditions during protein precipitation and } \\
\text { hydrolysis Antibody specificity }\end{array}$ \\
\hline AOPP & MS, colorimetric assays & \\
\hline oxLDL & Immunodetection (ELISA) & Antibody specificity \\
\hline IMA & $\mathrm{ABC}$ test, immunodetection (ELISA) & $\begin{array}{l}\text { Sensitive to } \mathrm{pH} \text { changes, temperature, and } \\
\text { time of sample storage Antibody specificity }\end{array}$ \\
\hline
\end{tabular}

In activated samples, platelet microparticles [103, 104, 115], platelet aggregates [116], and leukocyte-platelet aggregates $[117,118]$ are formed (Figure 1). In particular, platelet activation in whole blood induces the formation of platelet conjugates with granulocytes or monocytes [119] and leukocyte aggregates with platelets are more prone to apoptosis after in vitro activation (Figure 1) [117].

Regarding the normalization strategies, stimulation indexes calculated from the mean intensity fluorescence (MIF) values and expressed as fold change relative to unstimulated samples have been suggested for evaluating the production of ROS in both granulocytes $[120,121]$ and platelets $[122,123]$. However, these methods do not take into account probe leakage nor autofluorescence differences. While it is well known that autofluorescence generates false-positive monocytes [124], this aspect is neglected in platelet assays. Despite controversy regarding the relationship between CVD and platelet size, measured as mean platelet volume (MPV) or FS $[97,125,126]$, it is well known that FS increases after platelet activation [127] and that large and small platelet subpopulations have different autofluorescence profiles [128] (Figure 1). Consequently, differences in autofluorescence in unstimulated and stimulated samples imply that stimulation indexes do not necessarily measure ROS production. Therefore, it must always be taken into account that the fluorescence signals and not the radicals are measured and that the oxidation of the probe is not always related to ROS production. Overall, the reviewed potential bias and confounding factors suggest that accurate gating and normalization strategies must be applied in order to avoid misinterpretation of the results.

\section{Markers Based on ROS-Induced Modifications}

In addition to the measure of free-radical production, a different approach is measuring stable markers that may reflect a systemic or tissue-specific oxidative stress. Such molecules are modified by the interaction with ROS in the microenvironment [129] (Table 2).

Lipids, DNA, and proteins are examples of molecules that can be modified by excessive ROS in vivo (Table 2) [129]. Some of these modifications are known to have a direct effect on the function of target molecules, such as the inhibition of an enzymatic function, but other modifications just reflect the local degree of oxidative stress. This influences the clinical applicability of several oxidative stress markers since the functional significance or the causal role of oxidative modifications on biological functions is a key characteristic for the validity of a biomarker (Table 2 ).

While measures of oxidative stress in spinal cord [130] and tissues [131, 132] are restricted to particular disease conditions, venous blood and urinary samples are the most commonly used in clinical practice. In addition to urinary samples [133-135], other noninvasive and low-cost tools for the screening of oxidative stress, such as salivary 
[136-138] or exhaled breath [139-141] analysis, have been proposed. However, it has been reported that creatinine urinary markers are not suitable in patients with impaired renal function [135]. Therefore, the validity of a biomarker depends on the choice of the sample that should be dictated by subjects' characteristics and the best cost-benefit ratio.

3.1. Lipid Oxidation Products. Lipid oxidation end product determination is a widely used marker of oxidative stress.

The presence of unsaturated double bonds makes PUFAs, mainly arachidonic acid (AA), highly susceptible to oxidative damage in the presence of ROS or free radicals [5]. Lipids peroxidation may also occur through enzymatic reactions, catalyzed by lipooxygenase and cyclooxygenase (COX), which oxidize AA into prostaglandins, prostacyclin, tromboxane, and leukotrienes. Free radical-mediated oxidation involves an autocatalytic chain reaction triggered by ROS, mainly $\mathrm{HO}^{\bullet}$ and $\mathrm{ROO}^{\bullet}$, which catalyze a hydrogenatom subtraction at the unsaturated bonds generating a carbon radical that can further react with oxygen producing a lipid peroxyl radical. The chain reaction proceeds with lipid peroxyl radical acting as chain-carrying radicals and the formation of lipid hydroperoxydes. In the presence of transition metals, lipid hydroperoxides may generate lipid alkoxyl and $\mathrm{ROO}^{\bullet}$ as well as $\mathrm{HO}^{\circ}$, which can further sustain the chain oxidation reaction to produce short-chain oxidation products, including a variety of different aldehydes, alkanes, and alkenes. Malondialdehyde (MDA) and 4-hydroxy-2-nonenal (HNE) represent the most investigated end product of lipid oxidation [142]. HNE can be detected by high-performance liquid chromatography (HPLC) directly or as a derivatized product with 2,4-dinitrophenylhydrazine or 1,3-cyclohexanedione, by gas chromatography coupled with mass spectroscopy (GC-MS), and by means of immunological techniques using specific anti-HNE antibodies [142-144]. However, when 4-HNE aldehydes were determined using GC-MS system, they were significantly different in plasma and urine of patients with rheumatoid arthritis compared to healthy subjects, but differences between patients with low and high disease activity can be detected only in plasma samples, suggesting that only this sample is useful to monitor the progression of this autoimmune disease [145].

MDA, alkenals, and alkadienals constitute the thiobarbituric acid reactive substances (TBARS), which can react with two equivalents of thiobarbituric acid (TBA) to give a pink adduct complex, easily measured by a colorimetric or fluorimetric assay (Table 2). Despite TBA test for MDA determination being the most frequently used method to evaluate lipid peroxidation, it shows several pitfalls and has been criticized as being too unspecific and prone to artifacts [146-148]. TBA can react with several compounds, including sugars, amino acids, bilirubin, and albumin, producing interferences in the measurement (Table 2). There is a further MDA generation, which occurs during the procedure itself that may be prevented by adding an antioxidant, like butyl hydroxytoluene (BHT), and by reducing the heating time. An additional pitfall is the interference of hemolysis that falsely increases the measured MDA levels (Table 2). Thus, many protocols and modifications of the TBA test are available in the literature, and while direct MDA-
TBA adduct measurement has a low significance, the determination by HPLC combined with UV or fluorescence detection is a more reliable and reproducible method [149-151]. Despite the methodological bias, MDA measurement could have clinical relevance due to the potential pathogenic role of MDA on to the induction of IL-17 producing cells [152] and a possible link between lipid-peroxidation and T-helper 17 (Th17) cellmediated diseases, such as inflammatory bowel diseases [153].

F2-isoprostanes (F2-IsoPs), chemically stable prostaglandin-like isomers generated by the reaction of polyunsaturated fatty acids in membrane phospholipids and free radicals or ROS, represent another reliable marker assessing oxidative stress status in vivo [154-156]. In fact, they are initially formed in lipid membranes as a consequence of oxidative stress and then released in free form by phospholipase action. F2-IsoPs are unaffected by lipid content in diet and thus their measurement in biological fluids as well as exhaled breath condensate can provide an estimation of total body production, whereas measurement of F2-IsoPs esterified in tissues of interest can provide information to localize and quantify the specific oxidative stress. Despite these observations, the utility of F2-IsoPs as biomarkers of oxidative stress is highly limited since their reliable quantification is costly requiring gas/liquid chromatography coupled with mass spectroscopy techniques (HPLC/GC-MS). It must be taken into account that also measures of both MDA and 15(S)-8iso-PGF(2alpha) by GC-MS/MS in plasma samples may be markedly compromised by hemolysis [154]. Immunoassay techniques, based on specific antibodies, are under development, but their application is limited since the obtained results do not correlate well with mass spectrometry determination [155-157]. In addition to the methodological considerations, it must be taken into account that in some inflammatory conditions, the enzymatic product of arachidonic acid prostaglandin F2 $\alpha$ (PGF2 $\alpha$ ) must be evaluated with nonenzymatic oxidation products (F2-IsoPs) in different tissues [158]. In fact, it has been recently reported that PGF2 $\alpha$ levels, but not F2-IsoPs, were higher in cerebrospinal fluid of patients with multiple sclerosis (compared with controls); however, in plasma, both F2-IsoPs and PGF2 $\alpha$ were lower in patients with progressive disease and decreased with increasing disability score [158]. A good approach could be to study the profiling of eicosanoid metabolome, as recently suggested in animal models of rheumatoid arthritis [159, 160].

3.2. Markers of DNA Oxidation. Oxidation of DNA components by ROS/RNS is the major source of induced DNA damages leading to several types of DNA modifications including nucleotide oxidation, strand breakage, loss of bases, and adduct formation $[161,162]$. The $\mathrm{HO}^{\bullet}$ radical can react with all purine and pyrimidine bases, as well as deoxyribose backbone, generating various products, the most common one being 7,8-dihydroxy-8-oxo- $2^{\prime}$-deoxyguanosine (8oxodG) [163].

Oxidatively generated lesions can lead to decomposition in base fragments and the formation of carbon-centered radicals, which give rise, in most cases, to DNA strand breaks. Exposure of DNA to RNS can promote deamination 


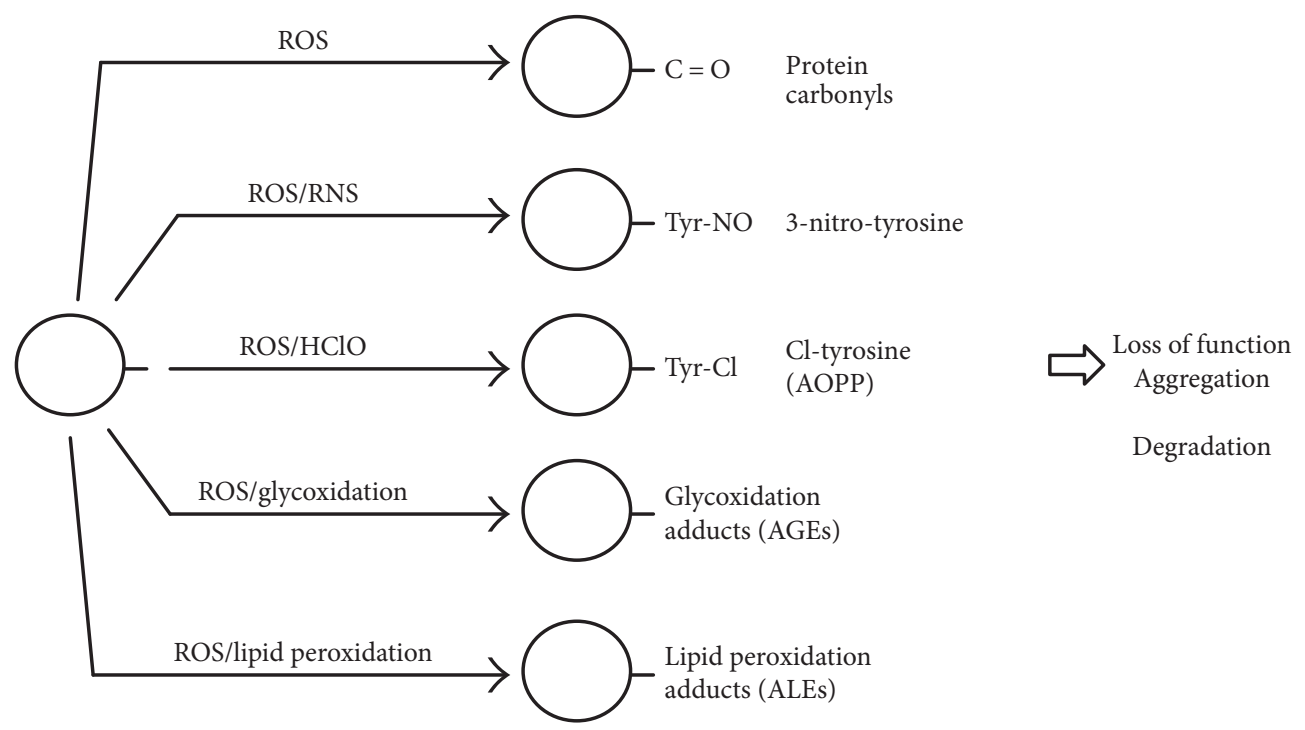

FIGURE 2: Irreversible oxidative modifications of proteins. AGEs: advanced glycation end products; ALEs: advanced peroxidation end products; AOPP: advanced oxidation protein products; HClO: hypochlorous acid; RNS: reactive nitrogen species; ROS reactive oxygen species.

of DNA bases and conversion of guanine into xanthine, oxanine, and 8-nitroguanine, which is rapidly lost from DNA by spontaneous depurination. The major end products of $\mathrm{HClO}$ include 5-chlorocytosine and 5-chlorouracil. These modified bases have been detected at sites of inflammation and are indicative of HClO-mediated DNA damage in vivo [164].

DNA damage may also be caused by the attack of reactive products resulting from ROS-induced modifications of other molecules, such as lipids. In this case, etheno-DNA adducts, such as $1, \mathrm{~N}(6)$-etheno-2'-deoxyadenosine ( $\varepsilon \mathrm{dA})$ and $3, \mathrm{~N}(4)$ etheno-2'-deoxycytidine $(\varepsilon \mathrm{dC})$, are formed and can be used as biomarkers of oxidative stress [165] and may serve as potential markers for assessing progression of inflammatory cancerprone diseases [166]. Elevated etheno-DNA adducts were found in tissues of patients suffering from chronic inflammatory processes [167] while increased levels of urinary $\varepsilon \mathrm{dA}$ were observed in subjects and workers exposed to diesel engine exhaust [168]. Etheno-DNA adducts can be measured by HPLC/MS-based techniques [165, 169].

It has been estimated that several thousands of 8-oxodG lesions may form daily in a mammalian cell, representing $5 \%$ of all oxidative lesions, and for this reason, 8 -oxoG is the most commonly used biomarker of DNA oxidation to measure oxidative stress [170-172]. However, analysis of 8oxodG and other oxidized purines and pyrimidines has been hampered for a long time by the occurrence of several drawbacks associated with their measurement. Optimized assays are now available, and the most reliable is represented by chromatography coupled with mass spectroscopy, even if commercial ELISA assays based on specific antibodies are available $[173,174]$. Although ELISA methods are less specific compared to HPLC with electrochemical detection (HPLC-ECD) and HPLC/GC-MS, some kits with specific antibodies resulted appropriate for urine samples [175].

The oxidized nucleotides are excreted into the urine, and their measurement has been proved to be predictive of the development of several diseases. High level of DNA oxidation, measured as urinary excretion of 8oxodG, is predictive for the risk of breast and lung cancer, atherosclerosis, and diabetes [176-179]. RNA oxidation, measured as 7,8-dihydroxy-8oxoguanosine (8oxoGuo), has been recently introduced as a marker of diseases, particularly neurodegeneration and diabetes, and high level of RNA oxidation has been also associated with breast cancer development in diabetic females [180].

3.3. Protein Oxidation Products. Proteins represent a wide target for ROS and RNS generated under normal or oxidative stress conditions and can be considered as general scavengers of these species. Several amino acidic residues can undergo oxidative modifications including oxidation of sulphur-containing residues, hydroxylation of aromatic and aliphatic groups, nitration of tyrosine residues, nitrosylation and glutathionylation of cysteine residues, chlorination of aromatic groups and primary amino groups, and conversion of some amino acid residues to carbonyl derivatives [181, 182] (Figure 2).

Oxidation can also lead to the cleavage of the polypeptide chain and to the formation of cross-linked protein aggregates [183, 184] (Figure 2).

Oxidation of iron-sulphur centers by $\mathrm{O}_{2}^{\bullet-}$ is irreversible and leads to enzyme inactivation. In addition, metals bound to the protein can generate, through the Fenton reaction, $\mathrm{HO}^{\bullet}$ radicals that rapidly oxidize the neighbor amino acid residues of the protein [185].

If the oxidative modifications of protein residues are not properly repaired or removed, they could affect the threedimensional structure and physicochemical properties of the protein that may also become toxic.

Irreversible modifications of proteins include carbonylation, nitrosilation, breaking of the histidine and tryptophan rings, and hydrolysis of the peptide bond in the presence of proline [186]. The latter mainly occurs in the collagen, rich in proline and hydroxyproline, which is particularly damaged under oxidative stress conditions [187]. 
Determination of protein oxidation has a biological significance and a good clinical relevance. A specific profile of oxidized proteins may be formed as a consequence of different oxidative stress or age-related diseases [188-190]. Biological significance of protein oxidation may also result from its chemical stability and high yield formation. Sample availability is an important factor that limits the reliability of a biomarker. Protein oxidation may be determined in blood and urine samples, although determination in specific tissue or cell samples may give more precise information. It must be noted that protein oxidation may occur during the analytical process thus generating some artefacts [191]. The rates of oxidation reactions are critically dependent on the sample temperature, its physical form, and the presence of oxygen and catalysts (metal ions and light) [192]. For these reasons, measurement of protein oxidation may be a useful marker, as long as it is characterized by a high reproducibility, sensitivity, and specificity.

Several methods have been developed for the detection of the different kinds of protein modifications. However, the biological and clinical relevance of protein oxidation as a biomarker is still limited by the availability of methodologies able to identify and quantify specific protein oxidative modifications.

3.3.1. Protein Carbonyls, ALEs, and AGEs. Carbonyl groups can be generated by many different mechanisms, as the oxidative cleavage of the protein backbone, in particular at the level of glutamyl side chains, and the oxidative deamination of lysine. Also, the attack of $\mathrm{HO}^{\bullet}$ radicals on proline, lysine, arginine, and threonine side chains generates carbonyl groups [193].

The measure of carbonyl levels in proteins is the most widely used marker of oxidative protein damage, and tissues injured by oxidative stress generally contain increased concentrations of carbonylated proteins [186, 194]. Moreover, this biomarker has some advantages in comparison with the measurement of other oxidation products because of the relative early formation and the relative stability of carbonylated proteins. Protein carbonyl levels increase with age and are elevated in several pathologic conditions including neurodegenerative diseases, obesity, or diabetes $[195,196]$.

Methods based on ELISA and HPLC are the most used in clinical assessments because of high throughput and standardization. Detection of protein carbonyl groups generally involves the derivatization of the $\mathrm{CO}$ group with 2,4-dinitrophenylhydrazine (DNPH) with the formation of a stable dinitrophenyl (DNP) hydrazone product. The latter can be detected by several methods which include the direct spectrophotometric measurement of DNP adducts, as well as more specific techniques based on anti-DNP antibodies, like ELISA, Western blot after one-dimensional or twodimensional electrophoretic separation, immunohistochemistry, and HPLC [197-199].

Functional groups of proteins can react with several products resulting from the ROS-induced oxidation of PUFAs and carbohydrate, generating inactive adduct derivatives classified as advanced peroxidation end products (ALEs) and advanced glycation end products (AGEs), respectively [200, 201] (Figure 2). In particular, lysine, histidine, and cysteine residues can react with lipid peroxidation products (HNE, MDA), through a Michael addition reaction, while lysine $\varepsilon$-amino groups can react with reducing sugars and their oxidative products, to generate several carbonyl derivates [202, 203].

AGEs are a heterogeneous group of molecules with carboxymethyl lysine, carboxymethyl valine, and pentosidine as the main protein products, while carboxymethyl lysine is a product of both lipid peroxidation and glycoxidation reactions [204-206].

AGEs increase with aging and their formation has been related to the level of carbohydrates; so, they have been linked to diabetes and obesity [207], as well as other diseases including atherosclerosis, Alzheimer's disease, and renal insufficiency [208, 209]. Mass spectrometry-based techniques represent a key method in identifying protein adducts and the specific site of modification but their use is still limited in routine clinical analysis [210, 211]. To address this, AGEs' assays are mostly based on the use of specific antibodies or spectrofluorimetric measurements based on the fluorescent properties of AGEs [212, 213]. Although promising results came from studies on skin autofluorescence in diabetic patients $[214,215]$, the serum fluorescence AGE (F-AGE) method did not distinguish women with gestational diabetes from the healthy controls [216].

The availability of polyclonal and monoclonal antibodies directed against different HNE-protein adducts (involving cysteine, lysine, or histidine residues) allowed the formulation of immunodetection methods which are commercially available. For example, specific antibodies are used to detect HNE-histidine adducts in tissues or biological samples and HNE-modified tau protein has been associated with neurofibrillary tangles in Alzheimer's disease [217].

The reliability of immuno-based methods is mostly dependent on the specificity of the antibodies utilized, that may lead to differences between the available commercial kits. A fructosamine assay for the detection of ketamine formed via a nonenzymatic glycation reaction of serum protein, and the HPLC measurement of furosine, a specific product obtained after hydrolysis of epsilon-aminofructose-lysine, are also alternative biomarkers [218, 219].

Specific AGEs, as pentosidine and carboxymethyl lysine, can be measured by HPLC [220, 221]. However, their use as biomarkers and the development of specific assays in clinical application are hampered by the structural heterogeneity of these products, due to different mechanisms of formation, and because few AGEs have been characterized.

In addition to the role as marker of oxidative stress, the clinical relevance of AGE is indicated by their pathogenic role in immune- and inflammatory-mediated diseases.

First of all, the role of the receptor for advanced glycation end products (RAGE)-NF-kB axis in neuroinflammation is in line with the nonenzymatic glycosylation theory of aging, suggesting a central role of the AGEs in the agerelated cognitive decline [17]. Besides, the soluble receptor for advanced glycation end products (sRAGE) plays an important role in the pathogenesis of the acute respiratory distress syndrome [222]. 
On the other hand, Turk et al. suggested a role for AGEimmune complexes in the pathogenesis of atherosclerosis. Compared to healthy subjects, both diabetic and nondiabetic patients with coronary artery disease had a higher concentration of circulating immune complexes containing the AGE moiety as antigen, whereas only diabetics had higher antiAGE antibodies [223]. Autoantibodies to IgG-AGE were detected in patients with rheumatoid arthritis, suggesting that glycation of IgG results in the generation of new immunogenic epitopes, potentially inducing circulating autoantibodies [224]. Therefore, AGEs could be one of the links between metabolic syndrome and immune activation.

3.3.2. Nitrotyrosine. 3-nitro-tyrosine (3-NO-Tyr) is the main product of tyrosine oxidation which may occur either within a polypeptide or in free tyrosine residues. This modification can be generated through several pathways that include the reaction with ROS and RNS like $\mathrm{ONOO}^{-}$and $\mathrm{NO}_{2}^{\bullet}$ [225-227] (Figure 2). $\mathrm{NO}^{\bullet}$ generated by NOS can react with $\mathrm{O}_{2}^{\bullet-}$ to form $\mathrm{ONOO}^{-}$that, at acidic $\mathrm{pH}$, is present as protonated form $(\mathrm{ONOOH})$ which is believed to decompose into $\mathrm{HO}^{\bullet}$ and $\mathrm{NO}_{2}^{\bullet}$ to an extent of $~ 30 \%$ [10]. Generally, tyrosine oxidation is a two-step process with the formation of a tyrosine radical, generated by different oxidative steps, followed by the reaction with $\mathrm{NO}_{2}^{\bullet}$. Accurate determination of $3-\mathrm{NO}-\mathrm{Tyr}$ in biological samples requires gas or liquid chromatographic techniques coupled to mass spectrometry [228-230], conditions that are not feasible for high throughput in clinical analysis. For a better determination, protein extracts from biological samples can be completely hydrolyzed before quantification of 3-NOTyr by chromatography. A pitfall in this technique is the possible nitration of tyrosine residues in the sample by the presence of nitrite and the acid conditions during protein precipitation and hydrolysis [231].

ELISA assay based on specific antibodies are also available, but their use is limited by the different affinity of antibodies for different nitrated proteins and the low sensitivity [232, 233]. 3-NO-Tyr has been described as a stable marker of oxidative/ nitrative stress in inflammatory diseases [234, 235], but its utility as clinical biomarker is still questioned. Some studies showed that 3-NO-Tyr plasma levels are increased in several conditions, such as asthma, diabetes, and cardiovascular diseases, and reduced following therapeutic treatments [236, 237]. Moreover, an involvement of 3-NO-Tyr in age-related neurodegenerative diseases has been suggested [238, 239].

3.3.3. Advanced Oxidation Protein Products (AOPP). The reaction of proteins with chlorinated oxidants such as hypochlorous acid results in chlorination of amino acid residues and formation of 3-chloro-tyrosine (3-Cl-Tyr) and 3,5dichloro-tyrosine as main products. These oxidation products are generally classified as advanced oxidation protein products (AOPP) (Figure 2) and include protein aggregates by disulphide bridges and/or tyrosine cross-linking. AOPP is a marker of oxidative stress that reflects the chronic kidney failure and has been identified as a marker of inflammation in many diseases [240-250]. Chloro-tyrosine, as well as 3-nitrotyrosine, can be produced by reaction with ipochlorous acid and $\mathrm{ONOO}^{-}$both generated during inflammation, and it has been observed that AOPP may act as a mediator of the inflammation process and monocyte activation [240]. AOPP levels result as elevated in diseases such as diabetes, uremia, systemic sclerosis, atherosclerosis, and cardiovascular diseases and in patients with renal complications, increasing with the progression of chronic renal failure [241-244].

AOPP level can be measured by colorimetric tests using a chloramine standard or human serum albumin derivatives [245]. 3-Cl-Tyr is a highly specific biomarker that can be detected with very sensitive methods such as mass spectrometry [231, 246]. 3-Cl-Tyr has been detected in patients with atherosclerosis [247] and rheumatoid arthritis [248], in children with cystic fibrosis [249], and in the airways of preterm infants [250].

3.3.4. oxLDL. Low-density lipoproteins can undergo oxidative modification, and this has been correlated with atherosclerosis and cardiovascular diseases [251, 252].

The most common test makes use of specific antibodies that recognize selected modifications of LDL amino acidic residues (i.e., aldehyde-modified lysine residues or oxidized phospholipid-modified residues). However, the use of oxLDL as a biomarker of oxidative stress has been criticized because of the heterogeneity of oxidation products, the low specificity of the antibodies, and the different results obtained depending on the assay utilized [253, 254].

In addition, the clearance of oxLDL and the formation of immunocomplexes must be taken into account. Patients with ischemic stroke with intracranial atherosclerosis had a higher baseline level of oxLDL and a greater decline after a standardized fat meal compared to those that presented extracranial atherosclerosis, indicating an increase of the clearance of the oxLDL after meal [255]. An increase in the uptake of oxLDL has been observed also in macrophages from type 2 diabetes (T2D) patients [256], potentially inducing foam cell formation and atherosclerosis. oxLDL may also induce maturation of dendritic cells and regulate the shift from classical (M1) to alternative (M2) macrophage activation and from $\mathrm{T}$ helper 1 (Th1) to T helper 2 (Th2) response, suggesting that these could act as a bridge between innate and adaptive immunity, involved in plaque development [27]. The Th2induced response could account to the presence of antioxLDL antibodies in subjects with T2D and impaired glucose tolerance [257], as well as to the anti-MDA-LDL IgGs found in serum of patients undergoing off-pump and on-pump coronary artery bypass grafting [258]. Therefore, oxLDL are not only a marker of oxidative stress but also a pathogenic factor whose values should be evaluated in the context of a global clinical examination.

3.3.5. Ischemia-Modified Albumin. Albumin, the most abundant protein in serum and other body fluids, is a carrier of many biomolecules. Albumin is susceptible to oxidation and carbonylation and may also act as an antioxidant system through the reversible oxidation of its cysteine residues. For this reason, it can be considered a general oxidative biomarker in several human diseases. 
TABLE 3

\begin{tabular}{|c|c|c|}
\hline Reversible cysteine modifications & Methods & Limitations and confoundings \\
\hline S-glutathionylation GSH/GSSG SH & $\begin{array}{l}\text { MS, ELISA, WB } \\
\text { Spectrofotometric }\end{array}$ & $\begin{array}{c}\text { For an accurate quantification, a specialized } \\
\text { instrumentation is required }\end{array}$ \\
\hline ROS-regulated transcription factors & Methods & Limitations and confoundings \\
\hline Nrf-2, NF-kB & Immunological techniques, RT-PCR & \\
\hline ROS-generating enzymes & Methods & Limitations and confoundings \\
\hline NOX, MPO, XO, NOS & $\begin{array}{l}\text { Immunological techniques, WB, PCR, } \\
\text { RT-PCR, enzymatic }\end{array}$ & $\begin{array}{c}\text { Antibody specificity } \\
\text { Different percentages of leukocytes' } \\
\text { populations }\end{array}$ \\
\hline Antioxidant enzymes & Methods & Limitations and confoundings \\
\hline SOD, CAT, GPX, GR & $\begin{array}{l}\text { Immunological techniques WB, PCR, } \\
\text { RT-PCR, enzymatic }\end{array}$ & $\begin{array}{c}\text { Antibody specificity } \\
\text { Different percentages of leukocytes' } \\
\text { populations }\end{array}$ \\
\hline
\end{tabular}

CAT: catalase; GPX: glutathione peroxidase; GR: glutathione reductase; GSH: glutathione; MPO: Myeloperoxidase; MS: mass spectroscopy; NOS: nitric oxide synthases; NOX: NADPH oxidase; PCR: reverse-transcription polymerase chain reaction; SOD: superoxide dismutase; WB: Western blot; XO: xanthine oxidase.

Myocardial ischemia results in structural changes to the $\mathrm{N}$-terminus of the serum albumin related to the production of ROS $[259,260]$. These changes reduce the ability of albumin to bind transition metals, particularly cobalt cations, which can be detected by the albumin cobalt-binding (ACB) test [261-263]. Besides the $\mathrm{N}$-terminal cobaltbinding site, albumin contains two additional sites that are negatively modulated by fatty acids binding to albumin. Therefore, it has been hypothesized that the release of fatty acids in myocardial ischemia is responsible for the lower cobalt-binding capability [264]. The ABC test indirectly detects Ischemia Modified Albumin (IMA) by measuring the decreased binding capacity of albumin for cobalt [265] and has been carried out by the Food and Drug Administration (FDA) to detect myocardial ischemia. Growing evidence suggest that IMA is not only specific for cardiac ischemia, but its elevated levels are also reported in patients with liver cirrhosis, pulmonary embolism, diabetes mellitus, cerebrovascular disease, and Alzheimer's disease [266-269]. Thus, measurements of IMA serum levels could be a new marker of oxidative imbalance. However, ACB test is sensitive to $\mathrm{pH}$ changes, altering the metal-binding capacity of the albumin, as well as temperature and time of sample storage. Analysis should be performed within $2 \mathrm{~h}$ or the serum should be separated and frozen $[270,271]$. Recently, several immunoassays based on specific antibodies anti-IMA have been introduced in the market.

\section{Redox Proteomic and Markers Based on Cysteine and Redox Enzymes}

The powerful strategy offered by the mass-proteomic approach makes it now possible to reach high sensitivity and specificity in determining oxidative modifications of selected proteins. If fact, redox proteomic can provide information on both the identification of the oxidized protein and the extent of oxidative damage occurring at the protein level [272-274]. Proteins may become reversible oxidized in response to a redox signalling, but irreversible oxidative modifications are associated with disorders and pathologies $[275,276]$. Thus, a profile of oxidative modification of plasma or tissue sample proteins is a promising approach that will help in clinical determination of several human diseases and pathological states [189, 276, 277]. This will also make the identification of novel biomarkers and therapeutic targets for different human diseases possible.

In particular, components whose deregulation can result in oxidative stress, such as the ROS-generating enzymes, and antioxidant defence systems, which change in response to increased redox stress, can be used to assess the redox state of the body or specific tissues and cells in health and disease.

In the context of redox proteomic, major players are cysteine residues (including the GSH system), antioxidant (SOD, CAT, and GPX), and ROS-generating enzymes, as well as the transcription factors involved in their regulation [278] (Table 3).

Surface-exposed cysteine residues are particularly sensitive to oxidation by ROS and RNS and are the most vulnerable among all amino acids [240].

Although the reactivity of thiol groups toward $\mathrm{H}_{2} \mathrm{O}_{2}$ is very low, the nucleophilicity and reactivity toward several ROS species, including $\mathrm{HO}^{\bullet}, \mathrm{HClO}, \mathrm{O}_{2}^{\bullet-}$, and $\mathrm{NO}^{\bullet}$, increase when the sulfur atom of the thiol group becomes deprotonated. Solvent exposure of the cysteine residue and the presence of neighbour polar residues exert a great influence on thiol group pKa. Thus, cysteine oxidation by ROS depends on the protein context and provides the basis for selective and specific modifications $[279,280]$.

The primary product of cysteine residue oxidation by $\mathrm{H}_{2} \mathrm{O}_{2}$ is the sulfenic acid (-SOH), whose stability and further reactivity may be influenced by the presence or availability of a proximal thiol group, resulting in the formation of a disulfide bond [281,282] (Figure 3). Additionally, sulfenic acid may further react with $\mathrm{H}_{2} \mathrm{O}_{2}$ to produce sulfinic $\left(-\mathrm{SO}_{2} \mathrm{H}\right)$ and sulfonic $\left(-\mathrm{SO}_{3} \mathrm{H}\right)$ acids (Figure 3). Cysteine residues may also react with $\mathrm{HO}^{\bullet}$ and $\mathrm{O}_{2}^{--}$species, resulting in the formation of a highly reactive radicalic sulfur atom (RS*), which can further react with another thiol residue generating a disulfide, while the reaction with $\mathrm{NO}^{\bullet}$ produces a S-nitrosylated cysteine [283].

Oxidation of cysteine residues is reversible, with the exception of sulfinic and sulfonic acids products; it may be 


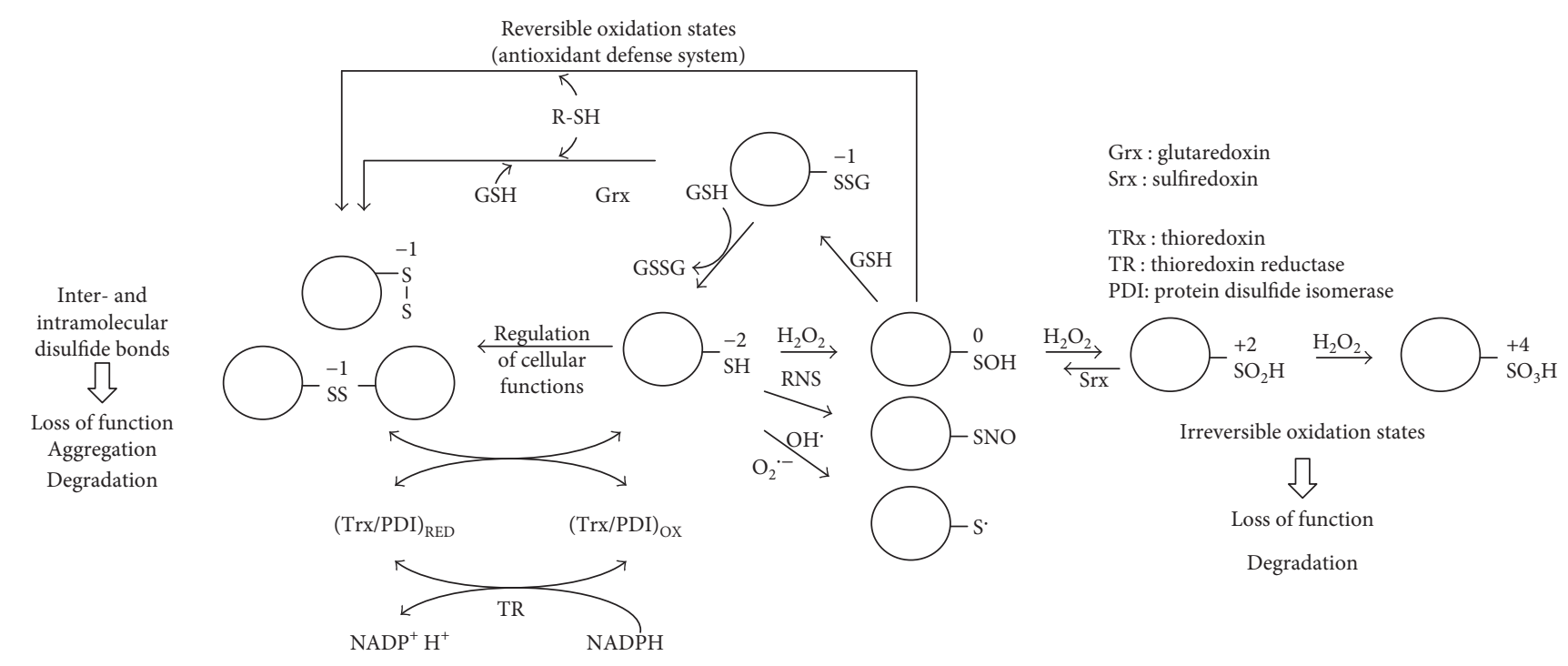

FIGURE 3: Reversible oxidation of protein cysteine residues. GSH: glutathione; $\mathrm{H}_{2} \mathrm{O}_{2}$ : hydrogen peroxide; $\mathrm{O}_{2}^{\bullet-}$ : superoxide; RNS: reactive nitrogen species; $\mathrm{RS}^{\bullet}$ : sulfur atom; $-\mathrm{SO}_{2} \mathrm{H}$ : sulfinic acid; $-\mathrm{SO}_{3} \mathrm{H}$ : sulfonic acid; $-\mathrm{SOH}$ : sulfenic acid.

reversed to the thiol form by reaction with GSH and/or specific enzymatic activities (thioredoxins, glutaredoxins, and protein disulfide isomerases) [284-286] (Figure 3).

The reversible protein oxidation is an important feature for the antioxidant defence systems, which can efficiently help in reducing the intracellular levels of oxidized proteins, produced upon cell exposure to damaging agents, and prevent the accumulation of misfolded or self-aggregating proteins [190, 273, 287-289] (Figure 3).

Reversible protein modifications may be also an important feature for signalling pathways involving ROS and RNS through the chemical modification of selected substrate proteins. This provides the basis for several redox-regulated cellular processes and enzymatic functions which imply redox-dependent modifications [290-292]. So, protein oxidative modifications can be a consequence of oxidative or nitrosative stress as well as the reflection of redoxregulated processes [273, 293].

4.1. Protein Glutathionilation. Reversible protein-Sglutathionylation can occur either under physiological conditions, within redox signalling pathways, or as result of GSH antioxidant activity through the reduction of oxidized cysteine residues and the formation of mixed disulfide protein-glutathione (PSSG). Cysteine- ( $\mathrm{SOH}-$ ) glutathionilation may act as a protective mechanism preventing further irreversible oxidation to sulfinic or sulfonic acids [294]. Reduction of PSSG can take place spontaneously, when the GSH/GSSG ratio is high, or can be catalyzed by protein thiol-disulfide oxidoreductases, such as glutaredoxins, protein disulfide isomerases, thioredoxin, peroxiredoxins, and sulfiredoxins [295]. Recent advances in redox proteomic techniques have led to the identification of many Sglutathionylated proteins and their involvement in redoxregulated pathways. Reversible protein-S-glutathionylation in monocytes and macrophages has emerged as a new and important signalling paradigm, which provides a molecular basis for the well-established relationship between metabolic disorders, oxidative stress, and cardiovascular diseases [296].

Measurement of S-glutathionylation of functional important proteins is a promising biomarker. However, this is hampered by complexity in the methodologies (accessing tissue samples and procedural artefacts) which requires special care in sample handling and preparation [297]. A simpler approach is analyzing S-glutathionylation of proteins in circulating cells. Glutathionylation of haemoglobin has been proposed as a marker of oxidative stress, and an increase in protein modification has been reported in patients with diabetes, hyperlipidaemia, and renal failure [298, 299].

Although S-glutathionylation can be easily measured by Western blotting under nonreducing conditions, the use of more effective approaches is required for an accurate quantification. MS techniques are valid but require specialized instrumentation. In addition, ELISA tests using monoclonal anti-glutathione antibody have been developed [300-302].

4.2. Glutathione and Cysteine. GSH is a tripeptide representing the most abundant nonprotein thiol present in the cell, where its concentration can reach the millimolar range $[303,304]$. GSH acts as an antioxidant defense system by its ability to scavenge ROS through the reversible oxidation to GSSG (Figure 3). GSSG can be enzymatically reduced to GSH by the activity of glutathione reductase (GR) and the reducing power of NADPH. Glutathione is mainly stored within the cytosol, where the ratio GSH/GSSG is ranging from 30 to 100 [305]. This ratio is ten times lower in the serum and in the endoplasmic reticulum and decreases in the presence of oxidative stress. Glutathione synthesis depends on the availability of cysteines, the rate-limiting precursor, and this makes its use as a marker of oxidative stress questionable. Besides, diurnal variation in GSH and cysteine has been reported [306]. However, several studies relate the GSH levels and GSH/GSSG ratio to pathological conditions [254]. The measurement of GSH, GSSG, and their ratio in 


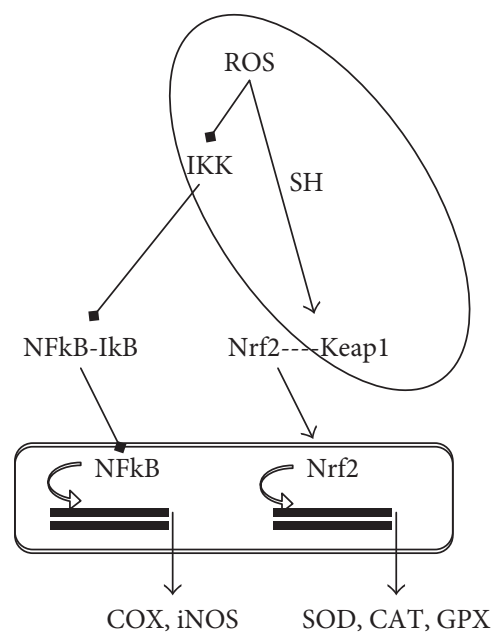

Figure 4: Cysteine-regulated gene expression. CAT catalase; COX: cyclooxygenase; GPX: glutathione peroxidase; IKK: I $\kappa$ kinases; iNOS: inducible nitric oxide synthase; Keap1: Kelch-like ECHassociating protein 1; Nfr2: nuclear factor-erythroid 2-related factor 2; NF-kB: nuclear factor kappa-light-chain-enhancer of activated B cells; ROS: reactive oxygen species; SH: thiol; SOD: superoxide dismutase.

blood has been considered an index of the redox status in the whole-organism and a useful marker of diseases in humans [307, 308]. Several methods have been used to determine the GSH in biological samples (spectrophotometry, HPLC, capillary electrophoresis, nuclear magnetic resonance, and mass spectrometry) [307]. However, GSH and its oxidate form GSSG do not represent powerful biomarkers of oxidative stress because of some methodological artifacts. For instance, sample acidification for protein precipitation leads to an increase in GSSG levels [308].

4.3. Nrf-2 and NF-kB. As mentioned above, oxidation of selected cysteine residues present in specific proteins may result in the regulation of cellular response to oxidative stress. This is the case for Nrf-2, a conserved transcription factor that is a master regulator of the antioxidant response system controlling the expression of more than 250 genes. Nrf-2 is normally sequestered into the cytoplasm complexed to the protein Keap1 (Kelch-like ECH-associating protein 1), which facilitates its polyubiquitination and proteasome-mediated degradation [309]. Keap1 contains specific cysteine residues sensitive to oxidation in the presence of oxidants or other electrophiles (Figure 4). Thus, Keap1 functions as a specific sensor of stress that upon oxidation, and resulting conformational change, releases Nrf-2 allowing its translocation into the nucleus.

Nrf-2 promotes the transcriptional activation of a specific set of target genes containing the antioxidant response elements (AREs) in their promoter regions and encoding antioxidant and detoxifying enzymes (i.e., glutathione Stransferase, glutathione synthetase, heme oxygenase 1, and NAPH-oxidoreductase) (Figure 4). Thus, Nrf-2 is related to the cellular defence against ROS and it has been observed that its activity declines with age as well as with degenerative disorders [310].
On the other hand, an increased Nrf-2 activity has been observed in transformed cells [311], where it provides a reduced sensitivity both to the large amounts of ROS generated during the active proliferation and to chemotherapeutic drugs, whose enzymatic elimination requires enhanced levels of NAPDH. For these reasons, Nrf- 2 can be considered a valid biomarker and its levels in tumour samples, quantified by immunological methods or by RT-PCR, may have a clinical significance. Recently, the determination of Nrf-2 levels, in combination with measuring high-mobility group box-1 (HMGB1) expression, might represent a useful tool in the early detection of post-trauma complications [312].

Whereas Nrf2 has a primary role in antioxidant enzymes gene expression, NF-kB is involved in the transcription of ROS-generating and inflammatory enzymes (Figure 4). As observed for Nrf2, some cysteine residues are involved in the translocation of NF-kB to the nucleus (Figure 4). In particular, cysteine 179 of I $\kappa$ kinases (IKK) is a target of the Sglutathionylation-induced inactivation and glutaredoxin reverses this effect [313]. Furthermore, electrophilic modifications of cysteine 179 of IKK inhibit NF-kB activation and have been suggested as one of the mechanisms involved in the anti-inflammatory and COX-inhibitory effects of nutraceuticals $[314,315]$. Similarly, antioxidants with catechol and electrophilic moieties induce the Nrf2-mediated gene expression of antioxidant enzymes acting as pro-oxidants rather than antioxidants $[316,317]$.

4.4. Enzymes. ROS-generating enzymes are involved in several cell functions and their alteration may result in imbalanced redox status (Figure 5).

The established role in diseases of XO [318] and NOX [319, 320] suggested their pharmacological inhibition in the prevention and treatment of pathologies related to oxidative stress.

Some ROS-generating enzymes can be found in the circulation and thus can be used as markers of oxidative stress, such as NOS and NOX (Figure 5) involved in oxidative burst.

It has been shown that high levels in the circulations of MPO, a heme peroxidase abundant in granules of human inflammatory cells, which catalyzes the conversion of $\mathrm{H}_{2} \mathrm{O}_{2}$ to $\mathrm{HClO}$ with the production of ROS (Figure 5), are associated with cardiovascular disease [321], chronic obstructive pulmonary disease [322], and Alzheimer's disease [323].

Oxidant species derived from MPO lead to the production of specific oxidation products, such as 3-Cl-Tyr. This can be used as biomarker in several diseases [324], as above described, and its levels correlate with MPO. However, expensive equipment are required to detect the levels of MPO-dependent specific biomarkers and this represents a limitation in their use. Moreover, the concentration of these biomarkers in biological samples is low, which complicates accurate measurement.

XO catalyzes the oxidation of hypoxanthine and xanthine to UA in the terminal steps of purine nucleotide metabolism [325], which also leads to the production of $\mathrm{O}_{2}^{\bullet-}$ [326] (Figure 5). Given that XO produces ROS in stoichiometric quantities along with UA, it represents one of the major sources of free oxygen radicals in human physiology. Upregulation of XO activity may lead to an increase in UA serum 

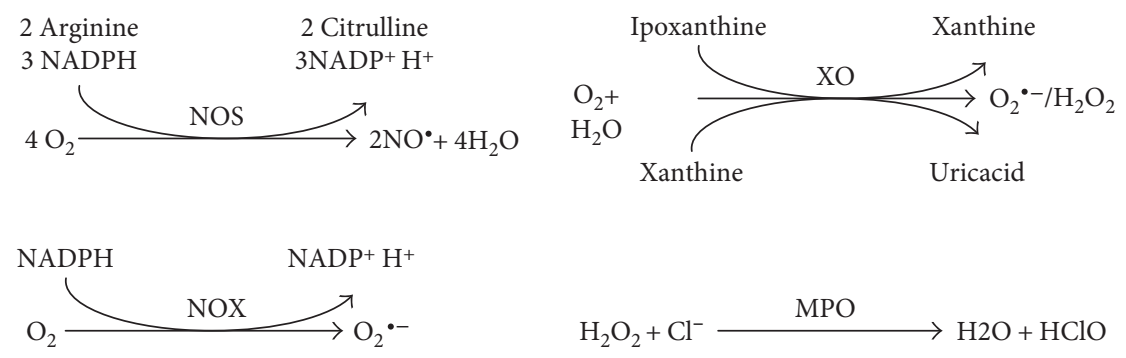

FIGURE 5: ROS generating enzymes. $\mathrm{H}_{2} \mathrm{O}_{2}$ : hydrogen peroxide; $\mathrm{HClO}$ : hypochlorous acid; MPO: myeloperoxidase; NOS: NO synthase; NOX: $\mathrm{NADPH}$ oxidase; $\mathrm{O}_{2}^{\bullet-}$ : superoxide; $\mathrm{XO}$ : xanthine oxidase.

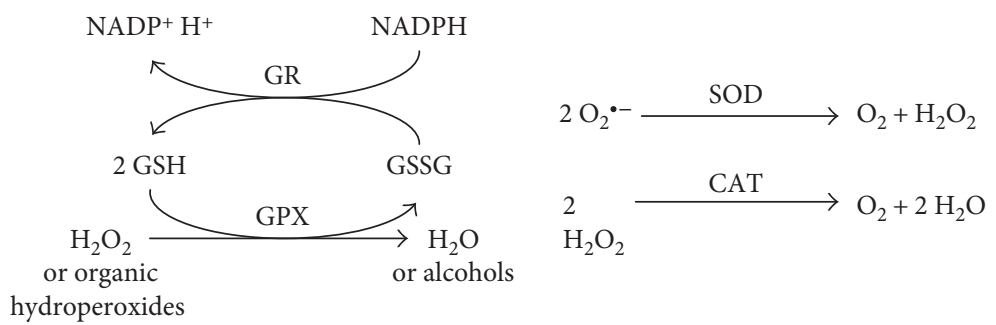

Figure 6: Antioxidant enzymes. CAT: catalase; GPX: glutathione peroxidase; GR: glutathione reductase; $\mathrm{H}_{2} \mathrm{O}_{2}$ : hydrogen peroxide; $\mathrm{O}_{2}^{\bullet-}$ : superoxide; SOD: superoxide dismutase.

levels, oxidative stress, and endothelial dysfunction [327-329]. $\mathrm{XO}$ exists in two interconvertible forms, $\mathrm{XO}$ (that oxidizes xanthine to UA using oxygen as the electron acceptor and produces superoxide or $\mathrm{H}_{2} \mathrm{O}_{2}$ ) and xanthine dehydrogenase $(\mathrm{XDH})$ (that carries out the same reaction but uses $\mathrm{NAD}^{+}$ and generates $\mathrm{NADH}$ ). $\mathrm{XDH}$ is the predominant form in well-oxygenized tissue [330], but it can be converted to XO under various conditions $[331,332]$. Inflammatory or hypoxic conditions promote $\mathrm{XDH}$ expression in tissues and vascular endothelial cells and stimulate XDH release into the circulation [333]. Once in the circulation, $\mathrm{XDH}$ is quickly converted, by reversible oxidation of the sulfhydryl residue or by irreversible proteolysis, into XO which binds to the endothelial surface, resulting in amplified XO-derived ROS formation [334]. This XO-induced oxidative stress has been detected in renal and cardiovascular diseases, such as heart failure, chronic obstructive pulmonary disease, pulmonary hypertension, sickle cell disease, and diabetes [334]. An increase in XO activity has been reported in patients with heart failure $[326,335]$, whereas XO activity and its plasma levels are raised in presence of inflammatory agents and interferon [336] and seems to play a key role in ischemia-reperfusion injury [337].

As described for MPO, an indicator of the enzyme activity in vivo could be the detection of a metabolite or a reaction product. Serum levels of UA may reflect XO activity, but they are also dependent on dietary intake, and purine metabolism, and renal filtration and reabsorption, as well as endothelia dysfunctions. Higher UA levels are associated with metabolic, cardiovascular, and renal abnormalities, and UA has been recently proposed as a biomarker and therapeutic target in diabetes [338-340]. UA is a powerful antioxidant in plasma and can scavenge $\mathrm{O}_{2}^{\bullet-}$ and $\mathrm{HO}^{\bullet}$, and allantoin is its oxidative product of which formation is independent of changes in UA levels [341-343]. This makes allantoin a promising biomarker of oxidative status, considering also its stability regardless of the storage or sample preparation, but its quantitative determination requires specific instrumental techniques as liquid/gas chromatography and mass spectrometry [344-346].

The most important antioxidant enzymes are SOD, CAT, and glutathione-dependent enzymes, such as GPX, GR, and glutathione transferases (GSTs) (Figure 6).

SODs are a family of enzymes catalyzing dismutation of superoxide into oxygen and $\mathrm{H}_{2} \mathrm{O}_{2}$. There are three isoforms of SOD, with a different cellular localization and metal cofactor: homodimeric $\mathrm{Cu} / \mathrm{Zn}$-SOD localized in the cytosol and in the mitochondrial intermembrane space, homotetrameric $\mathrm{Cu} / \mathrm{Zn}-\mathrm{SOD}$ with an extracellular distribution, and homotetrameric Mn-SOD localized in the mitochondria [347]. SOD acts also as pro-oxidant producing $\mathrm{H}_{2} \mathrm{O}_{2}$; therefore, other antioxidant enzymes such as CAT and GPX are required and an imbalance in their ratio may be dangerous.

SOD activity can be measured analyzing the inhibition in the rate of reduction of a tetrazolium salt by $\mathrm{O}_{2}^{\bullet-}$ generated through a xanthine/XO enzymatic system [348, 349].

CAT, which catalyzes the conversion of $\mathrm{H}_{2} \mathrm{O}_{2}$ into water and oxygen, is a homotetrameric protein containing four iron heme and largely located in the peroxisomes. CAT activity can be measured by several colorimetric/spectrophotometric assays [349, 350].

GSH redox cycle is regulated by GPX and GX. GPXs are a family of selenium-dependent isozymes that catalyze the reduction of $\mathrm{H}_{2} \mathrm{O}_{2}$ or organic hydroperoxides to water and alcohols through the oxidation of GSH to GSSG. GR then 
reconverts GSSG to GSH using the reducing power of NADPH [351]. GPX activity can be measured using cumene hydroperoxide and GSH as substrates in a coupled reaction with GR [352]. The GSSG formed after reduction of hydroperoxide is recycled to its reduced state by GR in the presence of NADPH. The oxidation of NADPH is accompanied by a decrease in absorbance at $340 \mathrm{~nm}$ proportional to GPX activity. GR activity can be measured in a similar manner using GSSG and NADPH as substrates [353].

Differently from ROS-generating enzymes, conflicting results came from human studies that evaluated the relationship between diseases or ageing and antioxidant enzymes. Despite meta-analyses suggesting that polymorphisms of antioxidant enzymes are associated with T2D [354] and hypertension [355], decreased or increased activities (or levels) have been reported for SOD, catalase, GPX, and/or GR in these diseases [356-367]. Activity of SOD or CAT was significantly higher in elderly hypertensives [356] and T2D [360, 361, 368] when compared with healthy controls. Increased SOD activity has been reported also in coronary artery disease patients [369] and in women with the polycystic ovary syndrome [370]. In patients with Crohn's disease, SOD and GPX increase during the active phase and return to normal during the remission phase [371]. It has been suggested that the increase in antioxidant enzymes may represent a compensatory upregulation in response to increased oxidative stress [361, 368]. Results of Karaouzene et al. suggest that this response depends on age [372]. Erythrocyte SOD and CAT activities were enhanced in obese young patients but reduced in obese older men [372]. The ARE/ Nrf2 pathway is the major player in the induction of the expression of antioxidant genes [309]. However, although phytochemicals contained in fruits and vegetables are known to induce Keap1/Nrf2 system [373] in a meta-analysis [374] of randomized controlled trials, no significant differences were observed between fruit or vegetable juices and placebo in SOD and CAT, despite the reduction of MDA.

In order to understand the contrasting results in human studies, some methodological considerations must be made. Conventional methods for measuring enzymes are enzyme activity, protein content (Western blots and immunological techniques), or gene expression (reverse-transcription polymerase chain reaction (RT-PCR)) (Table 3) [129]. First of all, it must be taken into account that different samples have different antioxidant content. In a meta-analysis, decreased activities of SOD and GPX were observed in plasma/serum of postmenopausal women with osteoporosis, but the activities of SOD in erythrocytes and of CAT in plasma/serum were not statistically different from the control group [375]. Concerning the measure of cellular enzymes, it must be considered that processing and cryopreservation procedures could affect peripheral blood mononuclear cell (PBMC) gene expression [376, 377]. In addition, PBMC exclude from the analysis the neutrophils that are the major component of the full blood count [378], reducing the clinical relevance of this sample compared to whole blood RNA. On the other hand, the different cell types present in blood have a different content of enzymes. In whole-blood iNOS, RNA was expressed predominantly in monocytes [379]. Although the presence of MPO in lymphocytes has been recently reported, it is very low compared to neutrophils/monocytes [380]. Concerning antioxidant enzymes, neutrophils have higher levels of SOD and catalase transcripts compared to monocytes [381]. On the other hand, GSH content and GPX transcript and activity are higher in monocytes [381]. In this context, results from meta-analysis document that neutrophil-to-lymphocyte ratio [382-387] and lymphocyteto-monocyte ratio $[388,389]$ were related to clinical oncological outcomes in cancer patients. Also, coronary artery disease is associated with altered ratio of leukocytes [390], the expansion of monocytes, and the reduction of the CD4/ CD8 $\mathrm{T}$ cell ratio, and $\mathrm{B}$ cell lymphopenia can be observed in end-stage renal disease [391]. Furthermore, also in heathy subjects, the normal ranges of the different leukocyte populations are very large [392]. Probably, the use of cell marker coding genes (CD4, CD8, CD14, etc.) as housekeeping genes could normalize the results for the physiologically or pathologically different content of cells between subjects [378]. This approach could also help in conditions, such as hyperglycemia, that can influence the expression of housekeeping genes [393].

\section{Measuring the Nonenzymatic Antioxidant Capacity in Body Fluids}

The nonenzymatic antioxidant capacity (NEAC), also named total antioxidant capacity (TAC), is defined as the moles of oxidants neutralized by one liter of body fluids [278, 394-396]. In plasma, nonenzymatic antioxidants include endogenous (e.g., UA, bilirubin, and thiols) and nutritional (e.g., tocopherols, ascorbic acid, carotenoids, and phenolics) compounds [278, 394]. Various assays for NEAC [129, 397-412] measure either their radical scavenging or reducing capacity. Reaction mechanisms include hydrogen atom transfer (HAT) and single electron transfer (SET) (Table 4). The latter reports on antioxidants' reductive capacity, including its metal reducing power, and could be considered an "indirect assay," whereas the former is a "direct assay" (competitive) in which the inhibition of the oxidation of an indicator substance is determined as a measure of the antioxidant capacity [406, 407]. The most common HAT methods are oxygen radical antioxidant capacity (ORAC) and the total radical-trapping antioxidant parameter (TRAP), performed in aqueous solutions with 2,2'azobis(2-methylpropionamidine) dihydrochloride (AAPH) as a thermolabile stoichiometric and water-soluble azoradical generator (Table 4 ).

The Crocin bleaching assay can be performed under both hydrophilic and lipophilic conditions by using AAPH or 2,2'azobis 2,4-dimethylnaleronitrile (AMVN), which is AAPH's lipophilic equivalent. Aldini et al. [401] monitored the oxidation of the lipid compartment of plasma by using $2,2^{\prime}$-azobis(4-methoxy-2,4-dimethylvaleronitrile) (MeO-AMVN), as lipid soluble radical initiator and C11-BODIPY ${ }^{581 / 591}$ as lipophilic fluorescence probe. The MeO-AMVN-C11-BODIPY ${ }^{581 / 591}$-based total antioxidant performance (TAP) assay was reported to be sensitive to plasma antioxidants localized in both the lipophilic and hydrophilic compartments [400]. In all HAT methods, $\mathrm{ROO}^{\circ}$ reacts with the target 
TABLE 4: Common used methods for NEAC measurements.

\begin{tabular}{|c|c|c|}
\hline Method & Reaction and quantification & Limitations and confoundings \\
\hline $\begin{array}{l}\text { HAT } \\
\text { ORAC }\end{array}$ & $\begin{array}{c}\text { AAPH-induced: } \\
\text { R-phycoerytherin (red) or fluorescein (green) } \\
\text { fluorescence decay } \\
\text { Competitive reaction kinetic, AUC }\end{array}$ & $\begin{array}{c}\text { Lipophilic antioxidants not included } \\
\text { Proteins }\end{array}$ \\
\hline $\begin{array}{l}\text { HAT } \\
\text { TRAP }\end{array}$ & $\begin{array}{c}\text { AAPH-induced: } \\
\text { R-phycoerytherin fluorescence decay (red) } \\
\text { DCFH } \rightarrow \text { DCF fluorescence increase (green) } \\
\text { Competitive reaction kinetic, lag phase }\end{array}$ & $\begin{array}{l}\text { Lipophilic antioxidants not included } \\
\text { Not all the antioxidants give a lag phase } \\
\text { Self-propagation of DCF radicals }\end{array}$ \\
\hline $\begin{array}{l}\text { HAT } \\
\text { Crocin bleaching }\end{array}$ & $\begin{array}{l}\text { AAPH- or AMVN-induced absorbance } \\
\text { decay }(450 \mathrm{~nm}) \\
\text { Competitive reaction kinetic, Stern-Volmer-like } \\
\text { relation }\end{array}$ & $\begin{array}{l}\text { Bilirubin and carotenoids that absorb at the } \\
\text { wavelength of determination }\end{array}$ \\
\hline $\begin{array}{l}\text { HAT } \\
\text { TAP }\end{array}$ & $\begin{array}{c}\text { MeO-AMVN induced } \\
\text { C11-BODIPY fluorescence increase (green) } \\
\text { Competitive reaction kinetic, AUC }\end{array}$ & \\
\hline TAS & $\begin{array}{l}\text { Fenton reaction-induced dianisidyl radical } \\
\text { absorbance increase }(444 \mathrm{~nm}) \\
\text { Competitive, endpoint, TEAC }\end{array}$ & \\
\hline SET (Randox) & $\begin{array}{l}\text { Fenton reaction-induced ABTS radical } \\
\text { formation }(734 \mathrm{~nm}) \\
\text { Competitive reaction, endpoint, TEAC }\end{array}$ & \\
\hline $\begin{array}{l}\text { SET } \\
\text { ABTS }^{\bullet+}\end{array}$ & $\begin{array}{c}\text { Absorbance decay }(734 \mathrm{~nm}) \\
\text { Noncompetitive, endpoint, TEAC }\end{array}$ & \\
\hline $\begin{array}{l}\text { SET } \\
\mathrm{DPPH}^{\bullet}\end{array}$ & $\begin{array}{l}\text { Absorbance decay }(515 \mathrm{~nm}) \\
\text { Noncompetitive, endpoint, EC50 }\end{array}$ & $\begin{array}{c}\text { Carotenoids that absorb at the wavelength of } \\
\text { determination }\end{array}$ \\
\hline $\begin{array}{l}\text { SET } \\
\text { FRAP }\end{array}$ & $\begin{array}{l}\text { Absorbance increase }(593 \mathrm{~nm}) \\
\text { Noncompetitive, endpoint }\end{array}$ & $\begin{array}{c}\text { SH not included } \\
\text { Biliverdin absorb at the wavelength of } \\
\text { determination }\end{array}$ \\
\hline $\begin{array}{l}\text { SET } \\
\text { CUPRAC }\end{array}$ & $\begin{array}{l}\text { Neocuproine absorbance increase }(450 \mathrm{~nm}) \text {. } \\
\text { Noncompetitive, endpoint }\end{array}$ & $\begin{array}{l}\text { Bilirubin and carotenoids that absorb at the } \\
\text { wavelength of determination }\end{array}$ \\
\hline
\end{tabular}

AAPH: 2,2'-azobis(2-methylpropionamidine) dihydrochloride; ABTS: 2,2'-azino-bis(3-ethylbenzothiazoline-6-sulphonic acid); AMVN: 2,2'-azobis 2,4dimethylnaleronitrile; AUC: area under the curve; CUPRAC: copper-reducing assay; DCFH: 2',7'-dichlorodihydrofluorescein; DPPH: 2,2-diphenyl-1picrylhydrazyl; EC50: efficient concentration (EC), the amount of antioxidant necessary to decrease by 50\%; FRAP: ferric reducing antioxidant power; HA: T hydrogen atom transfer; MeO-AMVN: 2,2'-azobis(4-methoxy-2,4-dimethylvaleronitrile); NEAC: nonenzymatic antioxidant capacity; ORAC: oxygen radical antioxidant capacity; SET: single electron transfer; SH: thiols; TAC: total antioxidant capacity; TAP: total antioxidant performance; TAS: total antioxidant status; TEAC: Trolox equivalent antioxidant capacity; TRAP: total radical-trapping antioxidant parameter.

compound resulting in changes of fluorescence or absorbance of probe (Table 4).

Area under the curve (AUC), lag phase, or Stern-Volmerlike relation are used in order to measure the competition reaction and the standard antioxidant Trolox is used as reference (Table 4). NEAC values are reported as Trolox equivalents (TEAC) also in the total antioxidant status (TAS) assay and in the competitive (Randox) SET-based 2,2'azino-bis(3-ethylbenzothiazoline-6-sulphonic acid (ABTS) assay, both based on the production of $\mathrm{HO}^{\bullet}$ via Fenton reaction [399]. In other SET assays, using the stable radical cation $\mathrm{ABTS}^{\bullet+}$ or 2,2-diphenyl-1-picrylhydrazyl (DPPH), the target compound extracts an electron from the antioxidant and changes color (Table 4). In these assays, it is assumed that antioxidant activity is equal to reducing capacity [406]. Other SET methods measure the reducing power of antioxidants through redox reaction with iron (ferric reducing antioxidant potential (FRAP)) or copper (cupric reducing antioxidant capacity (CUPRAC)) (Table 4). The latter has been applied to both lipophilic and hydrophilic fractions of serum [398].
However, as for Crocin bleaching assay, bilirubin and carotenoids that absorb at the wavelength of determination could interfere with the results (Table 4). Similarly, the oxidation product of bilirubin (biliverdin) absorbs at the wavelength of determination of FRAP method (Table 4). Although NEAC assays present the advantage of integration of the individual antioxidant actions of different compounds and their additive, synergistic, or antagonistic interactions, many limitations have been pointed out previously [129, 403-407] (Table 4). Different NEAC assays can give different results, both in disease states [396] and after dietary supplementation with antioxidant-rich plant foods and beverages [394, 412, 413]. In a meta-analysis, Lettieri et al. [394] reported that TRAP, ORAC, and FRAP, but not TEAC, displayed an increase in plasma NEAC in both acute and chronic studies. From that, the authors [394] suggested that FRAP could be more sensitive than the TEAC assay within the SET methods to assess plasma NEAC. Accordingly, Carrión-García et al. [414] found a statistically significant positive correlation between plasma FRAP and dietary FRAP, either derived 
from the food frequency questionnaire (FFQ) and/or from a 24-hour recall (24-HR), whereas plasma ORAC without proteins, but not plasma ORAC, was related with 24-HR-based dietary ORAC, suggesting that proteins rather than dietary antioxidants have a primary role in plasma antioxidant defences. Despite FRAP appearing to be the more sensitive method to evaluate the effects of antioxidant-rich foods on NEAC, it must be taken into account that reduced iron is the major player in the Fenton reaction. Therefore, an increase in the iron reducing power could be more likely detrimental than beneficial in conditions of high levels of iron and low levels of antioxidant enzymes [364, 396, 415-420]. On the other hand, an increase in antioxidant enzymes as adaptive response to oxidative stress has been observed in T2D [358, 359, 363, 368]. Simultaneously with increased MDA levels, significantly higher activities or levels of SOD and/or CAT were found [358, 359, 363, 368]. Some studies reported unchanged or decreased CAT and/or GPX and elevated SOD and lipoperoxidation markers in T2D [360, $361,412]$ and CVD $[369,421]$. The balance between SOD and CAT and/or GPX dictates $\mathrm{H}_{2} \mathrm{O}_{2}$ levels that may potentially react with reduced metals. As previously pointed out, in NEAC assays the contribution of the antioxidant enzymes is neglected $[405,406]$. Therefore, the lower total antioxidant status in these cases must be interpreted with caution $[421,422]$.

Despite a correspondence between the effect on F2-IsoPs (the golden standard of oxidative stress) and NEAC has been reported in $67 \%(14 / 21)$ of the interventions with foods and in $77 \%(10 / 13)$ of the interventions with galenics [413] of human studies in a systematic review, in the majority of the cases the correspondence was the lack of change for both biomarkers, whereas increases in NEAC and decreases in F2IsoPs were observed only in $9.5 \%$ (2/21) of interventions with foods and $30.7 \%(4 / 13)$ of interventions with supplements [413]. Furthermore, despite gas chromatography mass spectrometry or liquid chromatography mass spectrometry techniques giving a more reliable and precise measure of F2IsoPs, in the majority of these studies (5/6), enzyme-linked immunosorbent assay-based methods were used [413]. Last, but not least, in one of these studies [423], the increase in NEAC and the decrease in F2-IsoPs were not associated with lipid and glucose metabolism markers, nor with renal and liver functionality markers in uremic patients after 4 weeks of supplementation with Emblica officinalis extract, suggesting a low clinical relevance of NEAC in certain conditions. In this context, the major bias of all methods is that, despite hyperuricemia being detrimental and associated with CVD [424-426], UA is the major contributor of NEAC measured in plasma (60-80\%), saliva (70\%), and urine (75\%) [395]. In case-control studies, there was an accordance between UA concentration and NEAC, as well as between salivary or urinary NEAC and plasma or serum NEAC [395]. On the other hand, only in $44 \%$ of the interventions with antioxidant foods, beverages or supplements urinary NEAC was related to UA, probably due to the excretion of phenolic metabolites.

In order to avoid the UA interference, methods for UA independent NEAC have been proposed in both plasma and urine [427-430]. In particular, the consumption of
$500 \mathrm{~g}$ of strawberries daily for 9 days had no effect on circulating phenolics and plasma NEAC, whereas it increased UA-independent NEAC and urinary metabolites of polyphenols [431]. Furthermore, it has been suggested that urinary UA-independent NEAC normalized for creatinine could provide more reliable information about the antioxidant status in children and adults with Down syndrome [429].

Although UA-independent NEAC could be a good approach also for salivary NEAC, it has been observed that salivary NEAC was affected by emotional and psychological factors [432]. The latter could induce hyperactive sympathetic nervous system and the activation of platelets [433], potentially changing the plasma NEAC. In this context, it has been suggested that plasma and not serum should be preferred for NEAC measurement, in order to avoid ROS generation by platelets during processing (aggregation) [434] However, platelets' activation can occur during the time course of NEAC methods in plasma samples and, alternatively, vigorous vortexing produces platelets microparticles further confounding the results.

In fact, sample type, collection, processing, and methodological limitation must be taken into account when measuring NEAC. Despite the fact that the use of a refrigerated microcentrifuge to rapidly prepare plasma could avoid any thermal stress and instability of antioxidants in biological samples [434], recent results indicate that centrifugation at room temperature is the preferred option for many applications, giving lower microparticles and less hemolysis in plasma [435]. Hemolysis could bias many NEAC methods, and the presence of platelets and microparticles in the reaction mixture could affect the results. Considering that microparticle count is lower in serum compared with plasma after centrifugation at both room temperature $\left(1.73 \times 10^{\wedge} 7 / \mathrm{ml}\right.$ versus $\left.3.72 \times 10^{\wedge} 7 / \mathrm{ml}\right)$ and $4^{\circ} \mathrm{C}\left(1.33 \times 10^{\wedge} 7 / \mathrm{ml}\right.$ versus $7.4 \times 10^{\wedge} 7 / \mathrm{ml}$ ) [435], probably serum and not plasma could be the better sample for NEAC evaluation.

On the other hand, although NEAC of saliva or urine has led to increasing interest, due to simple and noninvasive collections, many factors could give spurious results. In particular, blood contamination, periodontal diseases, bacterial counts and flow rate must be evaluated in order to avoid misinterpretation of the results of salivary NEAC and normalize for dilution $[395,436]$. Also, urinary samples require normalization for dilution [395]. Despite results are normalized for the creatinine excretion, age, sex, muscle mass, renal diseases, and diet all have an influence on creatinine excretion [395].

From the mentioned above limitations and potential confounding, it appears that a clear association between increase in NEAC and health benefit is difficult to evaluate $[405,406]$. Therefore, as previously suggested, each study requires a careful design of the experimental protocol and caution should be taken in the interpretation of results.

\section{Conclusion}

A clinically useful biomarker, besides being correctly measured, must be diagnostic, have prognostic value, and correlate with the disease degree. It must also be reasonably 
stable, present in an easily accessible specimen, and its measurement should be cost-effective.

In order to evaluate the redox status in particular conditions (smoking habit, disease states), ex vivo free-radical production and oxidative stress in body fluids are measured. These methods are used also in human intervention studies to associate the levels of ingested antioxidants (by foods or supplements) with improvement of the body antioxidant status. Despite the fact that it has been suggested that nutraceuticals are capable of improving health, significant methodological bias must be taken into account in the interpretation of data from the measurement of reactive species in leukocytes and platelets by flow cytometry, from the evaluation of markers based on ROS-induced modifications, from the assay of the enzymatic players of redox status, and from the measurement of the total antioxidant capacity of human body fluids.

It has been suggested that the bias of each method could be overcome by the evaluation of oxidative stress by using more than one criterion $[129,404]$. In this context, indexes of redox status have been proposed [437, 438].

The OXY-SCORE [437] was computed by subtracting the protection score (GSH, alpha- and gamma-tocopherol levels, and antioxidant capacity) from the damage score (plasma free and total malondialdehyde, GSSG/GSH ratio, and urine F2-IsoPs). The oxidative-INDEX [438] was calculated by subtracting the OXY (the antioxidant capacity measured with the OXY adsorbent test) standardized variable from the ROM (the reactive oxygen metabolites measured with the d-ROM) standardized variable.

These scores are related to CVD, age, gender, and smoking habit [437-442]. The oxidative-INDEX has been successfully used also in case-control studies (liver diseases and cancers) [443-445] and in a human intervention study with antioxidant [446].

More recently, a multiple factor analysis (MFA) that allows for simultaneous analysis of multiple parameters, classified according to their physiological meaning in athletes following strenuous endurance exercise, was applied [447]. This integrative approach reveals a close relationship between the oxidative index, the inflammatory IL-8, and the cardiac marker $\mathrm{N}$-terminal pro-B-type natriuretic peptide (NT-proBNP). Athletes that showed a higher improvement of the oxidative index after the race, presented small changes in NT-proBNP and IL-8 levels, whereas subjects with minimal variation in the oxidative index had a marked postrace increase in NT-proBNP and IL- 8 concentrations.

On the other hand, in some diseases, the choice of the markers that must be considered in the global index should dictate the clinical relevance in the subjects selected. Condezo-Hoyos et al. [448] measured an array of oxidative stress biomarkers (SH, GSH, UA, ORAC, MDA-bound protein, protein carbonyls, AOPP, 3-nitrotyrosine, CAT, XO, and $\mathrm{MPO}$ ) in patients with chronic venous insufficiency (CVI) and used for the OXyVen index calculation the normalized and standardized plasma parameters which showed a significant statistical difference between CVI patients and controls (SH, MDA-bound protein, protein carbonyls, and CAT activity).
In conclusion, the clinical significance of biomarkers of oxidative stress in humans must come from a critical analysis of the markers that should be dictated by the study aim and design and should give overall an index of redox status in particular conditions.

\section{Conflicts of Interest}

The authors declare that there is no conflict of interests regarding the publication of this paper.

\section{Acknowledgments}

The authors thank Claudio Andrew Gobbi for the English language review of the manuscript.

\section{References}

[1] M. Valko, D. Leibfritz, J. Moncol, M. T. Cronin, M. Mazur, and J. Telser, "Free radicals and antioxidants in normal physiological functions and human disease," The International Journal of Biochemistry \& Cell Biology, vol. 39, no. 1, pp. 44-84, 2007.

[2] D. R. Bickers and M. Athar, "Oxidative stress in the pathogenesis of skin disease," The Journal of Investigative Dermatology, vol. 126, no. 12, pp. 2565-2575, 2006.

[3] R. Franco, R. Sanchez-Olea, E. M. Reyes-Reyes, and M. I. Panayiotidis, "Environmental toxicity, oxidative stress and apoptosis: menage a trois," Mutation Research, vol. 674, no. 1-2, pp. 3-22, 2009.

[4] M. Hodjat, M. A. Rezvanfar, and M. Abdollahi, "A systematic review on the role of environmental toxicants in stem cells aging," Food and Chemical Toxicology, vol. 86, pp. 298308, 2015.

[5] A. Negre-Salvayre, N. Auge, V. Ayala et al., "Pathological aspects of lipid peroxidation," Free Radical Research, vol. 44, no. 10, pp. 1125-1171, 2010.

[6] R. A. Roberts, R. A. Smith, S. Safe, C. Szabo, R. B. Tjalkens, and F. M. Robertson, "Toxicological and pathophysiological roles of reactive oxygen and nitrogen species," Toxicology, vol. 276, no. 2, pp. 85-94, 2010.

[7] A. Musatov and N. C. Robinson, "Susceptibility of mitochondrial electron-transport complexes to oxidative damage. Focus on cytochrome c oxidase," Free Radical Research, vol. 46, no. 11, pp. 1313-1326, 2012.

[8] J. El-Benna, M. Hurtado-Nedelec, V. Marzaioli, J. C. Marie, M. A. Gougerot-Pocidalo, and P. M. Dang, "Priming of the neutrophil respiratory burst: role in host defense and inflammation," Immunological Reviews, vol. 273, no. 1, pp. 180-193, 2016.

[9] M. Jaganjac, A. Cipak, R. J. Schaur, and N. Zarkovic, "Pathophysiology of neutrophil-mediated extracellular redox reactions," Frontiers in Bioscience (Landmark edition), vol. 21, pp. 839-855, 2016.

[10] W. H. Koppenol, P. L. Bounds, T. Nauser, R. Kissner, and H. Ruegger, "Peroxynitrous acid: controversy and consensus surrounding an enigmatic oxidant," Dalton Transactions, vol. 41, no. 45, pp. 13779-13787, 2012.

[11] K. Roy, Y. Wu, J. L. Meitzler et al., "NADPH oxidases and cancer," Clinical Science (London, England), vol. 128, no. 12, pp. 863-875, 2015. 
[12] M. Ushio-Fukai and Y. Nakamura, "Reactive oxygen species and angiogenesis: NADPH oxidase as target for cancer therapy," Cancer Letters, vol. 266, no. 1, pp. 37-52, 2008.

[13] P. Chiarugi and T. Fiaschi, "Redox signalling in anchoragedependent cell growth," Cellular Signalling, vol. 19, no. 4, pp. 672-682, 2007.

[14] R. Hu, C. L. Saw, R. Yu, and A. N. Kong, "Regulation of NF-E2-related factor 2 signaling for cancer chemoprevention: antioxidant coupled with antiinflammatory," Antioxidants \& Redox Signaling, vol. 13, no. 11, pp. 1679-1698, 2010.

[15] D. N. Granger and P. R. Kvietys, "Reperfusion injury and reactive oxygen species: the evolution of a concept," Redox Biology, vol. 6, pp. 524-551, 2015.

[16] S. Matsushima, H. Tsutsui, and J. Sadoshima, "Physiological and pathological functions of NADPH oxidases during myocardial ischemia-reperfusion," Trends in Cardiovascular Medicine, vol. 24, no. 5, pp. 202-5, 2014.

[17] Y. Sawikr, N. Sastry Yarla, I. Peluso, M. A. Kamal, G. Aliev, and A. Bishayee, "Neuroinflammation in Alzheimer's disease: the preventive and therapeutic potential of polyphenolic nutraceuticals," Advances in Protein Chemistry and Structural Biology, vol. 108, pp. 33-57, 2017.

[18] R. S. Ferrari and C. F. Andrade, "Oxidative stress and lung ischemia-reperfusion injury," Oxidative Medicine and Cellular Longevity, vol. 2015, Article ID 590987, 14 pages, 2015.

[19] M. Malek and M. Nematbakhsh, "Renal ischemia/reperfusion injury; from pathophysiology to treatment," Journal of Renal Injury Prevention, vol. 4, no. 2, pp. 20-27, 2015.

[20] S. Rohrbach, C. Troidl, C. Hamm, and R. Schulz, "Ischemia and reperfusion related myocardial inflammation: a network of cells and mediators targeting the cardiomyocyte," IUBMB Life, vol. 67, no. 2, pp. 110-119, 2015.

[21] G. A. Kurian, R. Rajagopal, S. Vedantham, and M. Rajesh, "The role of oxidative stress in myocardial ischemia and reperfusion injury and remodeling: revisited," Oxidative Medicine and Cellular Longevity, vol. 2016, Article ID 1656450, 14 pages, 2016.

[22] L. Y. Guan, P. Y. Fu, P. D. Li et al., "Mechanisms of hepatic ischemia-reperfusion injury and protective effects of nitric oxide," World Journal of Gastrointestinal Surgery, vol. 6, no. 7, pp. 122-128, 2014.

[23] T. Zhou, C. C. Chuang, and L. Zuo, "Molecular characterization of reactive oxygen species in myocardial ischemiareperfusion injury," BioMed Research International, vol. 2015, Article ID 864946, 9 pages, 2015.

[24] N. Poulose and R. Raju, "Aging and injury: alterations in cellular energetics and organ function," Aging and Disease, vol. 5, no. 2, pp. 101-108, 2014.

[25] P. B. Ham 3rd and R. Raju, "Mitochondrial function in hypoxic ischemic injury and influence of aging," Progress in Neurobiology, 2016, Epub ahead of print.

[26] J. Labat-Robert and L. Robert, "Longevity and aging. Role of free radicals and xanthine oxidase. A review," Pathologie et Biologie, vol. 62, no. 2, pp. 61-66, 2014.

[27] I. Peluso, G. Morabito, L. Urban, F. Ioannone, and M. Serafini, "Oxidative stress in atherosclerosis development: the central role of LDL and oxidative burst," Endocrine, Metabolic \& Immune Disorders Drug Targets, vol. 12, no. 4, pp. 351-360, 2012.
[28] D. Pietraforte, R. Vona, A. Marchesi et al., "Redox control of platelet functions in physiology and pathophysiology," Antioxidants \& Redox Signaling, vol. 21, no. 1, pp. 177-193, 2014.

[29] A. Assinger, F. Koller, W. Schmid, M. Zellner, E. Koller, and I. Volf, "Hypochlorite-oxidized LDL induces intraplatelet ROS formation and surface exposure of CD40L-a prominent role of CD36," Atherosclerosis, vol. 213, no. 1, pp. 129-134, 2010.

[30] C. C. Winterbourn, "The challenges of using fluorescent probes to detect and quantify specific reactive oxygen species in living cells," Biochimica et Biophysica Acta, vol. 1840, no. 2, pp. 730-738, 2014.

[31] S. I. Dikalov and D. G. Harrison, "Methods for detection of mitochondrial and cellular reactive oxygen species," Antioxidants \& Redox Signaling, vol. 20, no. 2, pp. 372-382, 2014.

[32] C. Elbim and G. Lizard, "Flow cytometric investigation of neutrophil oxidative burst and apoptosis in physiological and pathological situations," Cytometry. Part a, vol. 75, no. 6, pp. 475-481, 2009.

[33] M. Freitas, J. L. Lima, and E. Fernandes, "Optical probes for detection and quantification of neutrophils' oxidative burst. A review," Analytica Chimica Acta, vol. 649, no. 1, pp. 823, 2009.

[34] G. Finak, M. Langweiler, M. Jaimes et al., "Standardizing flow cytometry Immunophenotyping analysis from the Human ImmunoPhenotyping Consortium," Scientific Reports, vol. 6, p. 20686, 2016.

[35] B. Rajwa, P. K. Wallace, E. A. Griffiths, and M. Dundar, "Automated assessment of disease progression in acute myeloid leukemia by probabilistic analysis of flow cytometry data," IEEE Transactions on Biomedical Engineering, vol. 64, no. 5, pp. 1089-1098, 2017.

[36] N. J. Gormley, D. M. Turley, J. S. Dickey et al., "Regulatory perspective on minimal residual disease flow cytometry testing in multiple myeloma," Cytometry. Part B, Clinical Cytometry, vol. 90, no. 1, pp. 73-80, 2016.

[37] M. M. Sartor and D. J. Gottlieb, "A single tube 10-color flow cytometry assay optimizes detection of minimal residual disease in chronic lymphocytic leukemia," Cytometry. Part B, Clinical Cytometry, vol. 84, no. 2, pp. 96-103, 2013.

[38] C. Algrin, J. L. Golmard, M. Michallet et al., "Flow cytometry minimal residual disease after allogeneic transplant for chronic lymphocytic leukemia," European Journal of Haematology, vol. 98, no. 4, pp. 363-370, 2017.

[39] V. Bordoni, R. Casetti, G. Capuano et al., "A novel 8-color flow cytometry panel to study activation, maturation and senescence of CD4 and CD8 T lymphocytes in HIVinfected individuals at different stages of disease," International Journal of Immunopathology and Pharmacology, vol. 25, no. 2, pp. 415-424, 2012.

[40] B. B. Nkambule, G. M. Davison, and H. Ipp, “The evaluation of platelet function in HIV infected, asymptomatic treatment-naive individuals using flow cytometry," Thrombosis Research, vol. 135, no. 6, pp. 1131-1139, 2015.

[41] L. Whitby, A. Whitby, M. Fletcher, and D. Barnett, "Current laboratory practices in flow cytometry for the enumeration of CD $4^{+}$T-lymphocyte subsets," Cytometry. Part B, Clinical Cytometry, vol. 88, no. 5, pp. 305-311, 2015.

[42] R. El Hawary, S. Meshaal, C. Deswarte et al., "Role of flow cytometry in the diagnosis of chronic granulomatous disease: the Egyptian experience," Journal of Clinical Immunology, vol. 36, no. 6, pp. 610-618, 2016. 
[43] M. G. Macey, J. Sangster, P. A. Veys, and A. C. Newland, "Flow cytometric analysis of the functional ability of neutrophils from patients with autoimmune neutropenia," Journal of Microscopy, vol. 159, Part 3, pp. 277-283, 1990.

[44] G. T. Spear, H. A. Kessler, L. Rothberg, J. Phair, and A. L. Landay, "Decreased oxidative burst activity of monocytes from asymptomatic HIV-infected individuals," Clinical Immunology and Immunopathology, vol. 54, no. 2, pp. 184191, 1990.

[45] A. Gomes, E. Fernandes, and J. L. Lima, "Fluorescence probes used for detection of reactive oxygen species," Journal of Biochemical and Biophysical Methods, vol. 65, no. 2-3, pp. 45-80, 2005.

[46] B. Kalyanaraman, V. Darley-Usmar, K. J. Davies et al., "Measuring reactive oxygen and nitrogen species with fluorescent probes: challenges and limitations," Free Radical Biology \& Medicine, vol. 52, no. 1, pp. 1-6, 2012.

[47] I. Peluso, H. Manafikhi, R. Reggi, and M. Palmery, "Interference of flavonoids with fluorescent intracellular probes: methodological implications in the evaluation of the oxidative burst by flow cytometry," Cytometry. Part A, vol. 85, no. 8, pp. 663-677, 2014.

[48] M. Becatti, C. Fiorillo, A. M. Gori et al., "Platelet and leukocyte ROS production and lipoperoxidation are associated with high platelet reactivity in non-ST elevation myocardial infarction (NSTEMI) patients on dual antiplatelet treatment," Atherosclerosis, vol. 231, no. 2, pp. 392-400, 2013.

[49] I. Peluso, H. Manafikhi, F. Altieri, C. Zanza, and M. Palmery, "The effect of sample storage on the peroxidation of leukocytes index ratio (PLIR) measure," Scientific Reports, vol. 4, p. 6539, 2014.

[50] G. P. Drummen, B. M. Gadella, J. A. Post, and J. F. Brouwers, "Mass spectrometric characterization of the oxidation of the fluorescent lipid peroxidation reporter molecule C11-BODIPY(581/591)," Free Radical Biology \& Medicine, vol. 36, no. 12, pp. 1635-1644, 2004.

[51] G. P. Drummen, L. C. van Liebergen, J. A. Op den Kamp, and J. A. Post, "C11-BODIPY(581/591), an oxidation-sensitive fluorescent lipid peroxidation probe: (micro)spectroscopic characterization and validation of methodology," Free Radical Biology \& Medicine, vol. 33, no. 4, pp. 473-490, 2002.

[52] A. C. Nicolescu, Q. Li, L. Brown, and G. R. Thatcher, "Nitroxidation, nitration, and oxidation of a BODIPY fluorophore by RNOS and ROS," Nitric Oxide, vol. 15, no. 2, pp. 163176, 2006.

[53] I. Peluso, H. Manafikhi, R. Reggi, Y. Longhitano, C. Zanza, and M. Palmery, "Relationship between the peroxidation of leukocytes index ratio and the improvement of postprandial metabolic stress by a functional food," Oxidative Medicine and Cellular Longevity, vol. 2016, Article ID 5630985, 10 pages, 2016.

[54] J. Fernandez, L. Marin, R. Alvarez-Alonso et al., "Biosynthetic modularity rules in the bisintercalator family of antitumor compounds," Marine Drugs, vol. 12, no. 5, pp. 2668-2699, 2014.

[55] M. Ciz, P. Denev, M. Kratchanova, O. Vasicek, G. Ambrozova, and A. Lojek, "Flavonoids inhibit the respiratory burst of neutrophils in mammals," Oxidative Medicine and Cellular Longevity, vol. 2012, Article ID 181295, 6 pages, 2012.

[56] H. J. Bromme, L. Zuhlke, R. E. Silber, and A. Simm, "DCFH2 interactions with hydroxyl radicals and other oxidants-influence of organic solvents," Experimental Gerontology, vol. 43, no. 7, pp. 638-644, 2008.

[57] B. Laupeze, L. Amiot, L. Payen et al., "Multidrug resistance protein (MRP) activity in normal mature leukocytes and CD34-positive hematopoietic cells from peripheral blood," Life Sciences, vol. 68, no. 11, pp. 1323-1331, 2001.

[58] J. F. Arthur, J. Qiao, Y. Shen et al., "ITAM receptor-mediated generation of reactive oxygen species in human platelets occurs via Syk-dependent and Syk-independent pathways," Journal of Thrombosis and Haemostasis, vol. 10, no. 6, pp. 1133-1141, 2012.

[59] W. Siffert, G. Siffert, P. Scheid, and J. W. Akkerman, "Activation of $\mathrm{Na}^{+} / \mathrm{H}^{+}$exchange and $\mathrm{Ca}^{2+}$ mobilization start simultaneously in thrombin-stimulated platelets. Evidence that platelet shape change disturbs early rises of BCECF fluorescence which causes an underestimation of actual cytosolic alkalinization," The Biochemical Journal, vol. 258, no. 2, pp. 521-527, 1989.

[60] O. Aharonovitz, H. Fridman, A. A. Livne, and Y. Granot, "The effect of BCECF on intracellular $\mathrm{pH}$ of human platelets," Biochimica et Biophysica Acta, vol. 1284, no. 2, pp. 227-232, 1996.

[61] T. Bagrij, A. Klokouzas, S. B. Hladky, and M. A. Barrand, "Influences of glutathione on anionic substrate efflux in tumour cells expressing the multidrug resistance-associated protein, MRP1," Biochemical Pharmacology, vol. 62, no. 2, pp. 199-206, 2001.

[62] J. M. Maher, M. Z. Dieter, L. M. Aleksunes et al., "Oxidative and electrophilic stress induces multidrug resistanceassociated protein transporters via the nuclear factor-E2related factor-2 transcriptional pathway," Hepatology, vol. 46, no. 5, pp. 1597-1610, 2007.

[63] M. Iwanaga, K. Mori, T. Iida et al., "Nuclear factor kappa B dependent induction of gamma glutamylcysteine synthetase by ionizing radiation in T98G human glioblastoma cells," Free Radical Biology \& Medicine, vol. 24, no. 7-8, pp. 12561268, 1998.

[64] L. Deng, Y. C. Lin-Lee, F. X. Claret, and M. T. Kuo, "2-acetylaminofluorene up-regulates rat $\mathrm{mdr} 1 \mathrm{~b}$ expression through generating reactive oxygen species that activate NF-kappa B pathway," The Journal of Biological Chemistry, vol. 276, no. 1, pp. 413-420, 2001.

[65] F. Thevenod, J. M. Friedmann, A. D. Katsen, and I. A. Hauser, "Up-regulation of multidrug resistance P-glycoprotein via nuclear factor-kappaB activation protects kidney proximal tubule cells from cadmium- and reactive oxygen speciesinduced apoptosis," The Journal of Biological Chemistry, vol. 275, no. 3, pp. 1887-1896, 2000.

[66] Y. Shu and H. Liu, "Reversal of P-glycoprotein-mediated multidrug resistance by cholesterol derived from low density lipoprotein in a vinblastine-resistant human lymphoblastic leukemia cell line," Biochemistry and Cell Biology, vol. 85, no. 5, pp. 638-646, 2007.

[67] Y. Kimura, N. Kioka, H. Kato, M. Matsuo, and K. Ueda, "Modulation of drug-stimulated ATPase activity of human MDR1/P-glycoprotein by cholesterol," The Biochemical Journal, vol. 401, no. 2, pp. 597-605, 2007.

[68] R. Cermak, "Effect of dietary flavonoids on pathways involved in drug metabolism," Expert Opinion on Drug Metabolism \& Toxicology, vol. 4, no. 1, pp. 17-35, 2008.

[69] E. J. Nelson, N. T. Zinkin, and P. M. Hinkle, "Fluorescence methods to assess multidrug resistance in individual cells," 
Cancer Chemotherapy and Pharmacology, vol. 42, no. 4, pp. 292-299, 1998.

[70] N. J. Liptrott, M. Penny, P. G. Bray et al., "The impact of cytokines on the expression of drug transporters, cytochrome P450 enzymes and chemokine receptors in human PBMC," British Journal of Pharmacology, vol. 156, no. 3, pp. 497508, 2009.

[71] A. Kimura, Y. Ishida, T. Hayashi et al., "Interferon-gamma plays protective roles in sodium arsenite-induced renal injury by up-regulating intrarenal multidrug resistance-associated protein 1 expression," The American Journal of Pathology, vol. 169, no. 4, pp. 1118-1128, 2006.

[72] S. Tsujimura, K. Saito, S. Nakayamada et al., “Transcriptional regulation of multidrug resistance-1 gene by interleukin-2 in lymphocytes," Genes to Cells, vol. 9, no. 12, pp. 1265-1273, 2004.

[73] L. C. Borowski, R. P. Lopes, T. P. Gonzalez et al., "Is steroid resistance related to multidrug resistance-I (MDR-I) in rheumatoid arthritis?" International Immunopharmacology, vol. 7, no. 6, pp. 836-844, 2007.

[74] S. Liu, P. M. Beringer, L. Hidayat et al., "Probenecid, but not cystic fibrosis, alters the total and renal clearance of fexofenadine," Journal of Clinical Pharmacology, vol. 48, no. 8, pp. 957-965, 2008.

[75] W. Malorni, M. B. Lucia, G. Rainaldi et al., "Intracellular expression of P-170 glycoprotein in peripheral blood mononuclear cell subsets from healthy donors and HIV-infected patients," Haematologica, vol. 83, no. 1, pp. 13-20, 1998.

[76] T. Mattiello, R. Guerriero, L. V. Lotti et al., "Aspirin extrusion from human platelets through multidrug resistance protein4-mediated transport: evidence of a reduced drug action in patients after coronary artery bypass grafting," Journal of the American College of Cardiology, vol. 58, no. 7, pp. 752761, 2011.

[77] G. Jedlitschky, K. Tirschmann, L. E. Lubenow et al., "The nucleotide transporter MRP4 (ABCC4) is highly expressed in human platelets and present in dense granules, indicating a role in mediator storage," Blood, vol. 104, no. 12, pp. 3603-3610, 2004.

[78] I. Massimi, R. Guerriero, L. V. Lotti et al., “Aspirin influences megakaryocytic gene expression leading to up-regulation of multidrug resistance protein- 4 in human platelets," British Journal of Clinical Pharmacology, vol. 78, no. 6, pp. 13431353, 2014.

[79] A. C. Rodrigues, R. Curi, L. R. Britto et al., "Down-regulation of $\mathrm{ABCB} 1$ transporter by atorvastatin in a human hepatoma cell line and in human peripheral blood mononuclear cells," Biochimica et Biophysica Acta, vol. 1760, no. 12, pp. 18661873, 2006.

[80] M. Egashira, N. Kawamata, K. Sugimoto, T. Kaneko, and K. Oshimi, "P-glycoprotein expression on normal and abnormally expanded natural killer cells and inhibition of Pglycoprotein function by cyclosporin $\mathrm{A}$ and its analogue, PSC833," Blood, vol. 93, no. 2, pp. 599-606, 1999.

[81] R. C. Maia, K. Wagner, R. H. Cabral, and V. M. Rumjanek, "Heparin reverses rhodamine 123 extrusion by multidrug resistant cells," Cancer Letters, vol. 106, no. 1, pp. 101-108, 1996.

[82] L. M. Lien, Z. C. Chen, C. L. Chung et al., "Multidrug resistance protein 4 (MRP4/ABCC4) regulates thrombus formation in vitro and in vivo," European Journal of Pharmacology, vol. 737, pp. 159-167, 2014.
[83] K. Kock, M. Grube, G. Jedlitschky et al., "Expression of adenosine triphosphate-binding cassette (ABC) drug transporters in peripheral blood cells: relevance for physiology and pharmacotherapy," Clinical Pharmacokinetics, vol. 46, no. 6, pp. 449-470, 2007.

[84] A. Borgognone and F. M. Pulcinelli, "Reduction of cAMP and cGMP inhibitory effects in human platelets by MRP4mediated transport," Thrombosis and Haemostasis, vol. 108, no. 5, pp. 955-962, 2012.

[85] S. B. Cheepala, A. Pitre, Y. Fukuda et al., "The ABCC4 membrane transporter modulates platelet aggregation," Blood, vol. 126, no. 20, pp. 2307-2319, 2015.

[86] M. Sjolinder, S. Tornhamre, H. E. Claesson, J. Hydman, and J. Lindgren, "Characterization of a leukotriene C4 export mechanism in human platelets: possible involvement of multidrug resistance-associated protein 1," Journal of Lipid Research, vol. 40, no. 3, pp. 439-446, 1999.

[87] M. Rius, J. Hummel-Eisenbeiss, and D. Keppler, "ATPdependent transport of leukotrienes B4 and C4 by the multidrug resistance protein ABCC4 (MRP4)," The Journal of Pharmacology and Experimental Therapeutics, vol. 324, no. 1, pp. 86-94, 2008.

[88] D. P. Olson, B. J. Taylor, and S. P. Ivy, "Detection of MRP functional activity: calcein AM but not BCECF AM as a multidrug resistance-related protein (MRP1) substrate," Cytometry, vol. 46, no. 2, pp. 105-113, 2001.

[89] J. Wang, X. Yi, M. Liu et al., "Correlation between the in vitro functionality of stored platelets and the cytosolic esteraseinduced fluorescence intensity with CMFDA," PLoS One, vol. 10, no. 9, article e0138509, 2015.

[90] H. Schoenfeld, M. Muhm, U. Doepfmer, A. Exadaktylos, and H. Radtke, "Platelet activity in washed platelet concentrates," Anesthesia and Analgesia, vol. 99, no. 1, pp. 17-20, 2004.

[91] F. M. Tamimi, S. Montalvo, I. Tresguerres, and L. Blanco Jerez, "A comparative study of 2 methods for obtaining platelet-rich plasma," Journal of Oral and Maxillofacial Surgery, vol. 65, no. 6, pp. 1084-1093, 2007.

[92] E. Cecerska-Heryc, A. Jesionowska, S. Klaudyna et al., "Xanthine oxidoreductase reference values in platelet-poor plasma and platelets in healthy volunteers," Oxidative Medicine and Cellular Longevity, vol. 2015, Article ID 341926, 6 pages, 2015.

[93] M. H. Ginsberg, F. Kozin, M. O'Malley, and D. J. McCarty, "Release of platelet constituents by monosodium urate crystals," The Journal of Clinical Investigation, vol. 60, no. 5, pp. 999-1007, 1977.

[94] M. Ginsberg, P. Henson, J. Henson, and F. Kozin, "Mechanisms of platelet response to monosodium urate crystals," The American Journal of Pathology, vol. 94, no. 3, pp. 549568, 1979.

[95] J. F. Mustard, E. A. Murphy, M. A. Ogryzlo, and H. A. Smythe, "Blood Coagulation and platelet economy in subjects with primary gout," Canadian Medical Association Journal, vol. 89, pp. 1207-1211, 1963.

[96] M. Li, Z. Wang, T. Ma et al., "Enhanced platelet apoptosis in chronic uremic patients," Renal Failure, vol. 36, no. 6, pp. 847-853, 2014.

[97] Y. Chen, Y. Xiao, Z. Lin et al., "The role of circulating platelets microparticles and platelet parameters in acute ischemic stroke patients," Journal of Stroke and Cerebrovascular Diseases, vol. 24, no. 10, pp. 2313-2320, 2015. 
[98] M. George, M. R. Ganesh, A. Sridhar et al., "Evaluation of endothelial and platelet derived Microparticles in patients with acute coronary syndrome," Journal of Clinical and Diagnostic Research, vol. 9, no. 12, pp. OC09-OC13, 2015.

[99] G. Giannopoulos, G. Oudatzis, G. Paterakis et al., "Red blood cell and platelet microparticles in myocardial infarction patients treated with primary angioplasty," International Journal of Cardiology, vol. 176, no. 1, pp. 145-150, 2014.

[100] R. Suades, T. Padro, R. Alonso, P. Mata, and L. Badimon, "Lipid-lowering therapy with statins reduces microparticle shedding from endothelium, platelets and inflammatory cells," Thrombosis and Haemostasis, vol. 110, no. 2, pp. 366-377, 2013.

[101] O. Helal, C. Defoort, S. Robert et al., "Increased levels of microparticles originating from endothelial cells, platelets and erythrocytes in subjects with metabolic syndrome: relationship with oxidative stress," Nutrition, Metabolism, and Cardiovascular Diseases, vol. 21, no. 9, pp. 665-671, 2011.

[102] T. Nishizawa, T. Taniura, and S. Nomura, "Effects of febuxostat on platelet-derived microparticles and adiponectin in patients with hyperuricemia," Blood Coagulation \& Fibrinolysis, vol. 26, no. 8, pp. 887-892, 2015.

[103] S. Robert, P. Poncelet, R. Lacroix et al., "Standardization of platelet-derived microparticle counting using calibrated beads and a Cytomics FC500 routine flow cytometer: a first step towards multicenter studies?" Journal of Thrombosis and Haemostasis, vol. 7, no. 1, pp. 190-197, 2009.

[104] A. Larsson, T. Lundahl, M. Eriksson, K. Lundkvist, and T. Lindahl, "Endotoxin induced platelet microvesicle formation measured by flow cytometry," Platelets, vol. 7, no. 3, pp. 153158, 1996.

[105] C. Vors, G. Pineau, J. Drai et al., "Postprandial endotoxemia linked with chylomicrons and lipopolysaccharides handling in obese versus lean men: a lipid dose-effect trial," The Journal of Clinical Endocrinology and Metabolism, vol. 100, no. 9, pp. 3427-3435, 2015.

[106] M. I. Lassenius, K. H. Pietilainen, K. Kaartinen et al., "Bacterial endotoxin activity in human serum is associated with dyslipidemia, insulin resistance, obesity, and chronic inflammation," Diabetes Care, vol. 34, no. 8, pp. 1809-1815, 2011.

[107] Z. Huang and V. B. Kraus, "Does lipopolysaccharidemediated inflammation have a role in OA?" Nature Reviews. Rheumatology, vol. 12, no. 2, pp. 123-129, 2016.

[108] S. Araki, H. Matsuno, M. Haneda et al., "Correlation between albuminuria and spontaneous platelet microaggregate formation in type 2 diabetic patients," Diabetes Care, vol. 32, no. 11, pp. 2062-2067, 2009.

[109] S. Suzuki, H. Kudo, and T. Koyama, “Assessment of spontaneous platelet aggregation using laser light scattering in healthy subjects: an attempt to standardize," International Journal of Laboratory Hematology, vol. 36, no. 6, pp. 676685, 2014.

[110] L. Ayers, M. Kohler, P. Harrison et al., "Measurement of circulating cell-derived microparticles by flow cytometry: sources of variability within the assay," Thrombosis Research, vol. 127, no. 4, pp. 370-377, 2011.

[111] S. Zeng, X. Zhou, L. Ge et al., "Monocyte subsets and monocyte-platelet aggregates in patients with unstable angina," Journal of Thrombosis and Thrombolysis, vol. 38, no. 4, pp. 439-446, 2014.
[112] T. Ishikawa, M. Shimizu, S. Kohara, S. Takizawa, Y. Kitagawa, and S. Takagi, "Appearance of WBC-platelet complex in acute ischemic stroke, predominantly in atherothrombotic infarction," Journal of Atherosclerosis and Thrombosis, vol. 19, no. 5, pp. 494-501, 2012.

[113] B. Majumder, J. North, C. Mavroudis, R. Rakhit, and M. W. Lowdell, "Improved accuracy and reproducibility of enumeration of platelet-monocyte complexes through use of doublet-discriminator strategy," Cytometry. Part B, Clinical Cytometry, vol. 82, no. 6, pp. 353-359, 2012.

[114] A. Burdess, A. E. Michelsen, F. Brosstad, K. A. Fox, D. E. Newby, and A. F. Nimmo, "Platelet activation in patients with peripheral vascular disease: reproducibility and comparability of platelet markers," Thrombosis Research, vol. 129, no. 1, pp. 50-55, 2012.

[115] H. S. Leong, T. J. Podor, B. Manocha, and J. D. Lewis, "Validation of flow cytometric detection of platelet microparticles and liposomes by atomic force microscopy," Journal of Thrombosis and Haemostasis, vol. 9, no. 12, pp. 2466-2476, 2011.

[116] W. Jy, L. L. Horstman, H. Park, W. W. Mao, P. Valant, and Y. S. Ahn, "Platelet aggregates as markers of platelet activation: characterization of flow cytometric method suitable for clinical applications," American Journal of Hematology, vol. 57, no. 1, pp. 33-42, 1998.

[117] S. Hartz, B. Menart, and D. Tschoepe, "Leukocyte apoptosis in whole blood involves platelet-dependent coaggregation," Cytometry. Part a, vol. 52, no. 2, pp. 117-121, 2003.

[118] I. A. Hagberg and T. Lyberg, "Evaluation of circulating platelet-leukocyte conjugates: a sensitive flow cytometric assay well suited for clinical studies," Platelets, vol. 11, no. 3, pp. 151-160, 2000.

[119] B. Izzi, A. Pampuch, S. Costanzo et al., "Determinants of platelet conjugate formation with polymorphonuclear leukocytes or monocytes in whole blood," Thrombosis and Haemostasis, vol. 98, no. 6, pp. 1276-1284, 2007.

[120] S. J. Vowells, S. Sekhsaria, H. L. Malech, M. Shalit, and T. A. Fleisher, "Flow cytometric analysis of the granulocyte respiratory burst: a comparison study of fluorescent probes," Journal of Immunological Methods, vol. 178, no. 1, pp. 89-97, 1995.

[121] L. Kobzik, J. J. Godleski, and J. D. Brain, "Oxidative metabolism in the alveolar macrophage: analysis by flow cytometry," Journal of Leukocyte Biology, vol. 47, no. 4, pp. 295-303, 1990.

[122] N. Carrim, J. F. Arthur, J. R. Hamilton et al., “Thrombininduced reactive oxygen species generation in platelets: a novel role for protease-activated receptor 4 and GPIbalpha," Redox Biology, vol. 6, pp. 640-647, 2015.

[123] R. Carnevale, L. Loffredo, C. Nocella et al., "Epicatechin and catechin modulate endothelial activation induced by platelets of patients with peripheral artery disease," Oxidative Medicine and Cellular Longevity, vol. 2014, Article ID 691015, 9 pages, 2014.

[124] F. Li, M. Yang, L. Wang et al., "Autofluorescence contributes to false-positive intracellular Foxp3 staining in macrophages: a lesson learned from flow cytometry," Journal of Immunological Methods, vol. 386, no. 1-2, pp. 101-107, 2012.

[125] Z. Huczek, K. J. Filipiak, J. Kochman et al., "Baseline platelet size is increased in patients with acute coronary syndromes developing early stent thrombosis and predicts future residual platelet reactivity. A case-control study," Thrombosis Research, vol. 125, no. 5, pp. 406-412, 2010. 
[126] G. De Luca, M. Verdoia, E. Cassetti et al., "Mean platelet volume is not associated with platelet reactivity and the extent of coronary artery disease in diabetic patients," Blood Coagulation \& Fibrinolysis, vol. 24, no. 6, pp. 619-624, 2013.

[127] D. I. Won, D. H. Yang, D. H. Kim, S. C. Chae, and J. S. Suh, "Flow cytometric assessment of platelet aspirin resistance using light scattering," Cytometry. Part B, Clinical Cytometry, vol. 74, no. 2, pp. 110-117, 2008.

[128] M. Frojmovic and T. Wong, "Dynamic measurements of the platelet membrane glycoprotein IIb-IIIa receptor for fibrinogen by flow cytometry. II. Platelet size-dependent subpopulations," Biophysical Journal, vol. 59, no. 4, pp. 828-837, 1991.

[129] S. Knasmuller, A. Nersesyan, M. Misik et al., "Use of conventional and -omics based methods for health claims of dietary antioxidants: a critical overview," The British Journal of Nutrition, vol. 99, E Supplement 1, pp. ES3-E52, 2008.

[130] J. K. Juranek, G. K. Daffu, J. Wojtkiewicz, D. Lacomis, J. Kofler, and A. M. Schmidt, "Receptor for advanced glycation end products and its inflammatory ligands are upregulated in amyotrophic lateral sclerosis," Frontiers in Cellular Neuroscience, vol. 9, p. 485, 2015.

[131] I. Ozbay, C. Kucur, F. E. Kocak, B. Savran, and F. Oghan, "Advanced oxidation protein product levels as a marker of oxidative stress in paediatric patients with chronic tonsillitis," Acta Otorhinolaryngologica Italica, vol. 36, no. 5, pp. 381385, 2016.

[132] M. Mateu-Jimenez, A. Sanchez-Font, A. Rodriguez-Fuster et al., "Redox imbalance in lung cancer of patients with underlying chronic respiratory conditions," Molecular Medicine, vol. 22, 2016.

[133] G. A. Asare, G. Akuffo, D. Doku, B. Asiedu, and S. Santa, "Dynamics of urinary oxidative stress biomarkers: 8hydroxy-2'-deoxyguanosine and 8-isoprostane in uterine leiomyomas," Journal of Mid-Life Health, vol. 7, no. 1, pp. 8-14, 2016.

[134] A. Suehiro, K. Uchida, M. Nakanishi, and I. Wakabayashi, "Measurement of urinary advanced glycation end-products (AGEs) using a fluorescence assay for metabolic syndromerelated screening tests," Diabetes and Metabolic Syndrome: Clinical Research and Reviews, vol. 10, no. 1 Supplement 1, pp. S110-S113, 2016.

[135] N. Turk, A. Mornar, V. Mrzljak, and Z. Turk, "Urinary excretion of advanced glycation endproducts in patients with type 2 diabetes and various stages of proteinuria," Diabetes \& Metabolism, vol. 30, no. 2, pp. 187-192, 2004.

[136] J. Kaur, C. Politis, and R. Jacobs, "Salivary 8-hydroxy-2-deoxyguanosine, malondialdehyde, vitamin $\mathrm{C}$, and vitamin $\mathrm{E}$ in oral pre-cancer and cancer: diagnostic value and free radical mechanism of action," Clinical Oral Investigations, vol. 20, no. 2, pp. 315-319, 2016.

[137] K. Smriti, K. M. Pai, V. Ravindranath, and K. C. Pentapati, "Role of salivary malondialdehyde in assessment of oxidative stress among diabetics," Journal of Oral Biology and Craniofacial Research, vol. 6, no. 1, pp. 41-44, 2016.

[138] B. Antus, "Oxidative stress markers in sputum," Oxidative Medicine and Cellular Longevity, vol. 2016, Article ID 2930434, 12 pages, 2016.

[139] Z. Yildirim, B. Bozkurt, D. Ozol et al., "Increased exhaled 8-isoprostane and interleukin-6 in patients with Helicobacter pylori infection," Helicobacter, vol. 21, no. 5, pp. 389-394, 2016.
[140] E. M. Schumer, M. C. Black, M. Bousamra 2nd et al., "Normalization of exhaled carbonyl compounds after lung cancer resection," The Annals of Thoracic Surgery, vol. 102, no. 4, pp. 1095-1100, 2016.

[141] E. M. Schumer, J. R. Trivedi, V. van Berkel et al., "High sensitivity for lung cancer detection using analysis of exhaled carbonyl compounds," The Journal of Thoracic and Cardiovascular Surgery, vol. 150, no. 6, pp. 1517-1522, 2015, discussion 1522-4.

[142] B. C. Sousa, A. R. Pitt, and C. M. Spickett, "Chemistry and analysis of HNE and other prominent carbonyl-containing lipid oxidation compounds," Free Radical Biology \& Medicine, 2017, Epub ahead of print.

[143] C. Goldring, A. F. Casini, E. Maellaro, B. Del Bello, and M. Comporti, "Determination of 4-hydroxynonenal by highperformance liquid chromatography with electrochemical detection," Lipids, vol. 28, no. 2, pp. 141-145, 1993.

[144] S. Zelzer, H. Mangge, R. Oberreither et al., "Oxidative stress: determination of 4-hydroxy-2-nonenal by gas chromatography/mass spectrometry in human and rat plasma," Free Radical Research, vol. 49, no. 10, pp. 1233-1238, 2015.

[145] W. Luczaj, E. Gindzienska-Sieskiewicz, I. Jarocka-Karpowicz et al., "The onset of lipid peroxidation in rheumatoid arthritis: consequences and monitoring," Free Radical Research, vol. 50, no. 3, pp. 304-313, 2016.

[146] P. M. Abuja and R. Albertini, "Methods for monitoring oxidative stress, lipid peroxidation and oxidation resistance of lipoproteins," Clinica Chimica Acta, vol. 306, no. 1-2, pp. 117, 2001.

[147] D. Del Rio, A. J. Stewart, and N. Pellegrini, “A review of recent studies on malondialdehyde as toxic molecule and biological marker of oxidative stress," Nutrition, Metabolism, and Cardiovascular Diseases, vol. 15, no. 4, pp. 316-328, 2005.

[148] J. A. Knight, R. K. Pieper, and L. McClellan, "Specificity of the thiobarbituric acid reaction: its use in studies of lipid peroxidation," Clinical Chemistry, vol. 34, no. 12, pp. 2433-2438, 1988.

[149] A. M. Domijan, J. Ralic, S. Radic Brkanac, L. Rumora, and T. Zanic-Grubisic, "Quantification of malondialdehyde by HPLC-FL - application to various biological samples," Biomedical Chromatography, vol. 29, no. 1, pp. 41-46, 2015.

[150] D. Grotto, L. D. Santa Maria, S. Boeira et al., "Rapid quantification of malondialdehyde in plasma by high performance liquid chromatography-visible detection," Journal of Pharmaceutical and Biomedical Analysis, vol. 43, no. 2, pp. 619-624, 2007.

[151] A. S. Sim, C. Salonikas, D. Naidoo, and D. E. Wilcken, "Improved method for plasma malondialdehyde measurement by high-performance liquid chromatography using methyl malondialdehyde as an internal standard," Journal of Chromatography. B, Analytical Technologies in the Biomedical and Life Sciences, vol. 785, no. 2, pp. 337-344, 2003.

[152] K. Natarajan, G. D. Mathialagan, S. Raghavan, and N. Shanmugam, "The advanced Lipoxidation end product precursor malondialdehyde induces IL-17E expression and skews lymphocytes to the th17 subset," Cellular \& Molecular Biology Letters, vol. 20, no. 4, pp. 647-662, 2015.

[153] A. Ueno, A. Ghosh, D. Hung, J. Li, and H. Jijon, “Th17 plasticity and its changes associated with inflammatory bowel disease," World Journal of Gastroenterology, vol. 21, no. 43, pp. 12283-12295, 2015. 
[154] U. Dreissigacker, M. T. Suchy, N. Maassen, and D. Tsikas, "Human plasma concentrations of malondialdehyde (MDA) and the F2-isoprostane 15(S)-8-iso-PGF(2alpha) may be markedly compromised by hemolysis: evidence by GC-MS/MS and potential analytical and biological ramifications," Clinical Biochemistry, vol. 43, no. 1-2, pp. 159-167, 2010.

[155] J. Proudfoot, A. Barden, T. A. Mori et al., "Measurement of urinary $\mathrm{F}(2)$-isoprostanes as markers of in vivo lipid peroxidation-a comparison of enzyme immunoassay with gas chromatography/mass spectrometry," Analytical Biochemistry, vol. 272, no. 2, pp. 209-215, 1999.

[156] K. A. Smith, J. Shepherd, A. Wakil, and E. S. Kilpatrick, "A comparison of methods for the measurement of 8-isoPGF(2alpha): a marker of oxidative stress," Annals of Clinical Biochemistry, vol. 48, no. Pt 2, pp. 147-154, 2011.

[157] D. Il'yasova, J. D. Morrow, A. Ivanova, and L. E. Wagenknecht, "Epidemiological marker for oxidant status: comparison of the ELISA and the gas chromatography/mass spectrometry assay for urine 2,3-dinor-5,6-dihydro-15-F2t-isoprostane," Annals of Epidemiology, vol. 14, no. 10, pp. 793-797, 2004.

[158] M. A. Lam, G. J. Maghzal, M. Khademi et al., “Absence of systemic oxidative stress and increased CSF prostaglandin F2alpha in progressive MS," Neurology ${ }^{\circledR}$ Neuroimmunology \& Neuroinflammation, vol. 3, no. 4, p. e256, 2016.

[159] N. Wang, R. Dai, W. Wang, Y. Peng, X. Zhao, and K. Bi, "Simultaneous profiling of eicosanoid metabolome in plasma by UPLC-MS/MS method: application to identify potential makers for rheumatoid arthritis," Talanta, vol. 161, pp. 157-164, 2016.

[160] N. Wang, X. Zhao, W. Wang, Y. Peng, K. Bi, and R. Dai, "Targeted profiling of arachidonic acid and eicosanoids in rat tissue by UFLC-MS/MS: application to identify potential markers for rheumatoid arthritis," Talanta, vol. 162, pp. 479-487, 2017.

[161] H. Wiseman and B. Halliwell, "Damage to DNA by reactive oxygen and nitrogen species: role in inflammatory disease and progression to cancer," The Biochemical Journal, vol. 313, Part 1, pp. 17-29, 1996.

[162] M. Dizdaroglu, P. Jaruga, M. Birincioglu, and H. Rodriguez, "Free radical-induced damage to DNA: mechanisms and measurement," Free Radical Biology \& Medicine, vol. 32, no. 11, pp. 1102-1115, 2002.

[163] J. Cadet, T. Douki, D. Gasparutto, and J. L. Ravanat, “Oxidative damage to DNA: formation, measurement and biochemical features," Mutation Research, vol. 531, no. 1-2, pp. 5-23, 2003.

[164] A. M. Knaapen, N. Gungor, R. P. Schins, P. J. Borm, and F. J. Van Schooten, "Neutrophils and respiratory tract DNA damage and mutagenesis: a review," Mutagenesis, vol. 21, no. 4, pp. 225-236, 2006.

[165] H. Li, S. Cui, S. Wang et al., "Ultrasensitive UPLC-MS/MS method for analysis of etheno-DNA adducts in human white blood cells," Free Radical Research, vol. 49, no. 9, pp. 10491054, 2015.

[166] H. Bartsch and J. Nair, "Accumulation of lipid peroxidationderived DNA lesions: potential lead markers for chemoprevention of inflammation-driven malignancies," Mutation Research, vol. 591, no. 1-2, pp. 34-44, 2005.

[167] J. Nair, F. Gansauge, H. Beger, P. Dolara, G. Winde, and H. Bartsch, "Increased etheno-DNA adducts in affected tissues of patients suffering from Crohn's disease, ulcerative colitis, and chronic pancreatitis," Antioxidants \& Redox Signaling, vol. 8, no. 5-6, pp. 1003-1010, 2006.

[168] P. Bin, M. Shen, H. Li et al., "Increased levels of urinary biomarkers of lipid peroxidation products among workers occupationally exposed to diesel engine exhaust," Free Radical Research, vol. 50, no. 8, pp. 820-830, 2016.

[169] S. Cui, H. Li, S. Wang et al., "Ultrasensitive UPLC-MS-MS method for the quantitation of etheno-DNA adducts in human urine," International Journal of Environmental Research and Public Health, vol. 11, no. 10, pp. 1090210914, 2014.

[170] J. Cadet and J. R. Wagner, "Oxidatively generated base damage to cellular DNA by hydroxyl radical and one-electron oxidants: similarities and differences," Archives of Biochemistry and Biophysics, vol. 557, pp. 47-54, 2014.

[171] M. Dizdaroglu and P. Jaruga, "Mechanisms of free radicalinduced damage to DNA," Free Radical Research, vol. 46, no. 4, pp. 382-419, 2012.

[172] J. L. Ravanat, J. Cadet, and T. Douki, “Oxidatively generated DNA lesions as potential biomarkers of in vivo oxidative stress," Current Molecular Medicine, vol. 12, no. 6, pp. 655671, 2012.

[173] C. M. Gedik, A. Collins, and Escodd, "Establishing the background level of base oxidation in human lymphocyte DNA: results of an interlaboratory validation study," The FASEB Journal, vol. 19, no. 1, pp. 82-84, 2005.

[174] European Standards Committee on Urinary Lesion, AM. D. Evans, R. Olinski, S. Loft, and M. S. Cooke, "Toward consensus in the analysis of urinary 8-oxo-7,8-dihydro-2'-deoxyguanosine as a noninvasive biomarker of oxidative stress," The FASEB Journal, vol. 24, no. 4, pp. 1249-1260, 2010.

[175] M. S. Cooke, R. Olinski, S. Loft, and A. European Standards, "Committee on urinary lesion, measurement and meaning of oxidatively modified DNA lesions in urine," Cancer Epidemiology, Biomarkers \& Prevention, vol. 17, no. 1, pp. 3-14, 2008.

[176] H. Sova, A. Jukkola-Vuorinen, U. Puistola, S. Kauppila, and P. Karihtala, "8-Hydroxydeoxyguanosine: a new potential independent prognostic factor in breast cancer," British Journal of Cancer, vol. 102, no. 6, pp. 1018-1023, 2010.

[177] S. Loft, P. Svoboda, H. Kasai et al., "Prospective study of 8oxo-7,8-dihydro-2'-deoxyguanosine excretion and the risk of lung cancer," Carcinogenesis, vol. 27, no. 6, pp. 12451250, 2006.

[178] L. L. Wu, C. C. Chiou, P. Y. Chang, and J. T. Wu, "Urinary 8OHdG: a marker of oxidative stress to DNA and a risk factor for cancer, atherosclerosis and diabetics," Clinica Chimica Acta, vol. 339, no. 1-2, pp. 1-9, 2004.

[179] M. Kant, M. Akis, M. Calan et al., "Elevated urinary levels of 8-oxo-2'-deoxyguanosine, (5'R)- and (5'S)-8, $5^{\prime}$-cyclo-2'-deoxyadenosines, and 8-iso-prostaglandin F2alpha as potential biomarkers of oxidative stress in patients with prediabetes," DNA Repair (Amst), vol. 48, pp. 1-7, 2016.

[180] K. Broedbaek, V. Siersma, T. Henriksen et al., "Urinary markers of nucleic acid oxidation and cancer in type 2 diabetes," Redox Biology, vol. 4, pp. 34-39, 2015.

[181] E. R. Stadtman, “Protein oxidation and aging," Free Radical Research, vol. 40, no. 12, pp. 1250-1258, 2006.

[182] M. J. Davies, "Protein oxidation and peroxidation," The Biochemical Journal, vol. 473, no. 7, pp. 805-825, 2016. 
[183] C. Ott and T. Grune, "Protein oxidation and proteolytic signalling in aging," Current Pharmaceutical Design, vol. 20, no. 18, pp. 3040-3051, 2014.

[184] A. Hohn, T. Jung, and T. Grune, "Pathophysiological importance of aggregated damaged proteins," Free Radical Biology \& Medicine, vol. 71, pp. 70-89, 2014.

[185] E. R. Stadtman, "Oxidation of proteins by mixed-function oxidation systems: implication in protein turnover, aging and neutrophil function," Trends in Biochemical Sciences, vol. 11, no. 1, pp. 11-12, 1986.

[186] B. S. Berlett and E. R. Stadtman, "Protein oxidation in aging, disease, and oxidative stress," The Journal of Biological Chemistry, vol. 272, no. 33, pp. 20313-20316, 1997.

[187] J. C. Monboisse and J. P. Borel, "Oxidative damage to collagen,” EXS, vol. 62, pp. 323-327, 1992.

[188] V. Vanhooren, A. Navarrete Santos, K. Voutetakis et al., "Protein modification and maintenance systems as biomarkers of ageing," Mechanisms of Ageing and Development, vol. 151, pp. 71-84, 2015.

[189] D. A. Butterfield, L. Gu, F. Di Domenico, and R. A. Robinson, "Mass spectrometry and redox proteomics: applications in disease," Mass Spectrometry Reviews, vol. 33, no. 4, pp. 277301, 2014.

[190] A. Hohn, J. Konig, and T. Grune, "Protein oxidation in aging and the removal of oxidized proteins," Journal of Proteomics, vol. 92, pp. 132-159, 2013.

[191] N. Breusing and T. Grune, "Biomarkers of protein oxidation from a chemical, biological and medical point of view," Experimental Gerontology, vol. 45, no. 10, pp. 733737, 2010.

[192] C. L. Hawkins, P. E. Morgan, and M. J. Davies, "Quantification of protein modification by oxidants," Free Radical Biology \& Medicine, vol. 46, no. 8, pp. 965-988, 2009.

[193] E. R. Stadtman and R. L. Levine, "Free radical-mediated oxidation of free amino acids and amino acid residues in proteins," Amino Acids, vol. 25, no. 3-4, pp. 207-218, 2003.

[194] M. Chevion, E. Berenshtein, and E. R. Stadtman, "Human studies related to protein oxidation: protein carbonyl content as a marker of damage," Free Radical Research, Supplement 33, pp. S99-108, 2000.

[195] L. Gil, W. Siems, B. Mazurek et al., "Age-associated analysis of oxidative stress parameters in human plasma and erythrocytes," Free Radical Research, vol. 40, no. 5, pp. 495-505, 2006.

[196] R. Sultana, M. Perluigi, and D. A. Butterfield, "Protein oxidation and lipid peroxidation in brain of subjects with Alzheimer's disease: insights into mechanism of neurodegeneration from redox proteomics," Antioxidants \& Redox Signaling, vol. 8, no. 11-12, pp. 2021-2037, 2006.

[197] A. Z. Reznick and L. Packer, "Oxidative damage to proteins: spectrophotometric method for carbonyl assay," Methods in Enzymology, vol. 233, pp. 357-363, 1994.

[198] R. L. Levine, J. A. Williams, E. R. Stadtman, and E. Shacter, "Carbonyl assays for determination of oxidatively modified proteins," Methods in Enzymology, vol. 233, pp. 346-357, 1994.

[199] H. Buss, T. P. Chan, K. B. Sluis, N. M. Domigan, and C. C. Winterbourn, "Protein carbonyl measurement by a sensitive ELISA method," Free Radical Biology \& Medicine, vol. 23, no. 3, pp. 361-366, 1997.
[200] C. Delgado-Andrade, "Carboxymethyl-lysine: thirty years of investigation in the field of AGE formation," Food \& Function, vol. 7, no. 1, pp. 46-57, 2016.

[201] G. Vistoli, D. De Maddis, A. Cipak, N. Zarkovic, M. Carini, and G. Aldini, "Advanced glycoxidation and lipoxidation end products (AGEs and ALEs): an overview of their mechanisms of formation," Free Radical Research, vol. 47, Supplement 1, pp. 3-27, 2013.

[202] P. A. Grimsrud, H. Xie, T. J. Griffin, and D. A. Bernlohr, "Oxidative stress and covalent modification of protein with bioactive aldehydes," The Journal of Biological Chemistry, vol. 283, no. 32, pp. 21837-21841, 2008.

[203] M. Perluigi, R. Coccia, and D. A. Butterfield, “4-Hydroxy-2nonenal, a reactive product of lipid peroxidation, and neurodegenerative diseases: a toxic combination illuminated by redox proteomics studies," Antioxidants \& Redox Signaling, vol. 17, no. 11, pp. 1590-1609, 2012.

[204] J. Anguizola, R. Matsuda, O. S. Barnaby et al., "Review: glycation of human serum albumin," Clinica Chimica Acta, vol. 425, pp. 64-76, 2013.

[205] V. M. Monnier and D. R. Sell, "Prevention and repair of protein damage by the Maillard reaction in vivo," Rejuvenation Research, vol. 9, no. 2, pp. 264-273, 2006.

[206] M. X. Fu, J. R. Requena, A. J. Jenkins, T. J. Lyons, J. W. Baynes, and S. R. Thorpe, "The advanced glycation end product, Nepsilon-(carboxymethyl)lysine, is a product of both lipid peroxidation and glycoxidation reactions," The Journal of Biological Chemistry, vol. 271, no. 17, pp. 99829986, 1996.

[207] S. J. Loomis, Y. Chen, D. B. Sacks et al., "Cross-sectional analysis of AGE-CML, sRAGE, and esRAGE with diabetes and Cardiometabolic risk factors in a community-based cohort," Clinical Chemistry, vol. 63, no. 5, pp. 980-989, 2017.

[208] E. Sanchez, A. Betriu, D. Arroyo et al., "Skin autofluorescence and subclinical atherosclerosis in mild to moderate chronic kidney disease: a case-control study," PloS One, vol. 12, no. 1, article e0170778, 2017.

[209] E. Lohou, N. A. Sasaki, A. Boullier, and P. Sonnet, "Multifunctional diamine AGE/ALE inhibitors with potential therapeutical properties against Alzheimer's disease," European Journal of Medicinal Chemistry, vol. 122, pp. 702-722, 2016.

[210] M. Colzani, G. Aldini, and M. Carini, "Mass spectrometric approaches for the identification and quantification of reactive carbonyl species protein adducts," Journal of Proteomics, vol. 92, pp. 28-50, 2013.

[211] F. Di Domenico, G. Pupo, A. Tramutola et al., "Redox proteomics analysis of HNE-modified proteins in Down syndrome brain: clues for understanding the development of Alzheimer disease," Free Radical Biology \& Medicine, vol. 71, pp. 270280, 2014.

[212] J. M. Ashraf, S. Ahmad, I. Choi et al., "Recent advances in detection of AGEs: immunochemical, bioanalytical and biochemical approaches," IUBMB Life, vol. 67, no. 12, pp. 897913, 2015.

[213] C. Da Moura Semedo, M. Webb, H. Waller, K. Khunti, and M. Davies, "Skin autofluorescence, a non-invasive marker of advanced glycation end products: clinical relevance and limitations," Postgraduate Medical Journal, vol. 93, no. 1099, pp. 289-294, 2017. 
[214] C. Y. Liu, Q. F. Huang, Y. B. Cheng et al., “A comparative study on skin and plasma advanced glycation end products and their associations with arterial stiffness," Pulse (Basel, Switzerland), vol. 4, no. 4, pp. 208-218, 2017.

[215] S. Osawa, N. Katakami, A. Kuroda et al., "Skin Autofluorescence is associated with early-stage atherosclerosis in patients with type 1 diabetes," Journal of Atherosclerosis and Thrombosis, vol. 24, no. 3, pp. 312-326, 2017.

[216] J. P. J. Lobo, C. P. Brescansin, I. C. Santos-Weiss et al., "Serum fluorescent advanced glycation end (F-AGE) products in gestational diabetes patients," Archives of endocrinology and metabolism, vol. 13, p. 0, 2017.

[217] Q. Liu, M. A. Smith, J. Avila et al., "Alzheimer-specific epitopes of tau represent lipid peroxidation-induced conformations," Free Radical Biology \& Medicine, vol. 38, no. 6, pp. 746-754, 2005.

[218] R. N. Johnson, P. A. Metcalf, and J. R. Baker, "Fructosamine: a new approach to the estimation of serum glycosylprotein. An index of diabetic control," Clinica Chimica Acta, vol. 127, no. 1, pp. 87-95, 1983.

[219] E. Schleicher and O. H. Wieland, "Specific quantitation by HPLC of protein (lysine) bound glucose in human serum albumin and other glycosylated proteins," Journal of Clinical Chemistry and Clinical Biochemistry, vol. 19, no. 2, pp. 81-87, 1981.

[220] X. B. Xu, F. Ma, S. J. Yu, and Y. G. Guan, "Simultaneous analysis of Nepsilon-(carboxymethyl)lysine, reducing sugars, and lysine during the dairy thermal process," Journal of Dairy Science, vol. 96, no. 9, pp. 5487-5493, 2013.

[221] J. L. Scheijen, M. P. van de Waarenburg, C. D. Stehouwer, and C. G. Schalkwijk, "Measurement of pentosidine in human plasma protein by a single-column high-performance liquid chromatography method with fluorescence detection," Journal of Chromatography. B, Analytical Technologies in the Biomedical and Life Sciences, vol. 877, no. 7, pp. 610614, 2009.

[222] W. Gu, Z. Xu, F. Qi, Z. Sang, C. Wang, and F. Li, "Plasma levels of soluble receptor for advanced glycation end products in patients with acute respiratory distress syndrome," International Journal of Clinical and Experimental Medicine, vol. 7, no. 12, pp. 5558-5562, 2014.

[223] Z. Turk, M. Sesto, J. Skodlar et al., "Products of advanced glycation in patients with type 2 diabetes and vascular disease," Annals of Clinical Biochemistry, vol. 40, Part 5, pp. 552-559, 2003.

[224] S. Ahmad, S. Habib, Moinuddin, and A. Ali, "Preferential recognition of epitopes on AGE-IgG by the autoantibodies in rheumatoid arthritis patients," Human Immunology, vol. 74, no. 1, pp. 23-27, 2013.

[225] S. Bartesaghi, G. Ferrer-Sueta, G. Peluffo et al., "Protein tyrosine nitration in hydrophilic and hydrophobic environments," Amino Acids, vol. 32, no. 4, pp. 501-515, 2007.

[226] F. J. Schopfer, P. R. Baker, and B. A. Freeman, "NO-dependent protein nitration: a cell signaling event or an oxidative inflammatory response?" Trends in Biochemical Sciences, vol. 28, no. 12, pp. 646-654, 2003.

[227] J. M. Souza, G. Peluffo, and R. Radi, "Protein tyrosine nitration-functional alteration or just a biomarker?” Free Radical Biology \& Medicine, vol. 45, no. 4, pp. 357-366, 2008.

[228] D. Tsikas and M. W. Duncan, "Mass spectrometry and 3nitrotyrosine: strategies, controversies, and our current perspective," Mass Spectrometry Reviews, vol. 33, no. 4, pp. 237-276, 2014.

[229] Y. Kamisaki, K. Wada, K. Nakamoto, Y. Kishimoto, M. Kitano, and T. Itoh, "Sensitive determination of nitrotyrosine in human plasma by isocratic high-performance liquid chromatography," Journal of Chromatography. B, Biomedical Applications, vol. 685, no. 2, pp. 343-347, 1996.

[230] N. Rabbani and P. J. Thornalley, "Assay of 3-nitrotyrosine in tissues and body fluids by liquid chromatography with tandem mass spectrometric detection," Methods in Enzymology, vol. 440, pp. 337-359, 2008.

[231] J. P. Gaut, J. Byun, H. D. Tran, and J. W. Heinecke, “Artifactfree quantification of free 3-chlorotyrosine, 3-bromotyrosine, and 3-nitrotyrosine in human plasma by electron capturenegative chemical ionization gas chromatography mass spectrometry and liquid chromatography-electrospray ionization tandem mass spectrometry," Analytical Biochemistry, vol. 300, no. 2, pp. 252-259, 2002.

[232] S. Xu, J. Ying, B. Jiang et al., "Detection of sequence-specific tyrosine nitration of manganese SOD and SERCA in cardiovascular disease and aging," American Journal of Physiology. Heart and Circulatory Physiology, vol. 290, no. 6, pp. H2220-H2227, 2006.

[233] J. Khan, D. M. Brennand, N. Bradley, B. Gao, R. Bruckdorfer, and M. Jacobs, "3-Nitrotyrosine in the proteins of human plasma determined by an ELISA method," The Biochemical Journal, vol. 332, Part 3, pp. 807-808, 1998.

[234] C. Herce-Pagliai, S. Kotecha, and D. E. Shuker, "Analytical methods for 3-nitrotyrosine as a marker of exposure to reactive nitrogen species: a review," Nitric Oxide, vol. 2, no. 5, pp. 324-336, 1998.

[235] S. Meredith, G. Parekh, J. Towler et al., "Mapping nitrotyrosine modifications in fibrinogen by mass spectrometry as a biomarker for inflammatory disease," Free Radical Biology \& Medicine, vol. 75, Supplement 1, p. S50, 2014.

[236] G. Peluffo and R. Radi, "Biochemistry of protein tyrosine nitration in cardiovascular pathology," Cardiovascular Research, vol. 75, no. 2, pp. 291-302, 2007.

[237] N. R. Jayakumari, A. C. Reghuvaran, R. S. Rajendran et al., "Are nitric oxide-mediated protein modifications of functional significance in diabetic heart? ye'S, -NO', wh'Y-NO't?" Nitric Oxide, vol. 43, pp. 35-44, 2014.

[238] W. S. Yeo, Y. J. Kim, M. H. Kabir, J. W. Kang, M. Ahsan-UlBari, and K. P. Kim, "Mass spectrometric analysis of protein tyrosine nitration in aging and neurodegenerative diseases," Mass Spectrometry Reviews, vol. 34, no. 2, pp. 166-183, 2015.

[239] R. Sultana, H. F. Poon, J. Cai et al., "Identification of nitrated proteins in Alzheimer's disease brain using a redox proteomics approach," Neurobiology of Disease, vol. 22, no. 1, pp. 76-87, 2006.

[240] V. Witko-Sarsat, M. Friedlander, T. Nguyen Khoa et al., "Advanced oxidation protein products as novel mediators of inflammation and monocyte activation in chronic renal failure," Journal of Immunology, vol. 161, no. 5, pp. 25242532, 1998.

[241] W. Cao, F. F. Hou, and J. Nie, "AOPPs and the progression of kidney disease," Kidney International, vol. 4, no. 1, Supplement 2011, pp. 102-106, 2014.

[242] M. Cristani, A. Speciale, A. Saija, S. Gangemi, P. L. Minciullo, and F. Cimino, "Circulating advanced oxidation protein products as oxidative stress biomarkers and progression 
mediators in pathological conditions related to inflammation and immune dysregulation," Current Medicinal Chemistry, vol. 23, no. 34, pp. 3862-3882, 2016.

[243] M. Kalousova, J. Skrha, and T. Zima, “Advanced glycation end-products and advanced oxidation protein products in patients with diabetes mellitus," Physiological Research, vol. 51, no. 6, pp. 597-604, 2002.

[244] S. L. Du, X. Z. Zeng, J. W. Tian, J. Ai, J. Wan, and J. X. He, "Advanced oxidation protein products in predicting acute kidney injury following cardiac surgery," Biomarkers, vol. 20, no. 3, pp. 206-211, 2015.

[245] E. L. Taylor, K. R. Armstrong, D. Perrett, A. T. Hattersley, and P. G. Winyard, "Optimisation of an advanced oxidation protein products assay: its application to studies of oxidative stress in diabetes mellitus," Oxidative Medicine and Cellular Longevity, vol. 2015, Article ID 496271, 10 pages, 2015.

[246] S. L. Hazen, J. R. Crowley, D. M. Mueller, and J. W. Heinecke, "Mass spectrometric quantification of 3-chlorotyrosine in human tissues with attomole sensitivity: a sensitive and specific marker for myeloperoxidase-catalyzed chlorination at sites of inflammation," Free Radical Biology \& Medicine, vol. 23, no. 6, pp. 909-916, 1997.

[247] S. L. Hazen and J. W. Heinecke, "3-Chlorotyrosine, a specific marker of myeloperoxidase-catalyzed oxidation, is markedly elevated in low density lipoprotein isolated from human atherosclerotic intima," The Journal of Clinical Investigation, vol. 99, no. 9, pp. 2075-2081, 1997.

[248] S. M. Wu and S. V. Pizzo, " $\alpha_{2}$-Macroglobulin from rheumatoid arthritis synovial fluid: functional analysis defines a role for oxidation in inflammation," Archives of Biochemistry and Biophysics, vol. 391, no. 1, pp. 119-126, 2001.

[249] A. J. Kettle, T. Chan, I. Osberg et al., "Myeloperoxidase and protein oxidation in the airways of young children with cystic fibrosis," American Journal of Respiratory and Critical Care Medicine, vol. 170, no. 12, pp. 1317-1323, 2004.

[250] I. H. Buss, R. Senthilmohan, B. A. Darlow, N. Mogridge, A. J. Kettle, and C. C. Winterbourn, "3-Chlorotyrosine as a marker of protein damage by myeloperoxidase in tracheal aspirates from preterm infants: association with adverse respiratory outcome," Pediatric Research, vol. 53, no. 3, pp. 455-462, 2003.

[251] E. Verhoye, M. R. Langlois, and I. Asklepios, "Circulating oxidized low-density lipoprotein: a biomarker of atherosclerosis and cardiovascular risk?" Clinical Chemistry and Laboratory Medicine, vol. 47, no. 2, pp. 128-137, 2009.

[252] P. Holvoet, D. De Keyzer, and D. R. Jacobs Jr., "Oxidized LDL and the metabolic syndrome," Future Lipidology, vol. 3, no. 6, pp. 637-649, 2008.

[253] G. Maiolino, G. Rossitto, P. Caielli, V. Bisogni, G. P. Rossi, and L. A. Calo, "The role of oxidized low-density lipoproteins in atherosclerosis: the myths and the facts," Mediators of Inflammation, vol. 2013, Article ID 714653, 13 pages, 2013.

[254] J. Frijhoff, P. G. Winyard, N. Zarkovic et al., "Clinical relevance of biomarkers of oxidative stress," Antioxidants \& Redox Signaling, vol. 23, no. 14, pp. 1144-1170, 2015.

[255] S. Al Kasab, C. Cassarly, N. A. Le et al., "Postprandial clearance of oxidized low-density lipoprotein in patients with stroke due to atherosclerosis," Journal of Stroke and Cerebrovascular Diseases, vol. 26, no. 3, pp. 488-493, 2017.

[256] F. L. Balderas, M. Quezada-Larios, E. A. Garcia Latorre, and J. D. Mendez, "Increased uptake of oxidized LDL by macrophages from type 2 diabetics is inhibited by polyamines," Biomedicine \& Pharmacotherapy, vol. 77, pp. 5964, 2016.

[257] A. T. Babakr, O. M. Elsheikh, A. A. Almarzouki et al., "Relationship between oxidized low-density lipoprotein antibodies and obesity in different glycemic situations," Diabetes, Metabolic Syndrome and Obesity, vol. 7, pp. 513-520, 2014.

[258] A. A. Rahsepar, A. Mirzaee, F. Moodi et al., "Malondialdehyde-modified LDL IgG antibody levels and indices of cardiac function in valvular heart and coronary artery disease patients," Medical Principles and Practice, vol. 24, no. 5, pp. 424-431, 2015.

[259] G. Marx and M. Chevion, "Site-specific modification of albumin by free radicals. Reaction with copper(II) and ascorbate," The Biochemical Journal, vol. 236, no. 2, pp. 397-400, 1986.

[260] D. Roy, J. Quiles, D. C. Gaze, P. Collinson, J. C. Kaski, and G. F. Baxter, "Role of reactive oxygen species on the formation of the novel diagnostic marker ischaemia modified albumin," Heart, vol. 92, no. 1, pp. 113-114, 2006.

[261] D. Bar-Or, G. Curtis, N. Rao, N. Bampos, and E. Lau, "Characterization of the $\mathrm{Co}^{2+}$ and $\mathrm{Ni}^{2+}$ binding aminoacid residues of the N-terminus of human albumin. An insight into the mechanism of a new assay for myocardial ischemia," European Journal of Biochemistry, vol. 268, no. 1, pp. 42-47, 2001.

[262] R. H. Christenson, S. H. Duh, W. R. Sanhai et al., "Characteristics of an albumin cobalt binding test for assessment of acute coronary syndrome patients: a multicenter study," Clinical Chemistry, vol. 47, no. 3, pp. 464-470, 2001.

[263] D. C. Gaze, "Ischemia modified albumin: a novel biomarker for the detection of cardiac ischemia," Drug Metabolism and Pharmacokinetics, vol. 24, no. 4, pp. 333-341, 2009.

[264] E. Mothes and P. Faller, "Evidence that the principal CoIIbinding site in human serum albumin is not at the N-terminus: implication on the albumin cobalt binding test for detecting myocardial ischemia," Biochemistry, vol. 46, no. 8 , pp. 2267-2274, 2007.

[265] D. Bar-Or, E. Lau, and J. V. Winkler, "A novel assay for cobalt-albumin binding and its potential as a marker for myocardial ischemia-a preliminary report," The Journal of Emergency Medicine, vol. 19, no. 4, pp. 311-315, 2000.

[266] S. G. Ma, Y. Jin, W. Hu, F. Bai, W. Xu, and W. N. Yu, "Evaluation of ischemia-modified albumin and C-reactive protein in type 2 diabetics with and without ketosis," Biomarker Insights, vol. 7, pp. 19-26, 2012.

[267] A. Gunduz, S. Turedi, A. Mentese et al., "Ischemia-modified albumin levels in cerebrovascular accidents," The American Journal of Emergency Medicine, vol. 26, no. 8, pp. 874-8, 2008.

[268] E. Altunoglu, G. Guntas, F. Erdenen et al., "Ischemia-modified albumin and advanced oxidation protein products as potential biomarkers of protein oxidation in Alzheimer's disease," Geriatrics \& Gerontology International, vol. 15, no. 7, pp. 872-880, 2015.

[269] A. Kumar, "Ischemia-modified albumin: its diagnostic implications and shortfalls," Journal of Biomedical Science, vol. 1, pp. 2-4, 2012.

[270] E. Sbarouni, P. Georgiadou, and V. Voudris, "Ischemia modified albumin changes - review and clinical implications," Clinical Chemistry and Laboratory Medicine, vol. 49, no. 2, pp. 177-184, 2011. 
[271] P. O. Collinson and D. C. Gaze, "Ischaemia-modified albumin: clinical utility and pitfalls in measurement," Journal of Clinical Pathology, vol. 61, no. 9, pp. 1025-1028, 2008.

[272] A. G. Madian, A. D. Myracle, N. Diaz-Maldonado, N. S. Rochelle, E. M. Janle, and F. E. Regnier, "Differential carbonylation of proteins as a function of in vivo oxidative stress," Journal of Proteome Research, vol. 10, no. 9, pp. 3959-3972, 2011.

[273] A. Bachi, I. Dalle-Donne, and A. Scaloni, "Redox proteomics: chemical principles, methodological approaches and biological/biomedical promises," Chemical Reviews, vol. 113, no. 1, pp. 596-698, 2013.

[274] S. Boronat, S. Garcia-Santamarina, and E. Hidalgo, "Gel-free proteomic methodologies to study reversible cysteine oxidation and irreversible protein carbonyl formation," Free Radical Research, vol. 49, no. 5, pp. 494-510, 2015.

[275] L. J. Yan, "Protein redox modification as a cellular defense mechanism against tissue ischemic injury," Oxidative Medicine and Cellular Longevity, vol. 2014, Article ID 343154, 12 pages, 2014.

[276] M. Fedorova, R. C. Bollineni, and R. Hoffmann, "Protein carbonylation as a major hallmark of oxidative damage: update of analytical strategies," Mass Spectrometry Reviews, vol. 33, no. 2, pp. 79-97, 2014.

[277] M. A. Baraibar, R. Ladouce, and B. Friguet, "Proteomic quantification and identification of carbonylated proteins upon oxidative stress and during cellular aging," Journal of Proteomics, vol. 92, pp. 63-70, 2013.

[278] M. Serafini, D. Villano, G. Spera, and N. Pellegrini, "Redox molecules and cancer prevention: the importance of understanding the role of the antioxidant network," Nutrition and Cancer, vol. 56, no. 2, pp. 232-240, 2006.

[279] C. C. Winterbourn and M. B. Hampton, "Thiol chemistry and specificity in redox signaling," Free Radical Biology \& Medicine, vol. 45, no. 5, pp. 549-561, 2008.

[280] Y. Wang, J. Yang, and J. Yi, "Redox sensing by proteins: oxidative modifications on cysteines and the consequent events," Antioxidants \& Redox Signaling, vol. 16, no. 7, pp. 649-657, 2012.

[281] L. B. Poole, "The basics of thiols and cysteines in redox biology and chemistry," Free Radical Biology \& Medicine, vol. 80, pp. 148-157, 2015.

[282] M. Trujillo, B. Alvarez, and R. Radi, "One- and twoelectron oxidation of thiols: mechanisms, kinetics and biological fates," Free Radical Research, vol. 50, no. 2, pp. 150-171, 2016.

[283] B. C. Smith and M. A. Marletta, "Mechanisms of Snitrosothiol formation and selectivity in nitric oxide signaling," Current Opinion in Chemical Biology, vol. 16, no. 5-6, pp. 498-506, 2012.

[284] F. R. Laurindo, L. A. Pescatore, and C. Fernandes Dde, "Protein disulfide isomerase in redox cell signaling and homeostasis," Free Radical Biology \& Medicine, vol. 52, no. 9, pp. 1954-1969, 2012.

[285] E. M. Hanschmann, J. R. Godoy, C. Berndt, C. Hudemann, and C. H. Lillig, "Thioredoxins, glutaredoxins, and peroxiredoxins-molecular mechanisms and health significance: from cofactors to antioxidants to redox signaling," Antioxidants \& Redox Signaling, vol. 19, no. 13, pp. 1539-1605, 2013.

[286] J. Lu and A. Holmgren, "The thioredoxin antioxidant system," Free Radical Biology \& Medicine, vol. 66, pp. 75-87, 2014.
[287] M. Pajares, N. Jimenez-Moreno, I. H. Dias et al., "Redox control of protein degradation," Redox Biology, vol. 6, pp. 409-420, 2015.

[288] Z. Cai and L. J. Yan, "Protein oxidative modifications: beneficial roles in disease and health," Journal of biochemical and pharmacological research, vol. 1, no. 1, pp. 15-26, 2013.

[289] J. Tyedmers, A. Mogk, and B. Bukau, "Cellular strategies for controlling protein aggregation," Nature Reviews. Molecular Cell Biology, vol. 11, no. 11, pp. 777-788, 2010.

[290] M. A. Comini, "Measurement and meaning of cellular thiol:disufhide redox status," Free Radical Research, vol. 50, no. 2, pp. 246-271, 2016.

[291] Y. M. Go and D. P. Jones, "Thiol/disulfide redox states in signaling and sensing," Critical Reviews in Biochemistry and Molecular Biology, vol. 48, no. 2, pp. 173-181, 2013.

[292] C. Klomsiri, P. A. Karplus, and L. B. Poole, "Cysteine-based redox switches in enzymes," Antioxidants \& Redox Signaling, vol. 14, no. 6, pp. 1065-1077, 2011.

[293] S. B. Wall, J. Y. Oh, A. R. Diers, and A. Landar, "Oxidative modification of proteins: an emerging mechanism of cell signaling," Frontiers in Physiology, vol. 3, p. 369, 2012.

[294] M. D. Shelton, P. B. Chock, and J. J. Mieyal, "Glutaredoxin: role in reversible protein s-glutathionylation and regulation of redox signal transduction and protein translocation," Antioxidants \& Redox Signaling, vol. 7, no. 3-4, pp. 348-366, 2005.

[295] P. Ghezzi, "Protein glutathionylation in health and disease," Biochimica et Biophysica Acta, vol. 1830, no. 5, pp. 31653172, 2013.

[296] S. L. Ullevig, H. S. Kim, J. D. Short et al., "Protein Sglutathionylation mediates macrophage responses to metabolic cues from the extracellular environment," Antioxidants \& Redox Signaling, vol. 25, no. 15, pp. 836-851, 2016.

[297] R. Rossi, I. Dalle-Donne, A. Milzani, and D. Giustarini, "Oxidized forms of glutathione in peripheral blood as biomarkers of oxidative stress," Clinical Chemistry, vol. 52, no. 7, pp. 1406-1414, 2006.

[298] S. E. Bursell and G. L. King, "The potential use of glutathionyl hemoglobin as a clinical marker of oxidative stress," Clinical Chemistry, vol. 46, no. 2, pp. 145-146, 2000.

[299] T. Niwa, C. Naito, A. H. Mawjood, and K. Imai, "Increased glutathionyl hemoglobin in diabetes mellitus and hyperlipidemia demonstrated by liquid chromatography/electrospray ionization-mass spectrometry," Clinical Chemistry, vol. 46, no. 1, pp. 82-88, 2000.

[300] M. Johansson and M. Lundberg, "Glutathionylation of betaactin via a cysteinyl sulfenic acid intermediary," BMC Biochemistry, vol. 8, p. 26, 2007.

[301] G. A. Figtree, C. C. Liu, S. Bibert et al., "Reversible oxidative modification: a key mechanism of $\mathrm{Na}^{+}-\mathrm{K}^{+}$pump regulation," Circulation Research, vol. 105, no. 2, pp. 185-193, 2009.

[302] C. C. Liu, N. Fry, K. K. Galougahi, H. H. Rasmussen, and G. A. Figtree, "Glutathionylation of erythrocyte $\mathrm{Na}-\mathrm{K}$ pump in heart failure: a novel biomarker that reflects a key oxidative abnormality in the heart," Circulation, vol. 126, 2012.

[303] G. Wu, Y. Z. Fang, S. Yang, J. R. Lupton, and N. D. Turner, "Glutathione metabolism and its implications for health," The Journal of Nutrition, vol. 134, no. 3, pp. 489-492, 2004.

[304] S. C. Lu, "Regulation of glutathione synthesis," Molecular Aspects of Medicine, vol. 30, no. 1-2, pp. 42-59, 2009.

[305] F. Q. Schafer and G. R. Buettner, "Redox environment of the cell as viewed through the redox state of the glutathione 
disulfide/glutathione couple," Free Radical Biology \& Medicine, vol. 30, no. 11, pp. 1191-1212, 2001.

[306] R. A. Blanco, T. R. Ziegler, B. A. Carlson et al., "Diurnal variation in glutathione and cysteine redox states in human plasma," The American Journal of Clinical Nutrition, vol. 86, no. 4, pp. 1016-1023, 2007.

[307] A. Pastore, G. Federici, E. Bertini, and F. Piemonte, "Analysis of glutathione: implication in redox and detoxification," Clinica Chimica Acta, vol. 333, no. 1, pp. 19-39, 2003.

[308] R. Rossi, A. Milzani, I. Dalle-Donne et al., "Blood glutathione disulfide: in vivo factor or in vitro artifact?" Clinical Chemistry, vol. 48, no. 5, pp. 742-753, 2002.

[309] J. M. Lee and J. A. Johnson, "An important role of Nrf2-ARE pathway in the cellular defense mechanism," Journal of Biochemistry and Molecular Biology, vol. 37, no. 2, pp. 139143, 2004.

[310] R. Zhang, M. Xu, Y. Wang, F. Xie, G. Zhang, and X. Qin, "Nrf2-a promising therapeutic target for defensing against oxidative stress in stroke," Molecular Neurobiology, 2016, Epub ahead of print.

[311] I. Ganan-Gomez, Y. Wei, H. Yang, M. C. Boyano-Adanez, and G. Garcia-Manero, "Oncogenic functions of the transcription factor Nrf2," Free Radical Biology \& Medicine, vol. 65, pp. 750-764, 2013.

[312] F. Polito, M. Cicciu, M. Aguennouz et al., "Prognostic value of HMGB1 and oxidative stress markers in multiple trauma patients: a single-centre prospective study," International Journal of Immunopathology and Pharmacology, vol. 29, no. 3, pp. 504-509, 2016.

[313] N. L. Reynaert, A. van der Vliet, A. S. Guala et al., "Dynamic redox control of NF-kappaB through glutaredoxinregulated S-glutathionylation of inhibitory kappaB kinase beta," Proceedings of the National Academy of Sciences of the United States of America, vol. 103, no. 35, pp. 1308613091, 2006.

[314] P. S. Son, S. A. Park, H. K. Na, D. M. Jue, S. Kim, and Y. J. Surh, "Piceatannol, a catechol-type polyphenol, inhibits phorbol ester-induced NF-\{kappa\}B activation and cyclooxygenase- 2 expression in human breast epithelial cells: cysteine 179 of IKK\{beta $\}$ as a potential target," Carcinogenesis, vol. 31, no. 8, pp. 1442-1449, 2010.

[315] K. Heyninck, M. Lahtela-Kakkonen, P. Van der Veken, G. Haegeman, and W. Vanden Berghe, "Withaferin A inhibits NF-kappaB activation by targeting cysteine 179 in IKKbeta," Biochemical Pharmacology, vol. 91, no. 4, pp. 501-509, 2014.

[316] T. Ishii, M. Ishikawa, N. Miyoshi et al., "Catechol type polyphenol is a potential modifier of protein sulfhydryls: development and application of a new probe for understanding the dietary polyphenol actions," Chemical Research in Toxicology, vol. 22, no. 10, pp. 1689-1698, 2009.

[317] R. Sirota, D. Gibson, and R. Kohen, "The role of the catecholic and the electrophilic moieties of caffeic acid in Nrf2/ Keap1 pathway activation in ovarian carcinoma cell lines," Redox Biology, vol. 4, pp. 48-59, 2015.

[318] P. Higgins, J. Dawson, K. R. Lees, K. McArthur, T. J. Quinn, and M. R. Walters, "Xanthine oxidase inhibition for the treatment of cardiovascular disease: a systematic review and metaanalysis," Cardiovascular Therapeutics, vol. 30, no. 4, pp. 217-226, 2012.

[319] G. R. Drummond, S. Selemidis, K. K. Griendling, and C. G. Sobey, "Combating oxidative stress in vascular disease:
NADPH oxidases as therapeutic targets," Nature Reviews. Drug Discovery, vol. 10, no. 6, pp. 453-471, 2011.

[320] S. Sahoo, D. N. Meijles, and P. J. Pagano, "NADPH oxidases: key modulators in aging and age-related cardiovascular diseases?" Clinical Science (London, England), vol. 130, no. 5, pp. 317-335, 2016.

[321] H. Scharnagl, M. E. Kleber, B. Genser et al., "Association of myeloperoxidase with total and cardiovascular mortality in individuals undergoing coronary angiography-the LURIC study," International Journal of Cardiology, vol. 174, no. 1, pp. 96-105, 2014.

[322] J. D. Morrow, W. Qiu, D. Chhabra et al., "Identifying a gene expression signature of frequent COPD exacerbations in peripheral blood using network methods," BMC Medical Genomics, vol. 8, p. 1, 2015.

[323] S. Tzikas, D. Schlak, K. Sopova et al., "Increased myeloperoxidase plasma levels in patients with Alzheimer's disease," Journal of Alzheimer's Disease, vol. 39, no. 3, pp. 557-564, 2014.

[324] A. J. Kettle, A. M. Albrett, A. L. Chapman et al., "Measuring chlorine bleach in biology and medicine," Biochimica et Biophysica Acta, vol. 1840, no. 2, pp. 781-793, 2014.

[325] B. Ibrahim and P. J. Stoward, "The histochemical localization of xanthine oxidase," The Histochemical Journal, vol. 10, no. 5, pp. 615-617, 1978.

[326] T. P. Cappola, D. A. Kass, G. S. Nelson et al., “Allopurinol improves myocardial efficiency in patients with idiopathic dilated cardiomyopathy," Circulation, vol. 104, no. 20, pp. 2407-2411, 2001.

[327] S. D. Anker, W. Doehner, M. Rauchhaus et al., "Uric acid and survival in chronic heart failure: validation and application in metabolic, functional, and hemodynamic staging," Circulation, vol. 107, no. 15, pp. 1991-1997, 2003.

[328] S. Kojima, T. Sakamoto, M. Ishihara et al., "Coronary syndrome study, prognostic usefulness of serum uric acid after acute myocardial infarction (the Japanese Acute Coronary Syndrome Study)," The American Journal of Cardiology, vol. 96, no. 4, pp. 489-495, 2005.

[329] F. J. Nieto, C. Iribarren, M. D. Gross, G. W. Comstock, and R. G. Cutler, "Uric acid and serum antioxidant capacity: a reaction to atherosclerosis?" Atherosclerosis, vol. 148, no. 1, pp. 131-139, 2000.

[330] A. Sarnesto, N. Linder, and K. O. Raivio, "Organ distribution and molecular forms of human xanthine dehydrogenase/xanthine oxidase protein," Laboratory Investigation, vol. 74, no. 1, pp. 48-56, 1996.

[331] F. Stirpe and E. Della Corte, "The regulation of rat liver xanthine oxidase. Conversion in vitro of the enzyme activity from dehydrogenase (type $\mathrm{D}$ ) to oxidase (type $\mathrm{O}$ )," The Journal of Biological Chemistry, vol. 244, no. 14, pp. 38553863, 1969.

[332] T. Nishino, K. Okamoto, B. T. Eger, E. F. Pai, and T. Nishino, "Mammalian xanthine oxidoreductase - mechanism of transition from xanthine dehydrogenase to xanthine oxidase," The FEBS Journal, vol. 275, no. 13, pp. 3278-3289, 2008.

[333] R. Harrison, "Structure and function of xanthine oxidoreductase: where are we now?" Free Radical Biology \& Medicine, vol. 33, no. 6, pp. 774-797, 2002.

[334] N. Cantu-Medellin and E. E. Kelley, "Xanthine oxidoreductase-catalyzed reactive species generation: a 
process in critical need of reevaluation," Redox Biology, vol. 1, pp. 353-358, 2013.

[335] S. Baldus, R. Koster, P. Chumley et al., "Oxypurinol improves coronary and peripheral endothelial function in patients with coronary artery disease," Free Radical Biology \& Medicine, vol. 39, no. 9, pp. 1184-1190, 2005.

[336] P. Ghezzi, M. Bianchi, A. Mantovani, F. Spreafico, and M. Salmona, "Enhanced xanthine oxidase activity in mice treated with interferon and interferon inducers," Biochemical and Biophysical Research Communications, vol. 119, no. 1, pp. 144-149, 1984.

[337] J. M. McCord, "Oxygen-derived free radicals in postischemic tissue injury," The New England Journal of Medicine, vol. 312, no. 3, pp. 159-163, 1985.

[338] Y. Lytvyn, B. A. Perkins, and D. Z. Cherney, "Uric acid as a biomarker and a therapeutic target in diabetes," Canadian Journal of Diabetes, vol. 39, no. 3, pp. 239-246, 2015.

[339] M. Kaufman and M. Guglin, "Uric acid in heart failure: a biomarker or therapeutic target?" Heart Failure Reviews, vol. 18, no. 2, pp. 177-186, 2013.

[340] V. Filiopoulos, D. Hadjiyannakos, and D. Vlassopoulos, "New insights into uric acid effects on the progression and prognosis of chronic kidney disease," Renal Failure, vol. 34, no. 4, pp. 510-520, 2012.

[341] B. Halliwell and M. Whiteman, "Measuring reactive species and oxidative damage in vivo and in cell culture: how should you do it and what do the results mean?" British Journal of Pharmacology, vol. 142, no. 2, pp. 231-255, 2004.

[342] B. N. Ames, R. Cathcart, E. Schwiers, and P. Hochstein, "Uric acid provides an antioxidant defense in humans against oxidant- and radical-caused aging and cancer: a hypothesis," Proceedings of the National Academy of Sciences of the United States of America, vol. 78, no. 11, pp. 6858-6862, 1981.

[343] R. Kand'ar, P. Zakova, and V. Muzakova, "Monitoring of antioxidant properties of uric acid in humans for a consideration measuring of levels of allantoin in plasma by liquid chromatography," Clinica Chimica Acta, vol. 365, no. 1-2, pp. 249-256, 2006.

[344] D. Il'yasova, P. Scarbrough, and I. Spasojevic, "Urinary biomarkers of oxidative status," Clinica Chimica Acta, vol. 413, no. 19-20, pp. 1446-1453, 2012.

[345] M. Czerska, K. Mikolajewska, M. Zielinski, J. Gromadzinska, and W. Wasowicz, "Today's oxidative stress markers," Medycyna Pracy, vol. 66, no. 3, pp. 393-405, 2015.

[346] R. Kandar, "The ratio of oxidized and reduced forms of selected antioxidants as a possible marker of oxidative stress in humans," Biomedical Chromatography, vol. 30, no. 1, pp. 13-28, 2016.

[347] I. N. Zelko, T. J. Mariani, and R. J. Folz, "Superoxide dismutase multigene family: a comparison of the CuZn-SOD (SOD1), Mn-SOD (SOD2), and EC-SOD (SOD3) gene structures, evolution, and expression," Free Radical Biology \& Medicine, vol. 33, no. 3, pp. 337-349, 2002.

[348] A. V. Peskin and C. C. Winterbourn, "Assay of superoxide dismutase activity in a plate assay using WST-1," Free Radical Biology \& Medicine, vol. 103, pp. 188-191, 2017.

[349] C. Vives-Bauza, A. Starkov, and E. Garcia-Arumi, "Measurements of the antioxidant enzyme activities of superoxide dismutase, catalase, and glutathione peroxidase," Methods in Cell Biology, vol. 80, pp. 379-393, 2007.
[350] M. R. Slaughter and P. J. O'Brien, "Fully-automated spectrophotometric method for measurement of antioxidant activity of catalase," Clinical Biochemistry, vol. 33, no. 7, pp. 525-534, 2000.

[351] J. M. Harlan, J. D. Levine, K. S. Callahan, B. R. Schwartz, and L. A. Harker, "Glutathione redox cycle protects cultured endothelial cells against lysis by extracellularly generated hydrogen peroxide," The Journal of Clinical Investigation, vol. 73, no. 3, pp. 706-713, 1984.

[352] L. Flohe and W. A. Gunzler, "Assays of glutathione peroxidase," Methods in Enzymology, vol. 105, pp. 114-121, 1984.

[353] D. M. Goldberg and R. J. Spooner, "Assay of glutathione reductase," in Methods of Enzymatic Analysis, H. V. Bergmeyer, Ed., pp. 258-265, Verlag Chemie, Weinheim, Germany, 1983

[354] M. Banerjee and P. Vats, "Reactive metabolites and antioxidant gene polymorphisms in type 2 diabetes mellitus," Redox Biology, vol. 2, pp. 170-177, 2014.

[355] S. Eslami and A. Sahebkar, "Glutathione-S-transferase M1 and $\mathrm{T} 1$ null genotypes are associated with hypertension risk: a systematic review and meta-analysis of 12 studies," Current Hypertension Reports, vol. 16, no. 6, p. 432, 2014.

[356] J. Rybka, D. Kupczyk, K. Kedziora-Kornatowska et al., “Agerelated changes in an antioxidant defense system in elderly patients with essential hypertension compared with healthy controls," Redox Report, vol. 16, no. 2, pp. 71-77, 2011.

[357] D. V. Simic, J. Mimic-Oka, M. Pljesa-Ercegovac et al., "Byproducts of oxidative protein damage and antioxidant enzyme activities in plasma of patients with different degrees of essential hypertension," Journal of Human Hypertension, vol. 20, no. 2, pp. 149-155, 2006.

[358] M. Kumawat, T. K. Sharma, I. Singh et al., "Antioxidant enzymes and lipid peroxidation in type 2 diabetes mellitus patients with and without nephropathy," North American Journal of Medical Sciences, vol. 5, no. 3, pp. 213-219, 2013.

[359] M. Kumawat, T. K. Sharma, N. Singh et al., "Study of changes in antioxidant enzymes status in diabetic post menopausal group of women suffering from cardiovascular complications," Clinical Laboratory, vol. 58, no. 3-4, pp. 203-207, 2012.

[360] S. M. Bandeira, G. S. Guedes, L. J. da Fonseca et al., "Characterization of blood oxidative stress in type 2 diabetes mellitus patients: increase in lipid peroxidation and SOD activity," Oxidative Medicine and Cellular Longevity, vol. 2012, Article ID 819310, 13 pages, 2012.

[361] H. M. Turk, A. Sevinc, C. Camci et al., "Plasma lipid peroxidation products and antioxidant enzyme activities in patients with type 2 diabetes mellitus," Acta Diabetologica, vol. 39, no. 3, pp. 117-122, 2002.

[362] T. Atli, K. Keven, A. Avci et al., "Oxidative stress and antioxidant status in elderly diabetes mellitus and glucose intolerance patients," Archives of Gerontology and Geriatrics, vol. 39, no. 3, pp. 269-275, 2004.

[363] F. N. Ahmed, F. N. Naqvi, and F. Shafiq, "Lipid peroxidation and serum antioxidant enzymes in patients with type 2 diabetes mellitus," Annals of the New York Academy of Sciences, vol. 1084, pp. 481-489, 2006.

[364] N. Kurtul, E. Bakan, H. Aksoy, and O. Baykal, "Leukocyte lipid peroxidation, superoxide dismutase and catalase activities of type 2 diabetic patients with retinopathy," Acta Medica (Hradec Králové), vol. 48, no. 1, pp. 35-38, 2005. 
[365] F. J. Tinahones, M. Murri-Pierri, L. Garrido-Sanchez et al., "Oxidative stress in severely obese persons is greater in those with insulin resistance," Obesity (Silver Spring), vol. 17, no. 2, pp. 240-246, 2009.

[366] A. K. Arya, D. Pokharia, and K. Tripathi, "Relationship between oxidative stress and apoptotic markers in lymphocytes of diabetic patients with chronic non healing wound," Diabetes Research and Clinical Practice, vol. 94, no. 3, pp. 377-384, 2011.

[367] K. Gawlik, J. W. Naskalski, D. Fedak et al., "Markers of antioxidant defense in patients with type 2 diabetes," Oxidative Medicine and Cellular Longevity, vol. 2016, Article ID 2352361, 6 pages, 2016.

[368] A. Likidlilid, N. Patchanans, T. Peerapatdit, and C. Sriratanasathavorn, "Lipid peroxidation and antioxidant enzyme activities in erythrocytes of type 2 diabetic patients," Journal of the Medical Association of Thailand, vol. 93, no. 6, pp. 682-693, 2010.

[369] B. J. Lee, Y. C. Lin, Y. C. Huang, Y. W. Ko, S. Hsia, and P. T. Lin, "The relationship between coenzyme Q10, oxidative stress, and antioxidant enzymes activities and coronary artery disease," Scientific World Journal, vol. 2012, no. article 792756, 2012.

[370] M. Murri, M. Luque-Ramirez, M. Insenser, M. Ojeda-Ojeda, and H. F. Escobar-Morreale, "Circulating markers of oxidative stress and polycystic ovary syndrome (PCOS): a systematic review and meta-analysis," Human Reproduction Update, vol. 19, no. 3, pp. 268-288, 2013.

[371] M. Iborra, I. Moret, F. Rausell et al., "Role of oxidative stress and antioxidant enzymes in Crohn's disease," Biochemical Society Transactions, vol. 39, no. 4, pp. 11021106, 2011.

[372] N. Karaouzene, H. Merzouk, M. Aribi et al., "Effects of the association of aging and obesity on lipids, lipoproteins and oxidative stress biomarkers: a comparison of older with young men," Nutrition, Metabolism, and Cardiovascular Diseases, vol. 21, no. 10, pp. 792-799, 2011.

[373] S. Qin and D. X. Hou, "Multiple regulations of Keap1/Nrf2 system by dietary phytochemicals," Molecular Nutrition \& Food Research, vol. 60, no. 8, pp. 1731-1755, 2016.

[374] F. S. Tonin, L. M. Steimbach, A. Wiens, C. M. Perlin, and R. Pontarolo, "Impact of natural juice consumption on plasma antioxidant status: a systematic review and meta-analysis," Molecules, vol. 20, no. 12, pp. 22146-22156, 2015.

[375] Q. Zhou, L. Zhu, D. Zhang et al., "Oxidative stress-related biomarkers in postmenopausal osteoporosis: a systematic review and meta-analyses," Disease Markers, vol. 2016, Article ID 7067984, 12 pages, 2016.

[376] J. Yang, N. Diaz, J. Adelsberger et al., "The effects of storage temperature on PBMC gene expression," BMC Immunology, vol. 17, p. 6, 2016.

[377] M. G. Barnes, A. A. Grom, T. A. Griffin, R. A. Colbert, and S. D. Thompson, "Gene expression profiles from peripheral blood mononuclear cells are sensitive to short processing delays," Biopreservation and Biobanking, vol. 8, no. 3, pp. 153-162, 2010.

[378] A. Ambayya, A. T. Su, N. H. Osman et al., "Haematological reference intervals in a multiethnic population," PLoS One, vol. 9, no. 3, article e91968, 2014.

[379] C. B. Chiwakata, C. J. Hemmer, and M. Dietrich, "High levels of inducible nitric oxide synthase mRNA are associated with increased monocyte counts in blood and have a beneficial role in plasmodium falciparum malaria," Infection and Immunity, vol. 68, no. 1, pp. 394-399, 2000.

[380] S. S. Okada, E. M. de Oliveira, T. H. de Araujo et al., "Myeloperoxidase in human peripheral blood lymphocytes: production and subcellular localization," Cellular Immunology, vol. 300, pp. 18-25, 2016.

[381] P. Pietarinen-Runtti, E. Lakari, K. O. Raivio, and V. L. Kinnula, "Expression of antioxidant enzymes in human inflammatory cells," American Journal of Physiology. Cell Physiology, vol. 278, no. 1, pp. C118-C125, 2000.

[382] X. Yin, Y. Xiao, F. Li, S. Qi, Z. Yin, and J. Gao, "Prognostic role of neutrophil-to-lymphocyte ratio in prostate cancer: a systematic review and meta-analysis," Medicine (Baltimore), vol. 95, no. 3, article e2544, 2016.

[383] H. Yodying, A. Matsuda, M. Miyashita et al., "Prognostic significance of neutrophil-to-lymphocyte ratio and platelet-tolymphocyte ratio in oncologic outcomes of esophageal cancer: a systematic review and meta-analysis," Annals of Surgical Oncology, vol. 23, no. 2, pp. 646-654, 2016.

[384] J. Sun, X. Chen, P. Gao et al., "Can the neutrophil to lymphocyte ratio be used to determine gastric cancer treatment outcomes? A Systematic Review and Meta-Analysis," Disease Markers, vol. 2016, Article ID 7862469, 10 pages, 2016.

[385] Y. Luo, D. L. She, H. Xiong, S. J. Fu, and L. Yang, "Pretreatment neutrophil to lymphocyte ratio as a prognostic predictor of urologic tumors: a systematic review and meta-analysis," Medicine (Baltimore), vol. 94, no. 40, article e1670, 2015.

[386] J. J. Yang, Z. G. Hu, W. X. Shi, T. Deng, S. Q. He, and S. G. Yuan, "Prognostic significance of neutrophil to lymphocyte ratio in pancreatic cancer: a meta-analysis," World Journal of Gastroenterology, vol. 21, no. 9, pp. 2807-2815, 2015.

[387] A. J. Templeton, M. G. McNamara, B. Seruga et al., "Prognostic role of neutrophil-to-lymphocyte ratio in solid tumors: a systematic review and meta-analysis," Journal of the National Cancer Institute, vol. 106, no. 6, p. dju124, 2014.

[388] T. F. Nishijima, H. B. Muss, S. S. Shachar, K. Tamura, and Y. Takamatsu, "Prognostic value of lymphocyte-to-monocyte ratio in patients with solid tumors: a systematic review and meta-analysis," Cancer Treatment Reviews, vol. 41, no. 10, pp. 971-978, 2015.

[389] J. J. Teng, J. Zhang, T. Y. Zhang, S. Zhang, and B. S. Li, “Prognostic value of peripheral blood lymphocyte-to-monocyte ratio in patients with solid tumors: a meta-analysis," OncoTargets and therapy, vol. 9, pp. 37-47, 2016.

[390] N. G. Kounis, G. D. Soufras, G. Tsigkas, and G. Hahalis, "White blood cell counts, leukocyte ratios, and eosinophils as inflammatory markers in patients with coronary artery disease," Clinical and Applied Thrombosis/Hemostasis, vol. 21, no. 2, pp. 139-143, 2015.

[391] N. D. Vaziri, M. V. Pahl, A. Crum, and K. Norris, "Effect of uremia on structure and function of immune system," Journal of Renal Nutrition, vol. 22, no. 1, pp. 149-156, 2012.

[392] S. Mocellin, M. Provenzano, C. R. Rossi, P. Pilati, D. Nitti, and M. Lise, "Use of quantitative real-time PCR to determine immune cell density and cytokine gene profile in the tumor microenvironment," Journal of Immunological Methods, vol. 280, no. 1-2, pp. 1-11, 2003.

[393] P. Kar, H. Chawla, S. Saha, N. Tandon, and R. Goswami, "Identification of reference housekeeping-genes for mRNA expression studies in patients with type 1 diabetes," 
Molecular and Cellular Biochemistry, vol. 417, no. 1-2, pp. 49-56, 2016.

[394] D. Lettieri-Barbato, F. Tomei, A. Sancini, G. Morabito, and M. Serafini, "Effect of plant foods and beverages on plasma non-enzymatic antioxidant capacity in human subjects: a meta-analysis," The British Journal of Nutrition, vol. 109, no. 9, pp. 1544-1556, 2013.

[395] I. Peluso and A. Raguzzini, "Salivary and urinary Total antioxidant capacity as biomarkers of oxidative stress in humans," Pathology Research International, vol. 2016, Article ID 5480267, 14 pages, 2016.

[396] I. Peluso, A. Cavaliere, and M. Palmery, "Plasma total antioxidant capacity and peroxidation biomarkers in psoriasis," Journal of Biomedical Science, vol. 23, no. 1, p. 52, 2016.

[397] S. Z. Bathaie, A. Shams, and F. Moghadas Zadeh, "Kermani, Crocin bleaching assay using purified di-gentiobiosyl Crocin (-crocin) from Iranian saffron," Iranian Journal of Basic Medical Sciences, vol. 14, no. 5, pp. 399-406, 2011.

[398] R. Apak, K. Guclu, M. Ozyurek, B. Bektasoglu, and M. Bener, "Cupric ion reducing antioxidant capacity assay for antioxidants in human serum and for hydroxyl radical scavengers," Methods in Molecular Biology, vol. 594, pp. 215-239, 2010.

[399] O. Erel, "A new automated colorimetric method for measuring total oxidant status," Clinical Biochemistry, vol. 38, no. 12, pp. 1103-1111, 2005.

[400] G. Beretta, G. Aldini, R. M. Facino, R. M. Russell, N. I. Krinsky, and K. J. Yeum, “Total antioxidant performance: a validated fluorescence assay for the measurement of plasma oxidizability," Analytical Biochemistry, vol. 354, no. 2, pp. 290-298, 2006.

[401] G. Aldini, K. J. Yeum, R. M. Russell, and N. I. Krinsky, “A method to measure the oxidizability of both the aqueous and lipid compartments of plasma," Free Radical Biology \& Medicine, vol. 31, no. 9, pp. 1043-1050, 2001.

[402] M. Takashima, M. Horie, M. Shichiri, Y. Hagihara, Y. Yoshida, and E. Niki, "Assessment of antioxidant capacity for scavenging free radicals in vitro: a rational basis and practical application," Free Radical Biology \& Medicine, vol. 52, no. 7, pp. 1242-1252, 2012.

[403] R. Amorati and L. Valgimigli, "Advantages and limitations of common testing methods for antioxidants," Free Radical Research, vol. 49, no. 5, pp. 633-649, 2015.

[404] I. Pinchuk, H. Shoval, Y. Dotan, and D. Lichtenberg, "Evaluation of antioxidants: scope, limitations and relevance of assays," Chemistry and Physics of Lipids, vol. 165, no. 6, pp. 638-647, 2012.

[405] C. G. Fraga, P. I. Oteiza, and M. Galleano, "In vitro measurements and interpretation of total antioxidant capacity," Biochimica et Biophysica Acta, vol. 1840, no. 2, pp. 931-934, 2014.

[406] P. C. Hollman, A. Cassidy, B. Comte et al., "The biological relevance of direct antioxidant effects of polyphenols for cardiovascular health in humans is not established," The Journal of Nutrition, vol. 141, no. 5, pp. 989S-1009S, 2011.

[407] G. Bartosz, "Non-enzymatic antioxidant capacity assays: limitations of use in biomedicine," Free Radical Research, vol. 44, no. 7, pp. 711-720, 2010.

[408] D. Huang, B. Ou, and R. L. Prior, "The chemistry behind antioxidant capacity assays," Journal of Agricultural and Food Chemistry, vol. 53, no. 6, pp. 1841-1856, 2005.
[409] L. M. Magalhaes, M. A. Segundo, S. Reis, and J. L. Lima, "Methodological aspects about in vitro evaluation of antioxidant properties," Analytica Chimica Acta, vol. 613, no. 1, pp. 1-19, 2008.

[410] E. Niki, "Assessment of antioxidant capacity in vitro and in vivo," Free Radical Biology \& Medicine, vol. 49, no. 4, pp. 503-515, 2010.

[411] C. Lopez-Alarcon and A. Denicola, "Evaluating the antioxidant capacity of natural products: a review on chemical and cellular-based assays," Analytica Chimica Acta, vol. 763, pp. 1-10, 2013.

[412] A. R. Collins, "Assays for oxidative stress and antioxidant status: applications to research into the biological effectiveness of polyphenols," The American Journal of Clinical Nutrition, vol. 81, no. 1 Supplement, pp. 261S-267S, 2005.

[413] T. Petrosino and M. Serafini, "Antioxidant modulation of F2isoprostanes in humans: a systematic review," Critical Reviews in Food Science and Nutrition, vol. 54, no. 9, pp. 1202-1221, 2014.

[414] C. J. Carrión-García, E. J. Guerra-Hernandez, B. GarciaVillanova, and E. Molina-Montes, "Non-enzymatic antioxidant capacity (NEAC) estimated by two different dietary assessment methods and its relationship with NEAC plasma levels," European Journal of Nutrition, 2016, Epub ahead of print.

[415] K. S. De Bona, L. P. Belle, P. E. Bittencourt et al., "Erythrocytic enzymes and antioxidant status in people with type 2 diabetes: beneficial effect of Syzygium cumini leaf extract in vitro," Diabetes Research and Clinical Practice, vol. 94, no. 1, pp. 84-90, 2011.

[416] S. Bhatia, R. Shukla, S. Venkata Madhu, J. Kaur Gambhir, and K. Madhava Prabhu, "Antioxidant status, lipid peroxidation and nitric oxide end products in patients of type 2 diabetes mellitus with nephropathy," Clinical Biochemistry, vol. 36, no. 7, pp. 557-562, 2003.

[417] J. Kasznicki, M. Kosmalski, A. Sliwinska et al., "Evaluation of oxidative stress markers in pathogenesis of diabetic neuropathy," Molecular Biology Reports, vol. 39, no. 9, pp. 8669-8678, 2012.

[418] V. Ramakrishna and R. Jailkhani, "Oxidative stress in noninsulin-dependent diabetes mellitus (NIDDM) patients," Acta Diabetologica, vol. 45, no. 1, pp. 41-46, 2008.

[419] S. Merzouk, A. Hichami, S. Madani et al., "Antioxidant status and levels of different vitamins determined by high performance liquid chromatography in diabetic subjects with multiple complications," General Physiology and Biophysics, vol. 22, no. 1, pp. 15-27, 2003.

[420] K. Kaviarasan, M. M. Arjunan, and K. V. Pugalendi, "Lipid profile, oxidant-antioxidant status and glycoprotein components in hyperlipidemic patients with/without diabetes," Clinica Chimica Acta, vol. 362, no. 1-2, pp. 4956, 2005.

[421] M. Jandric-Balen, V. Bozikov, D. Bistrovic et al., "Antioxidant enzymes activity in patients with peripheral vascular disease, with and without presence of diabetes mellitus," Collegium Antropologicum, vol. 27, no. 2, pp. 735-743, 2003.

[422] K. Komosinska-Vassev, K. Olczyk, P. Olczyk, and K. WinszSzczotka, "Effects of metabolic control and vascular complications on indices of oxidative stress in type 2 diabetic patients," Diabetes Research and Clinical Practice, vol. 68, no. 3, pp. 207-216, 2005. 
[423] T. S. Chen, S. Y. Liou, and Y. L. Chang, "Supplementation of Emblica officinalis (Amla) extract reduces oxidative stress in uremic patients," The American Journal of Chinese Medicine, vol. 37, no. 1, pp. 19-25, 2009.

[424] J. Maiuolo, F. Oppedisano, S. Gratteri, C. Muscoli, and V. Mollace, "Regulation of uric acid metabolism and excretion," International Journal of Cardiology, vol. 213, pp. 8-14, 2016.

[425] W. Doehner, E. A. Jankowska, J. Springer, M. Lainscak, and S. D. Anker, "Uric acid and xanthine oxidase in heart failure - emerging data and therapeutic implications," International Journal of Cardiology, vol. 213, pp. 15-19, 2016.

[426] M. Gliozzi, N. Malara, S. Muscoli, and V. Mollace, "The treatment of hyperuricemia," International Journal of Cardiology, vol. 213, pp. 23-27, 2016.

[427] H. Benkhai, S. Lemanski, H. Below et al., "Can physical stress be measured in urine using the parameter antioxidative potential?” GMS Krankenhaushygiene interdisziplinär, vol. 5, no. 2, 2010.

[428] N. Malliaraki, D. Mpliamplias, M. Kampa, K. Perakis, A. N. Margioris, and E. Castanas, "Total and corrected antioxidant capacity in hemodialyzed patients," BMC Nephrology, vol. 4, p. 4, 2003.

[429] C. Campos, R. Guzman, E. Lopez-Fernandez, and A. Casado, "Urinary uric acid and antioxidant capacity in children and adults with Down syndrome," Clinical Biochemistry, vol. 43, no. 3, pp. 228-233, 2010.

[430] D. Duplancic, L. Kukoc-Modun, D. Modun, and N. Radic, "Simple and rapid method for the determination of uric acid-independent antioxidant capacity," Molecules, vol. 16, no. 8, pp. 7058-7068, 2011.

[431] A. Prymont-Przyminska, A. Zwolinska, A. Sarniak et al., "Consumption of strawberries on a daily basis increases the non-urate 2,2-diphenyl-1-picryl-hydrazyl (DPPH) radical scavenging activity of fasting plasma in healthy subjects," Journal of Clinical Biochemistry and Nutrition, vol. 55, no. 1, pp. 48-55, 2014.

[432] T. Atsumi, S. Fujisawa, Y. Nakabayashi, T. Kawarai, T. Yasui, and $\mathrm{K}$. Tonosaki, "Pleasant feeling from watching a comical video enhances free radical-scavenging capacity in human whole saliva," Journal of Psychosomatic Research, vol. 56, no. 3, pp. 377-379, 2004.

[433] A. Vidovic, M. Grubisic-Ilic, D. Kozaric-Kovacic et al., "Exaggerated platelet reactivity to physiological agonists in war veterans with posttraumatic stress disorder," Psychoneuroendocrinology, vol. 36, no. 2, pp. 161-172, 2011.

[434] A. Ghiselli, M. Serafini, F. Natella, and C. Scaccini, “Total antioxidant capacity as a tool to assess redox status: critical view and experimental data," Free Radical Biology \& Medicine, vol. 29, no. 11, pp. 1106-1114, 2000.

[435] W. Ammerlaan, J. P. Trezzi, P. Lescuyer, C. Mathay, K. Hiller, and F. Betsou, "Method validation for preparing serum and plasma samples from human blood for downstream proteomic, metabolomic, and circulating nucleic acid-based applications," Biopreservation and Biobanking, vol. 12, no. 4, pp. 269-280, 2014.

[436] D. A. Granger, D. Cicchetti, F. A. Rogosch, L. C. Hibel, M. Teisl, and E. Flores, "Blood contamination in children's saliva: prevalence, stability, and impact on the measurement of salivary cortisol, testosterone, and dehydroepiandrosterone," Psychoneuroendocrinology, vol. 32, no. 6, pp. 724-733, 2007.
[437] F. Veglia, G. Cighetti, M. De Franceschi et al., “Age- and gender-related oxidative status determined in healthy subjects by means of OXY-SCORE, a potential new comprehensive index," Biomarkers, vol. 11, no. 6, pp. 562-573, 2006.

[438] C. Vassalle, "An easy and reliable automated method to estimate oxidative stress in the clinical setting," Methods in Molecular Biology, vol. 477, pp. 31-39, 2008.

[439] C. Vassalle, C. Novembrino, S. Maffei et al., "Determinants of oxidative stress related to gender: relevance of age and smoking habit," Clinical Chemistry and Laboratory Medicine, vol. 49, no. 9, pp. 1509-1513, 2011.

[440] C. Vassalle, R. Sciarrino, S. Bianchi, D. Battaglia, A. Mercuri, and S. Maffei, "Sex-related differences in association of oxidative stress status with coronary artery disease," Fertility and Sterility, vol. 97, no. 2, pp. 414-419, 2012.

[441] F. Veglia, V. Cavalca, and E. Tremoli, “OXY-SCORE: a global index to improve evaluation of oxidative stress by combining pro- and antioxidant markers," Methods in Molecular Biology, vol. 594, pp. 197-213, 2010.

[442] F. Veglia, J. P. Werba, E. Tremoli et al., "Assessment of oxidative stress in coronary artery bypass surgery: comparison between the global index OXY-SCORE and individual biomarkers," Biomarkers, vol. 14, no. 7, pp. 465-472, 2009.

[443] M. Nishimura, A. Takaki, N. Tamaki et al., "Serum oxidativeanti-oxidative stress balance is dysregulated in patients with hepatitis C virus-related hepatocellular carcinoma," Hepatology Research, vol. 43, no. 10, pp. 1078-1092, 2013.

[444] M. Terao, A. Takaki, T. Maruyama et al., "Serum oxidative/ anti-oxidative stress balance is dysregulated in potentially pulmonary hypertensive patients with liver cirrhosis: a case control study," Internal Medicine, vol. 54, no. 22, pp. 28152826, 2015.

[445] Y. Shimomura, A. Takaki, N. Wada et al., "The serum oxidative/anti-oxidative stress balance becomes dysregulated in patients with non-alcoholic steatohepatitis associated with hepatocellular carcinoma," Internal Medicine, vol. 56, no. 3, pp. 243-251, 2017.

[446] C. Novembrino, G. Cighetti, R. De Giuseppe et al., "Effects of encapsulated fruit and vegetable juice powder concentrates on oxidative status in heavy smokers," Journal of the American College of Nutrition, vol. 30, no. 1, pp. 49-56, 2011.

[447] C. Vassalle, P. Piaggi, N. Weltman et al., "Innovative approach to interpret the variability of biomarkers after ultra-endurance exercise: the multifactorial analysis," Biomarkers in Medicine, vol. 8, no. 6, pp. 881-891, 2014.

[448] L. Condezo-Hoyos, M. Rubio, S. M. Arribas et al., "A plasma oxidative stress global index in early stages of chronic venous insufficiency," Journal of Vascular Surgery, vol. 57, no. 1, pp. 205-213, 2013. 


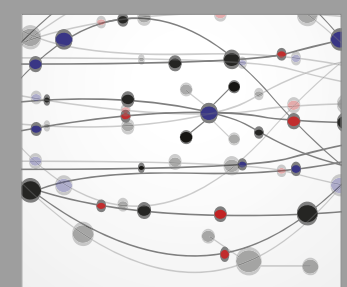

The Scientific World Journal
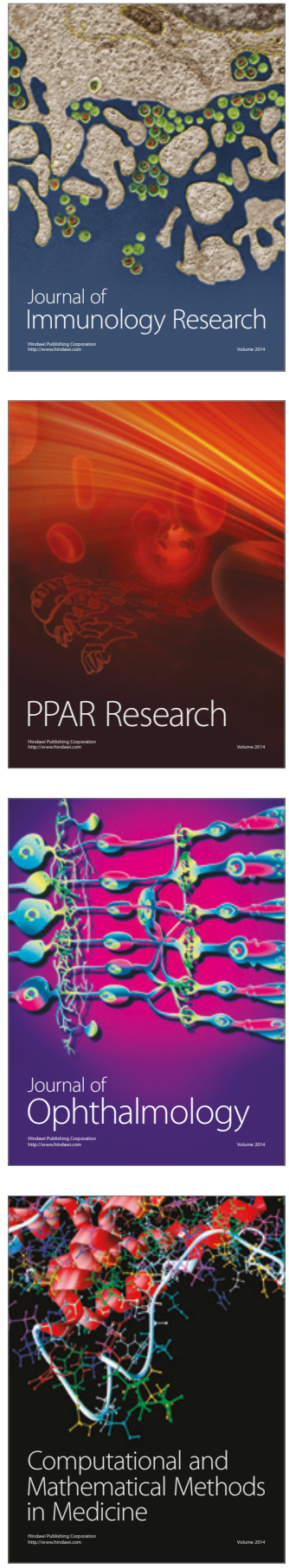

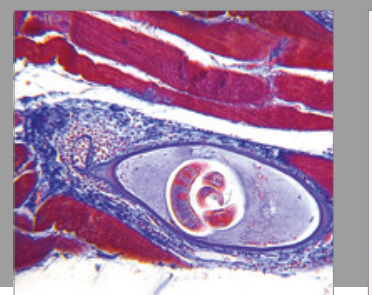

Gastroenterology Research and Practice
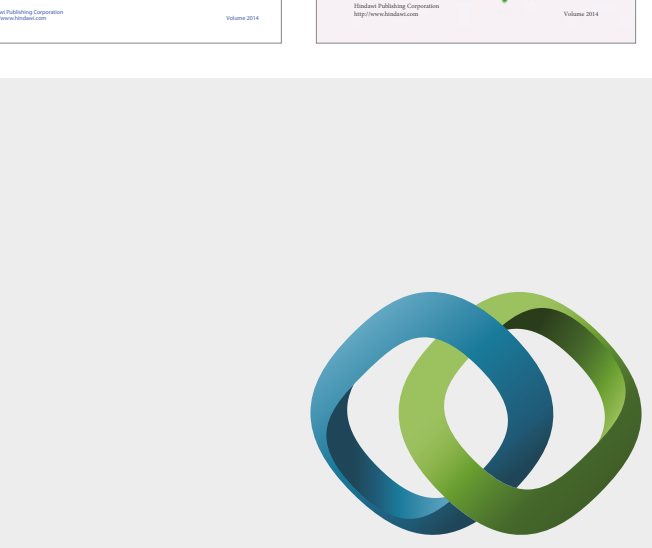

\section{Hindawi}

Submit your manuscripts at

https://www.hindawi.com
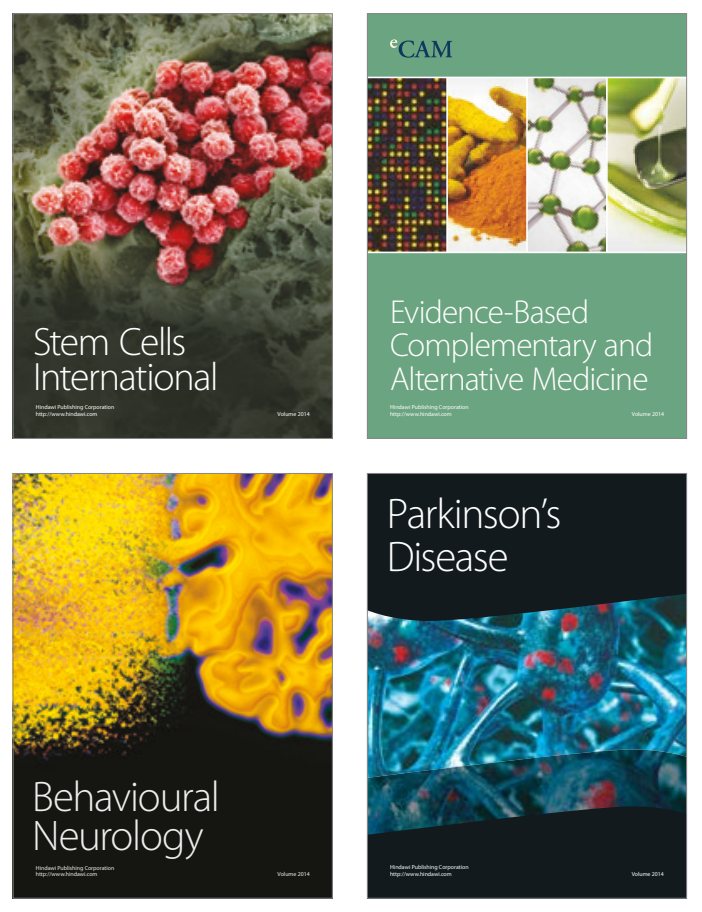
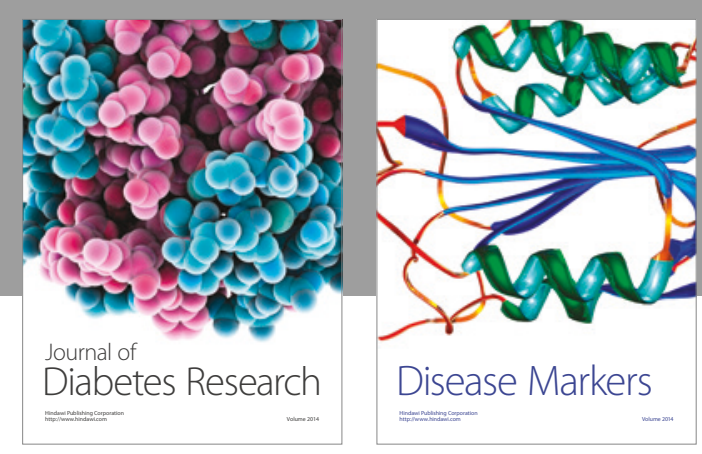

Disease Markers
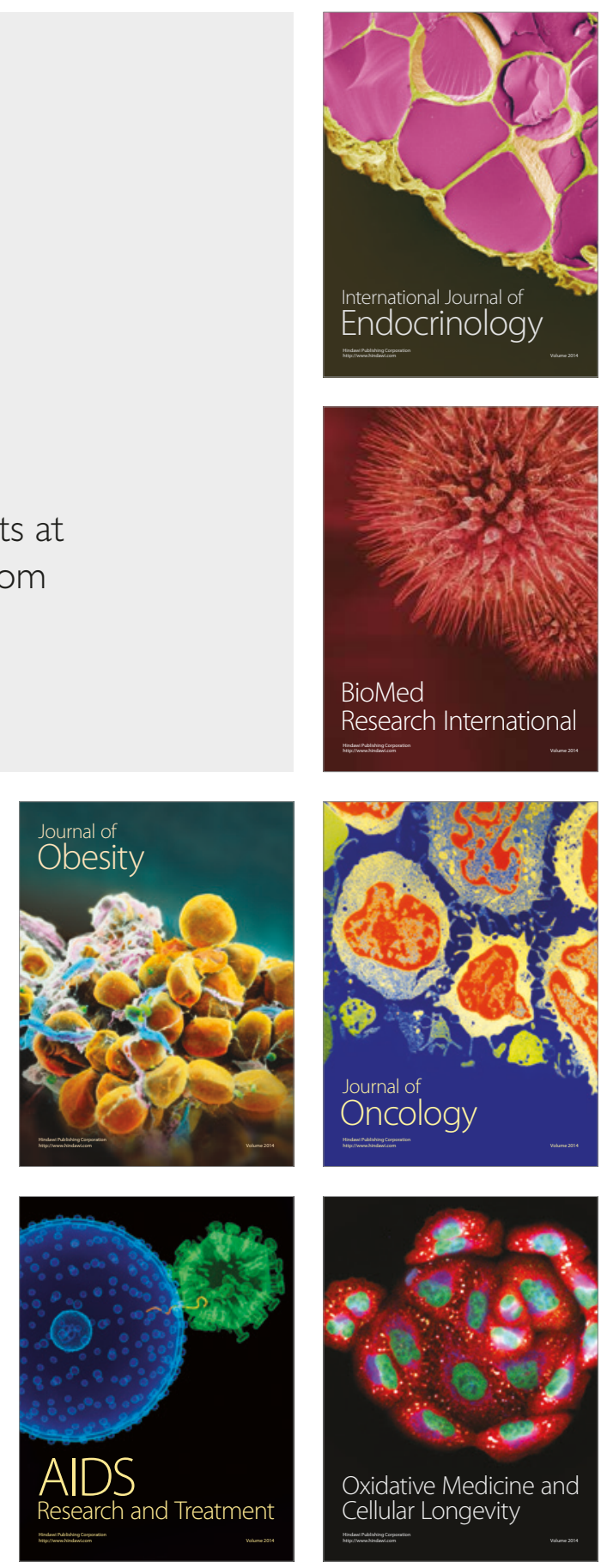